\title{
Recent progress on nanostructured conducting polymers and composites: synthesis, application and future aspects
}

\author{
Lin Zhang ${ }^{1^{*}}$, Wenya $\mathrm{Du}^{1}$, Amit Nautiyal ${ }^{2}$, Zhen $\mathrm{Liu}^{3}$ and Xinyu Zhang ${ }^{2^{*}}$
}

\begin{abstract}
Conducting polymers (CPs) have been widely investigated due to their extraordinary advantages over the traditional materials, including wide and tunable electrical conductivity, facile production approach, high mechanical stability, light weight, low cost and ease in material processing. Compared with bulk CPs, nanostructured CPs possess higher electrical conductivity, larger surface area, superior electrochemical activity, which make them suitable for various applications. Hybridization of CPs with other nanomaterials has obtained promising functional nanocomposites and achieved improved performance in different areas, such as energy storage, sensors, energy harvesting and protection applications. In this review, recent progress on nanostructured CPs and their composites is summarized from research all over the world in more than 400 references, especially from the last three years. The relevant synthesizing experiences are outlined and abundant application examples are illustrated. The approaches of production of nanostructured CPs are discussed and the efficacy and benefits of newest trends for the preparation of multifunctional nanomaterials/nanocomposites are presented. Mechanism of their electrical conductivity and the ways to tailor their properties are investigated. The remaining challenges in developing better CPs based nanomaterials are also elaborated.
\end{abstract}

Keywords: conducting polymer, synthesis, composite, nanostructures, electronic devices

\section{INTRODUCTION}

Conducting polymers (CPs) are polymers having highly $\pi$-conjugated polymeric chains with metal-like electronic, magnetic and optical properties. They have become the leading materials in polymer science ever since the discovery of highly conducting polyacetylene (PAc) in 1976 $[1,2]$. Chemist Hideki Shirakawa, physicist Alan J. Heeger and chemist Alan G. MacDiarmid first discovered the oxidation of acetylene by iodine that resulted in PAc with $10^{8}$ fold increment in conductivity [3,4]. Iodine-doped PAc can reach the conductivity of silver that is one of the best readily available electrical conductors. Based on this revolutionary discovery, the three were awarded the Nobel Prize in Chemistry in 2000 and therefore opened new doors to the exploration of electric organic polymers [5]. CPs have garnered enormous academic and industrial interest owing to their unique and tunable properties. CPs show semiconducting characteristics before a "doping" process, which involves oxidizing or reducing CPs. The electrical properties can be modulated by doping process that greatly increases the number of charge carriers in CPs. Since the discovery of conducting PAc, a variety of CPs have been developed and widely used due to relatively high conductivity, as listed in Table 1, including polyaniline (PANI), polypyrrole (PPy), poly(3,4-ethylenedioxythiophene) (PEDOT), polythiophene (PT), polyacetylene (PA), polyparaphenylene (PPP) and others, as illustrated in Fig. 1.

Recently, nanostructured materials have been widely studied for both fundamental research and potential applications because of their unique properties at nano level. Development of novel multifunctional materials is primarily driven by sustainable technologies and novel methods for achieving nanostructures effortlessly [6]. Compared with bulk polymers, nanostructured conducting polymers (NCPs) have received special attention

\footnotetext{
${ }^{1}$ Electronic Materials Research Laboratory, Key Laboratory of the Ministry of Education and International Center for Dielectric Research, Xi'an Jiaotong University, Xi'an 710049, China

${ }^{2}$ Department of Chemical Engineering, Auburn University, Auburn, AL 36849, USA

${ }^{3}$ Department of Physics \& Engineering, Frostburg State University, Frostburg, MD 21532, USA

*Corresponding authors (emails: zhanglin.materials@gmail.com (Zhang L), xzz0004@auburn.edu (Zhang X))
} 
<smiles>CC(C)(C)Nc1ccc(C(C)(C)C)cc1</smiles>

Polyaniline (PANI)<smiles>CC(C)(C)/C=C/c1ccc(C(C)(C)C)cc1</smiles><smiles>CC(C)(C)c1ccc(C(C)(C)C)[nH]1</smiles>

Polypyrrole (PPy)<smiles>Cc1ccc(NC(C)(C)C)c(C)c1</smiles>

Poly (o-toluidine) (POT)<smiles>CC(C)(C)c1ccc(C(C)(C)C)s1</smiles>

Polythiophene (PT)

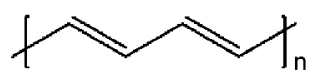

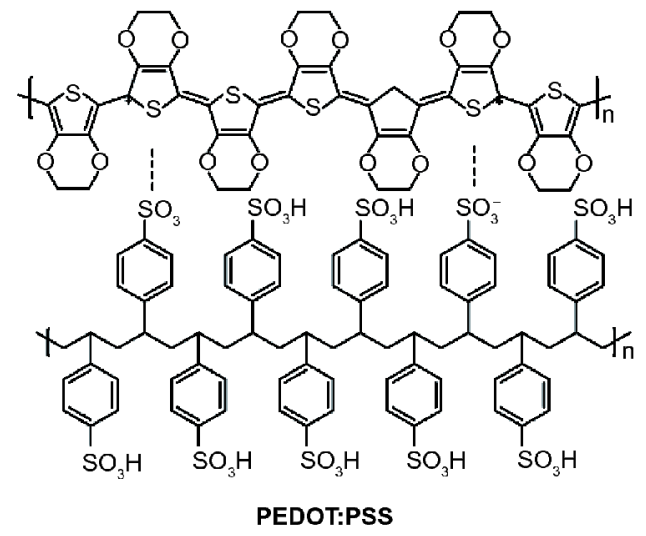

Polyacetylene (PA)

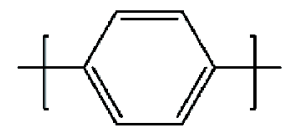

Poly (p-phenylene) (PPP)

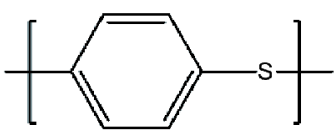

Poly (p-phenylene sulfide) (PPS)

Figure 1 Chemical structures of representative conducting polymers.

Table 1 Conductivity of common conducting polymers

\begin{tabular}{ccc}
\hline Conducting polymers & Conductivity $\left(\mathrm{S} \mathrm{cm}^{-1}\right)$ & Type of doping \\
\hline Polyaniline (PANI) & $30-200$ & $\mathrm{n}, \mathrm{p}$ \\
Polypyrrole (PPy) & $10-7500$ & $\mathrm{p}$ \\
$\begin{array}{c}\text { Poly(3,4-ethylenediox- } \\
\text { ythiophene) (PEDOT) }\end{array}$ & $0.4-400$ & $\mathrm{n}, \mathrm{p}$ \\
Polythiophene (PT) & $10-1000$ & $\mathrm{p}$ \\
Polyacetylene (PA) & $200-1000$ & $\mathrm{n}, \mathrm{p}$ \\
$\begin{array}{c}\text { Polyparaphenylene } \\
\text { (PPP) }\end{array}$ & 500 & $\mathrm{n}, \mathrm{p}$ \\
$\begin{array}{c}\text { Polyparaphenylene } \\
\text { sulfide (PPS) }\end{array}$ & $3-300$ & $\mathrm{p}$ \\
$\begin{array}{c}\text { Polyparavinylene (PPv) } \\
\text { Polyisothionaphthene } \\
\text { (PITN) }\end{array}$ & $1-1000$ & $\mathrm{p}$ \\
\hline
\end{tabular}

Reproduced from references [12-14].

owing to their facile synthesis, high surface area, superior electrical conductivity, high carrier mobility, enhanced electrochemical activity, special optical properties and biocompatibility. In the past, multidimensional NCPs with different morphologies and structures have been synthesized, such as 0D (nanospheres, nanoparticles), 1D (nanorods, nanowires, nanofibers, nanobelts, nano-ribbons and hollow-type structures nanotubes), 2D (nanorings, nanosheets, nanodiscs, nanoclips). Various physical and chemical strategies have been used for nanocomposites fabrication, including physical template synthesis (i.e., hard and soft method), and template-free approach (i.e., self-assembly or interfacial polymerization, electrospinning, seeding approach) $[7,8]$.

Over the last decade, the number of studies on NCPs has rapidly increased and significant progress has been achieved due to several reasons [9]. First, it is important to understand the mechanism of charge transfer and charge transport processes during the redox reactions which results in the outstanding electrical properties [10]. Doping can significantly increase the number of charge carriers and enhance the conductivity. The fundamental feature of all CPs is the extended conjugated $\pi$-system 
along the polymer backbone that gives them metal-like properties (electronic, magnetic and optical). Meanwhile, CPs also possess properties of the conventional polymers, such as excellent mechanical properties, good environmental stability, low processing temperature, low cost, etc. Second, it is imperative to synthesize CPs-based composites to fully utilize the advantages of CPs and overcome the limitations, i.e., solubility [11]. The conductivity and solubility of CPs are controllable by modifying their chemical structures. For example, polymers can obtain good solubility and processability by introducing specific functional groups, i.e., poly(3-hexylthiophene). Furthermore, hybrid nanomaterials, a combination of CPs with different types of materials, such as metals (i.e., $\mathrm{Ag}, \mathrm{Au}$ and $\mathrm{Pd}$ ), metal oxides (i.e., $\mathrm{Fe}_{2} \mathrm{O}_{3}$, $\mathrm{MnO}_{2}, \mathrm{NiO}, \mathrm{CuO}, \mathrm{TiO}_{2}, \mathrm{WO}_{3}, \mathrm{ZnO}, \mathrm{SnO}_{2}, \mathrm{~V}_{2} \mathrm{O}_{5}, \mathrm{RuO}_{2}$ ), chalcogenides (i.e., $\mathrm{MoS}_{2}, \mathrm{WS}_{2}, \mathrm{Bi}_{2} \mathrm{~S}_{3}, \mathrm{CdS}$, CdSe, CdTe), carbonaceous materials (i.e., graphene, graphene oxide, carbon fibers and nanotubes), and other non-conducting polymers, have been intensively investigated.

NCP based composites exhibit outstanding performances owing to the synergistic performance derived from each component [15]. Finally, it is motivating to investigate suitable applications of NCPs and NCP-based composites by the increasing number of academic and industrial laboratories $[9,16]$, including energy conversion and storage (batteries, supercapacitors, dielectric capacitors, solar cells, fuel cells) $[6,7,14,17-22]$, chemical sensors [23-26], biosensors [27-29], catalysis [30,31], optical devices [32], electroactive devices [33,34], biomedical devices [12,13], electromagnetic interference shielding [35], corrosion protection [16,36], antistatic agent [9], removal of heavy metal ions [37], tissue engineering [38] and other applications. NCPs and NCPbased composites can provide significant improvement of properties, including enhancing electrolyte diffusion for batteries and supercapacitors, improving dielectric performance in ferroelectric polymers-based capacitors, supporting effective exciton dissociation in solar cells, reducing response times and enhancing sensitivity of biosensors and chemical sensors and raising anti-corrosion efficiency.

Therefore, it is necessary for a deep understanding of recent progress and development of CPs with multidimensional nanostructures and NCP-based composites. An overview of the different methods employed in the synthesis of NCPs and hybrid composites is summarized. Significant electric performance and applications of CPs composites in recent research are presented. Currently the representative investigation of NCPs for special de- vices is highlighted, as shown in Fig. 2. The prospects of scientific and technological challenges for synthetic approaches and potential applications are discussed. The emerging novel synthesis of representative nanostructures of conductive polymers and nanocomposites serve as the main goal of this review: multi-dimensions with multifunctions and multi-applications.

\section{SYNTHETIC APPROACHES TO NANOSTRUCTURED CONDUCTING POLYMERS}

The polymerization of CPs includes three major steps: oxidation, coupling and propagation. These three steps serve as integrated and key components which determine the physical and chemical properties of CPs. The oxidation step can be triggered by various methods, such as chemical oxidants, electrochemical potential, photoactive reagent and harsh reaction media [14]. Compared to bulk CPs, the synthesis of NCPs has similar methods but involves more considerations and requirements, because NCPs exhibit superior performance versus their bulk formations which is strongly related to synthetic approaches [39]. Significant progress has been achieved in the preparation and synthesis of NCPs over the past two decades [14]. Various methods for synthesizing nanoscopic zero-dimensional (0D), one-dimensional (1D), two-dimensional (2D), or three-dimensional (3D) CPs have been developed, which can be categorized under two main approaches: template-based approach including hard template and soft template, and template-free approaches, such as interfacial method, seeding method, electrospinning method, etc.

\section{Template-based approaches}

The template-based nano-structuring approach provides ease in synthesis, efficient and highly controlled NCPs. In template-based approaches, a template is used to guide the NCPs to grow in designed shapes and sizes. There are two main kinds of template approaches: hard templates relying on physically moulding the CPs into shapes and soft templates relying on self-assembly of the CPs $[10,31,39]$.

\section{Hard template}

The hard template method is a feasible, controllable and widely exploited tool for synthesis of nanostructured inorganic semiconductors, metals and polymers [40]. In this method, a physical template is used as a mould or scaffold to grow nanostructures. These templates can be colloidal nanoparticles or nano-sized channels to provide 


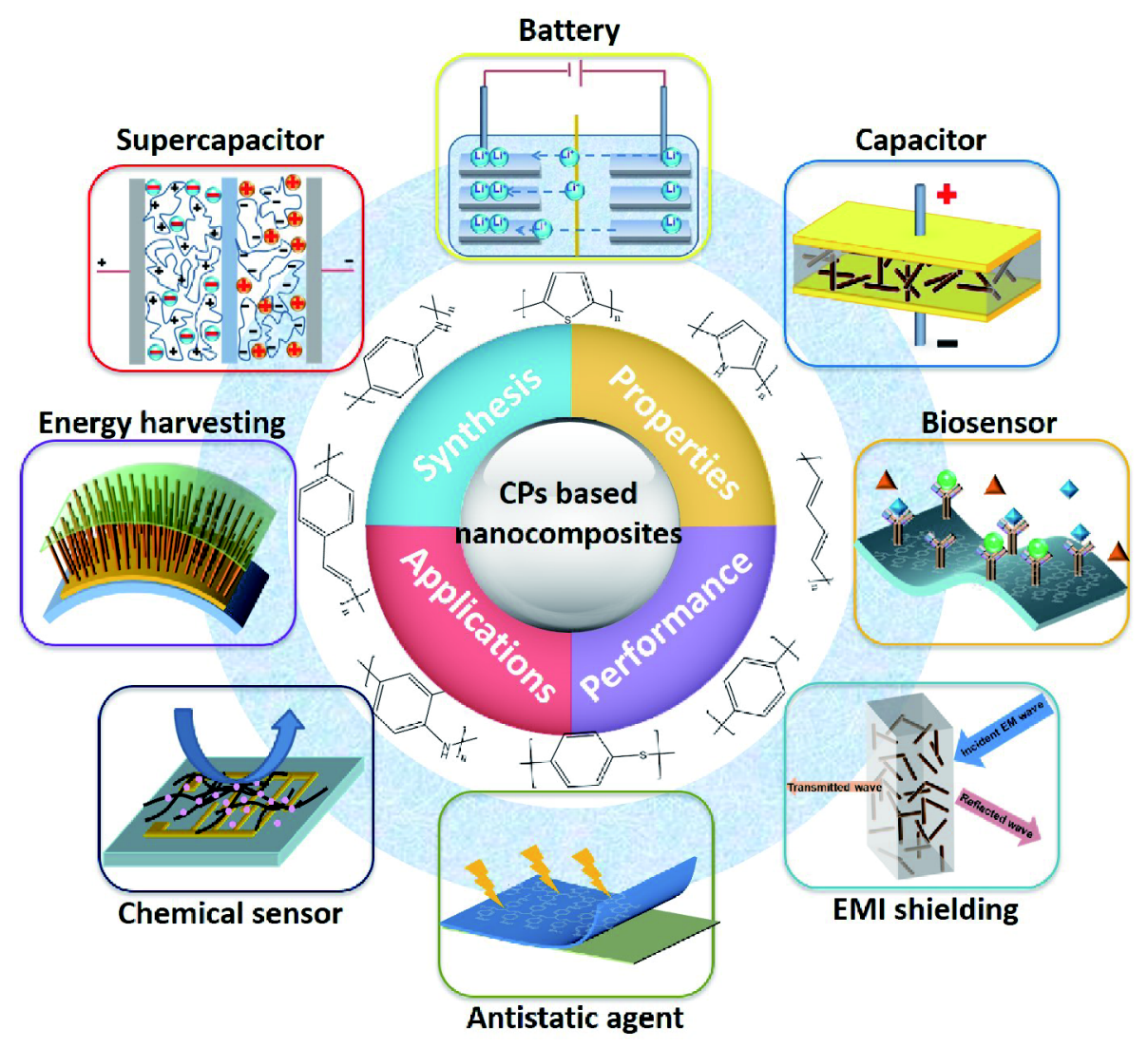

Figure 2 An overview of conducting polymers based nanocomposites and applications.

a complete control of the size and shape of NCPs [8]. The advantage of hard template method is that both chemical and electrochemical polymerization can be used in the following steps. For chemical template synthesis, the hard template is immersed in a solution with monomer, oxidant and dopant for monomer polymerized either on their surface or in the pores/channels. The properties of the chemically synthesized NCPs are dependent on the reaction conditions, such as the characteristics of template, the concentration of monomer, type of oxidant, reaction time and temperature. For electrochemical template synthesis, the template with a metal film as electrode can achieve NCPs. Besides the chemical factors, the properties of NCPs can also be influenced by the concentration of monomers/dopants, range and duration of the potential, and charge transport during the polymerization process [40].

For 0D NCPs, colloidal nanoparticles are usually used as templates. The monomers are polymerized onto the surface of nanoparticles to form a core-shell structure
[41,42]. Metal oxide nanoparticles or polymer microspheres are the most widely used colloidal nanoparticles [43]. The final shape and size of NCPs strongly depend on the dimension of colloidal nanoparticles. There are several advantages in this method, such as homogeneous size distribution, easy to obtain in large quantity, and easy to synthesize [8]. For example, hollow octahedral PANI was synthesized using uniform octahedral $\mathrm{Cu}_{2} \mathrm{O}$ crystals (0.6-1.3 $\mu \mathrm{m}$ in rhombic length) as a template in the solution with dopant and oxidant. $\mathrm{Cu}_{2} \mathrm{O}$ provided the novel structure and can be removed easily by the oxidative initiator [44]. However, post-processing for template removal is tedious and may influence the final shape of hollow nanostructures.

For 1D NCPs, template with nano-sized channel or porous membrane has been used to restrict the deposition/growth for the fabrication of aligned CP nanowires/ tubes, which was proposed by Martin [45]. Anodic aluminum oxide (AAO) and particle track-etched membranes (PTM) have been widely applied with good 

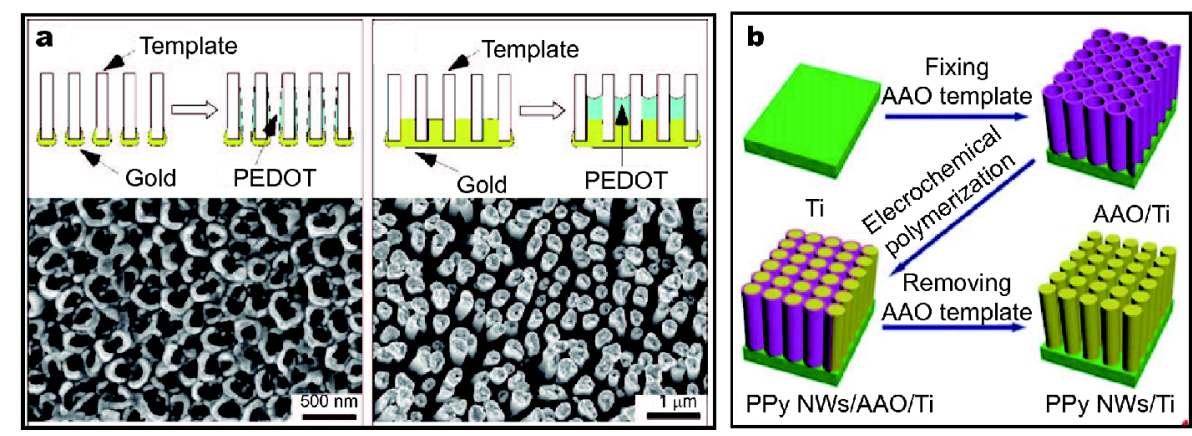

Figure 3 (a) Growth mechanism of PEDOT nanostructures at lower oxidation potentials $(<1.4 \mathrm{~V})$ : the predominance of electrochemically active sites on sharp electrode edges. Two base electrodes are considered: (left) annular and (right) flat-top electrodes. SEM images present the base electrode morphologies. Reprinted with permission from Ref. [50] (Copyright 2008, American Chemical Society). (b) Schematic depiction of PPy nanowires preparation by electrochemical polymerization with AAO as the template. Reprinted with permission from Ref. [49] (Copyright 2016, Royal Society of Chemistry).

controllability to produce CP nanowires/tubes $[14,45-$ 47]. The diameters of PTMs pores can be as small as $10 \mathrm{~nm}$ and the density of pores ranges from $10^{5}$ to $10^{9}$ pores per $\mathrm{cm}^{2}$ [40]. Many NCPs such as PANI [45,47], PPy [48,49], PEDOT [50,51], have been chemically or electrochemically synthesized in the form of nanowires or nanotubes by different membranes. As shown in Fig. 3a, a fundamental study on PEDOT nanotubes and nanowires in an AAO template indicates that high monomer concentration and low electrochemical polymerization potential favor the formation of nanowires [50], whereas nanotubes are favorable at high oxidation potentials and low monomer concentrations. This is mainly due to the rate competition between monomer diffusion and electrochemical polymerization. In Fig. 3b, PPy nanowirebased triboelectric nanogenerators were synthesized by using electrochemical polymerization method with AAO as template [49]. The Ti substrate was used as electrode and fixed with the AAO template. PPy nanowires grew along the AAO pores by an electrochemical polymerization method and the nanostructure was finally achieved by dissolving AAO template in $\mathrm{NaOH}$ solution. The morphology of grown NCPs can be influenced by several factors such as diffusion and reaction kinetics, interaction between wall of the pores and polymer at higher oxidation potential. The controlled synthetic technique for nanowires/tubes made it feasible to investigate the performances of electrical devices [49]. However, size and pore density of the solid template challenged to produce the NCPs in large-scale using this method.

\section{Soft template}

The soft template synthesis, a frequently used technique to produce NCPs, uses surfactants micelles to confine the polymerization of CPs into low dimensional nanomaterials with specific shapes and size [8]. Compared to hard template, this approach is relatively simple and inexpensive and is able to synthesize NCPs in large quantities. Factors such as microstructure, morphology and concentration of molecular template determine the final size and morphology of NCPs. Typically, micro-emulsion and reversed micro-emulsion polymerization are used to produce such nanostructured materials. Some cationic surfactants such as octyltrimethylammonium bromide (OTAB), decyltrimethylammonium bromide (DTAB) and cetyltrimethylammonium bromide $(\mathrm{CTAB})$ were utilized to form micelles that serve as nanoreactors. The CTAB or DTAB with long alkyl chains can produce $1 \mathrm{D}$ nanostructure, for example PPy nanowires/ribbons in widths of $25-85 \mathrm{~nm}$, while OTAB or nonionic surfactants with shorter chains can produce non-1D nanostructures. Both surfactant and the monomer concentrations strongly influence the morphology of the resulting PPy nanostructures [52,53]. Jang et al. [54] first reported the synthesis of PPy core-shell nanomaterials by microemulsion polymerization using different oxidants, i.e., copper (II) chloride and iron (III) chloride, as shown in Fig. 4a. Finally, PPy hollow nanospheres could be obtained by one-step solvent etching of linear core and surfactants where the core and shell were created. This is due to the difference in oxidation potentials of oxidants used that ensured the double layer structure. The transmission electron microscopy (TEM) and scanning electron microscopy (SEM) images of PPy nanoparticles and hollow spheres are shown in Fig. 4b. The authors also found the increase in surfactant concentration reduces the average size of nanoparticles and increase in the amount of monomer (in this case PPy) results in the 

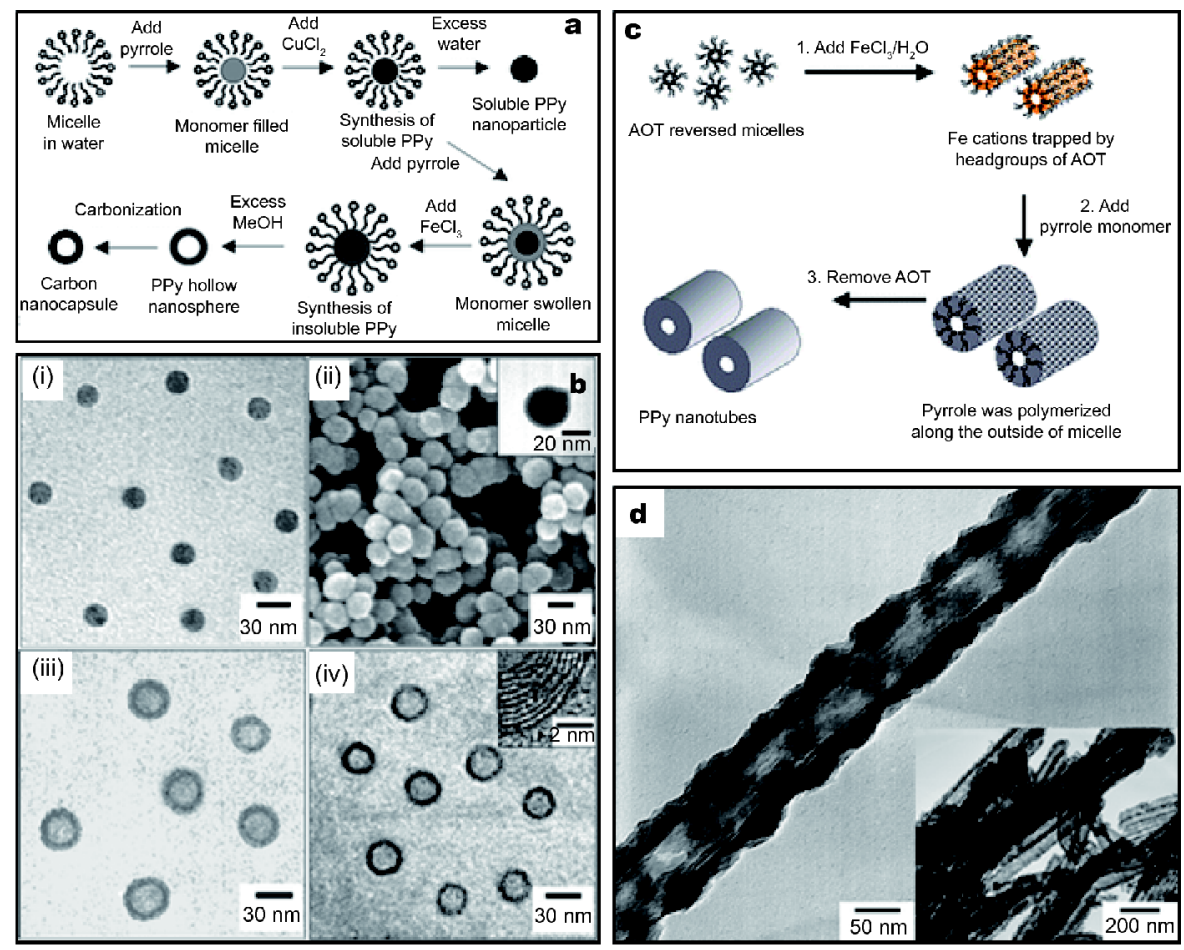

Figure 4 (a) Schematic of the microemulsion fabrication of polypyrrole hollow nanospheres and their carbon derivative. (b) TEM and SEM images of PPy nanoparticles and hollow spheres: (i) soluble polypyrrole nanoparticles; (ii) linear PPy core/shell nanoparticles; (iii) polypyrrole nanocapsules and (iv) carbon nanocapsules. Reprinted with permission from Ref. [54] (Copyright 2004, Royal Society of Chemistry). (c) Schematic of PPy nanotubes fabrication using reverse microemulsion polymerization, (d) TEM image of PPy nanotubes. Reprinted with permission from Ref. [55] (Copyright 2003, Royal Society of Chemistry).

enlarged size of the micelle.

It should be noted that surfactant templates discussed above require effort to synthesize hollow nanostructures. To make it effortless, reverse microemulsion polymerization can be adopted as an effective way to produce nanotubes [7]. Different from microemulsion system, aggregation of surfactant molecules in reverse microemulsion is due to solvation of polar group and hydrogen bonding promoted by water. In this method, nanosized aqueous domains can incorporate various kinds of reactants. These water domains are confined within the reverse micelles and act as nanoreactors for the growth of NCPs. The added ions in the aqueous solution can assist in the formation of rod-shaped structures. Jang et al. [55] first reported the fabrication of PPy nanotubes by reverse microemulsion polymerization in a polar solvent and investigated the mechanism behind the nanotubes formation. As shown in Fig. 4c, d, PPy nanotubes exhibited hollow structure with diameter of $95 \mathrm{~nm}$, length of $5 \mu \mathrm{m}$ and wall thickness of $22 \mathrm{~nm}$. The obtained PPy nanotubes showed enhanced conductivity and higher aspect ratios than that prepared by the self-assembly method. Simi- larly, uniform and well controlled PEDOT nanotubes and nanorods were fabricated indicating these soft-template based on sodium bis(2-ethylhexyl) sulfosuccinate (AOT) reversed micelles is a feasible method to prepare 1D hollow nanostructure [56-59]. However, poor stability of the soft templates and difficulty in a refined control of final morphology of the NCPs are challenging tasks to overcome [7].

In the above discussion on soft template methods, most reports focused on the synthesis of $0 \mathrm{D}$ or $1 \mathrm{D}$ nanostructures. There are few highlighted strategies on fabrication of 2D or even 3D nanostructures. Zhang et al. [60] described a novel, one-step, general oxidative template assembly (OTA) approach to synthesize 2D clip-like nanostructures of PPy, PANI and PEDOT using cetrimonium cations and peroxydisulfate anions, $(\mathrm{CTA})_{2} \mathrm{~S}_{2} \mathrm{O}_{8}$ as a template. As shown in Fig. 5, both PANI and PEDOT powder exhibited nanoclip morphology with diameters of $\sim 100 \mathrm{~nm}$ for PANI and $\sim 200 \mathrm{~nm}$ for PEDOT. This diameter difference is due to the varying sizes of the individual polymer chains and the packing patterns of different polymers. This OTA approach could 


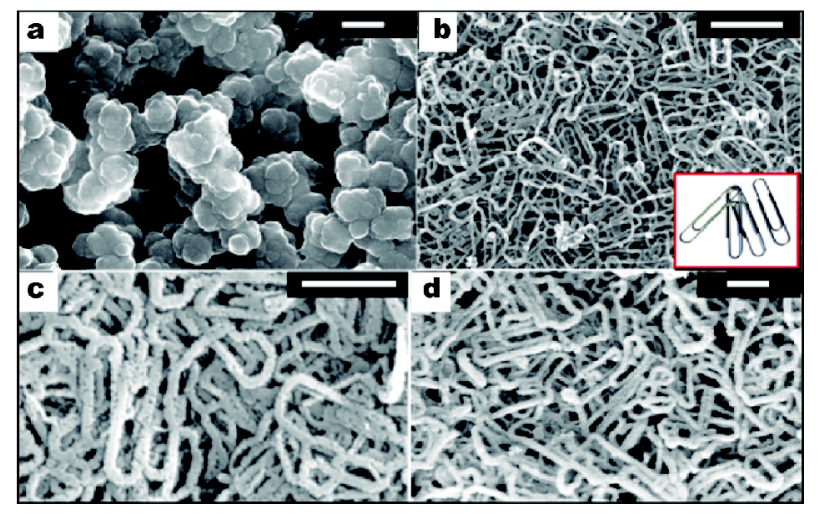

Figure 5 SEM images of (a) granular PPy.Cl (scale bar, $200 \mathrm{~nm}$ ), (b) $\mathrm{PPy} \cdot \mathrm{Cl}$ nanoclips (scale bar, $1 \mu \mathrm{m}$; inset: digital picture of paper clips), (c) PANI $\cdot \mathrm{HCl}$ nanoclips (scale bar, $1 \mu \mathrm{m}$ ), and (d) PEDOT.Cl nanoclips (scale bar, $1 \mu \mathrm{m}$ ). Reprinted with permission from Ref. [60] (Copyright 2010, American Chemical Society).

be used to control the bulk morphology and permit largescale production of NCPs. Li et al. [61] developed an in situ sacrificial oxidative template route for the bulk synthesis of $2 \mathrm{D}$ nanorings and flat hollow capsules of PANI nanostructures.

\section{Template-free approaches}

The template-free approach is considered to be a simple self-assembly and an economical method compared with template-based approach as it requires no external template and no post treatment. Although there are varieties of synthetic approaches to NCPs, it is necessary and desirable to make pure, uniform and template free $\mathrm{CP}$ nanostructures, which only use the mixture of components to achieve a well-ordered structure for the final products. The NCPs can be synthesized by controlling synthesis conditions, such as temperature and molar ratio of monomer to dopant. The most widely used template-free approach includes interfacial, seeding, electrospinning and other nanomanufacturing approaches.

\section{Interfacial approach}

$\mathrm{CPs}$ in $1 \mathrm{D}$ and $2 \mathrm{D}$ nanostructures with uniform diameters, i.e., PANI and PPy nanofibers/nanoneedles/nanoclips can be formed in bulk by one step facile aqueous/ organic interfacial polymerization [62]. Interfacial polymerization reaction regarded as a non-template approach, uses high local concentrations of both monomer and dopant anions at the liquid-liquid interface to promote the formation of monomer-anion (or oligomer-anion) aggregates. The monomer of CPs is dissolved in an organic solvent while the oxidant ammonium perox- ydisulfate is dissolved in an aqueous acidic solution. Different from the conventional aqueous-phase synthesis, the interfacial approach is similar to the synthesis of Nylon and is performed in an immiscible organic/aqueous biphasic system to enable the initiation and propagation of the polymer reaction with fewer nucleation sites [63]. The interaction occurred between initiator molecules and monomers is essentially restricted in a $2 \mathrm{D}$ space (the aqueous/organic interface). NCPs are formed at the interface, and rapidly diffused into the aqueous phase, leaving the interface available for further reaction. PANI nanofibers have been synthesized by different groups using this approach [62-65]. For example, aniline is dissolved in an organic solvent (chloroform or toluene, insoluble in water), while an oxidant ammonium persulfate (APS) is dissolved in an aqueous solution containing strong acid as a dopant for $\mathrm{CPs}\left(\mathrm{HCl}\right.$ or $\left.\mathrm{HClO}_{4}\right)$. The oxidation of aniline occurs around the interface between two immiscible solvents. PANI nanofibers form at the interface within several minutes [64]. As the reaction proceeds, the color of the organic phase becomes darker and finally stops changing, indicating reaction completion. Matsui et al. [66] first reported the synthesis of PEDOT in nanoneedles by an interfacial polymerizationcrystallization process. The aqueous/organic interface consists of 3,4-ethylenedioxythiophene in an organic solvent and ferric chloride as an oxidant in aqueous phase. They also obtained PANI $(63 \mathrm{~nm} \times 12 \mathrm{~nm})$ and PPy $(70 \mathrm{~nm} \times 20 \mathrm{~nm})$ in a rice-like shape at the liquid/ liquid interface using the same method [67]. The resulting crystalline polymers exhibited fast conductance switching time between the insulating and conducting states in the order of milliseconds. This liquid-liquid interfacial method yielded uniform and needle-shaped CPs via oxidative coupling processes in a single crystal state, which is considered as the main advantage over other synthetic methods.

\section{Seeding approach}

Seeding approach first proposed by Zhang and Manohar [68-71], is a relatively novel method to rapidly synthesize bulk quantities of various $\mathrm{CP}$ nanowires/fibers in onestep with control of bulk nanoscale polymer morphologies. In this approach, the type and morphology of nanofibrillar seeds are very important for nanofiber synthesis, which can be selected from a variety of organic, inorganic, and biological systems: (a) PANI nanofibers, (b) single-walled carbon nanotube (SWCNT) bundles, (c) nanofibrous hexapeptide and (d) nanofibers of $\mathrm{V}_{2} \mathrm{O}_{5}$ [7]. This approach includes two techniques, "nanofiber 


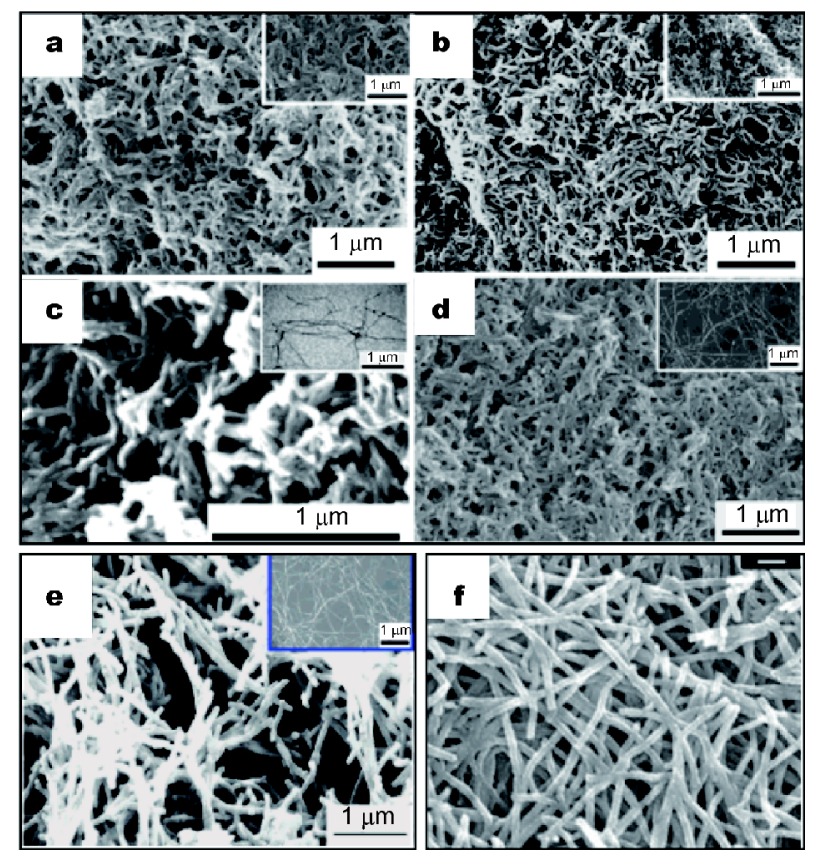

Figure 6 SEM images of nanofibers synthesized by seeding the reaction: (a) PANI nanofibers by emeraldine. $\mathrm{HCl}$ nanofibers, (b) PANI nanofibers by HiPco SWNT, (c) PANI nanofibers by hexapeptide $\mathrm{AcPHF}_{6}$, (d) PANI nanofibers by $\mathrm{V}_{2} \mathrm{O}_{5}$ nanofibers. Reprinted with permission from Ref. [68] (Copyright 2004, American Chemical Society). (e) PPy nanofibers by $\mathrm{V}_{2} \mathrm{O}_{5}$ nanofibers. Reprinted with permission from Ref. [69] (Copyright 2004, American Chemical Society). (f) PEDOT nanofibers by $\mathrm{V}_{2} \mathrm{O}_{5}$ nanofibers (scale bar, $500 \mathrm{~nm}$ ). Reprinted with permission from Ref. [70] (Copyright 2005, Royal Society of Chemistry).

seeding" and "sacrificial template", to synthesize nanofibers and nanotubes of CPs [6]. As shown in Fig. 6, the nanofiber seeding method provided a precise control of the morphology in bulk quantities, such as nanofibers of PANI $\left(20-60 \mathrm{~nm}\right.$ in diameter and $2-10 \mathrm{~S} \mathrm{~cm}^{-1}$ in conductivity) [68], PPy (60-90 $\mathrm{nm}$ in diameter and $\sim 50 \mathrm{~S} \mathrm{~cm}^{-1}$ in conductivity) [69], and PEDOT (100-180 $\mathrm{nm}$ in diameter and $\sim 16 \mathrm{~S} \mathrm{~cm}^{-1}$ in conductivity) [70]. These NCPs have been fabricated in one-step without requiring large organic dopants, surfactants, and/ or bulk quantities of insoluble templates. Seeding a conventional chemical oxidative polymerization of the monomers with very small amounts of nanofiber seeds (usually $<1 \%$ ) dramatically changes the morphology of NCPs from particles to almost exclusively nanofibers. This approach overcomes a key synthetic challenge in the control of nanostructure of CPs by uncovering an important chemical property for seed templates to effectively orchestrate fibrillar polymer growth. Furthermore, a one-step and "green-nano" approach reported by Zhang et al. [72] suggested to synthesize bulk quantities of PPy

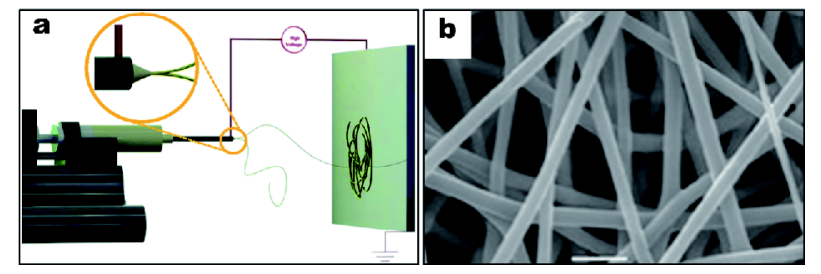

Figure 7 (a) Schematic of electrospinning. Reprinted with permission from Ref. [11] (Copyright 2016, Royal Society of Chemistry). (b) SEM images of electrospun PANI fibers (scale bar: $2 \mu \mathrm{m}$ ). Reprinted with permission from Ref. [77] (Copyright 2014, WILEY-VCH Verlag GmbH \& Co. KGaA, Weinheim).

nanofibers $\left(80-100 \mathrm{~nm}\right.$ in diameter) by $\mathrm{V}_{2} \mathrm{O}_{5}$ nanofiber seeds and ferrous chloride $\left(\mathrm{FeCl}_{2}\right)$, along with the green oxidant $\mathrm{H}_{2} \mathrm{O}_{2}$. The $\mathrm{H}_{2} \mathrm{O}_{2}$ is a green oxidant because the by-product of the reaction is just water, and its combination with different catalysts will offer varied oxidative powers. In summary, the seeding approach provides the opportunity to synthesize bulk quantities of NCPs rapidly in one-step, which is more facile and efficient than template-based methods. For better understanding, the precise synthesis mechanism for these nanostructures from this approach should be investigated in future.

\section{Electrospinning approach}

Electrospinning has been considered as one of the simplest and most effective physical methods to prepare nanoscale 1D structures (nanofibers and nanorods) without any template $[73,74]$. The basic set up of electrospinning system includes three major components: high-voltage power supply, spinneret and an electrical conductive collector, as shown in Fig. 7a [11]. Electrospinning occurs when the repulsion force of a charged solution overcomes the surface tension of the solution under a high electrostatic field between the spinneret and collector. The jet can be simultaneously pulled, stretched, elongated and bent by the electrical force, forming nano/ micro-fibers by rapid solvent evaporation [6]. The main advantage of electrospinning method is to mass-produce continuous long nanofibers, which are difficult to synthesize using other synthetic approaches [39]. Compared to conventional fibers, electrospinning fibers possess special characteristics, such as high aspect ratio, high surface to volume ratio, controlled length, pore size and superior mechanical properties [11]. PANI nanofibers have been synthesized by many research groups using different methods [75]; however, it was a great challenge to produce neat PANI nanofiber by electrospinning due to poor solubility of PANI in common solvents [76]. Electrospun PANI fibers doped with different levels of 
acid were synthesized for gas sensing application [77]. The fibers have different conductivity (vary from $2 \times 10^{-6}$ to $50 \mathrm{~S} \mathrm{~cm}^{-1}$ ) with similar diameters $(500-850 \mathrm{~nm})$. The typical morphology is shown in Fig. 7b. Usually PANI is required to be doped by organic acids to increase its solubility in organic solvents. Previous studies reported the synthesis of PANI with other insulating copolymer i.e., polyethylene oxide (PEO), to form nanofiber with increased elasticity. However, the conductivity of PANI/ PEO was drastically reduced, and the physical and chemical properties were altered [78]. Cardenas et al. [79] successfully fabricated pure PANI sub-micron sized fibers using electrospinning technique, without doping by high molecular weight acids or gaining stability by other polymers. Different from the work reported by MacDiarmid et al. [80] in which $20 \mathrm{wt} . \%$ of PANI was placed in $98 \%$ sulfuric acid, this work used a solution with a considerably lower concentration of PANI (1 wt.\%) in 98\% formic acid. Li et al. [81] first fabricated electrospun conducting PPy fiber $\left(3 \mu \mathrm{m}\right.$ in diameter and $0.5 \mathrm{~S} \mathrm{~cm}^{-1}$ in conductivity). Highly conducting soluble PPy was polymerized using APS as the oxidant and dodecylbenzene sulfonic acid (DBSA) as the dopant source. The polymerization conditions, such as the concentration of the oxidant, polymerization temperature and time determined the electrical conductivity and solubility of a polymer. PPy nanofibers $(70-300 \mathrm{~nm}$ in diameter) were electrospun using different dopants and oxidants [11]. Another approach developed PPy hollow fibers by combining electrospinning and solid-phase extraction [82]. Till now, by improved or modified electrospinning technique, nanofibers with part or even good orientation could be fabricated. Martin et al. [83] reported the fabrication of aligned PEDOT fibers and tubes based on electrospinning and oxidative chemical polymerization. One-dimensional NCPs fabricated by electrospinning approach exhibit unique electronic and optical properties that can be modified through doping and have wide application in rechargeable batteries, chemical and biological sensors, electromagnetic shielding and wearable electronics, which will be discussed in following sections.

\section{Other approaches}

Some other template-free methods have been also reported to produce NCPs.

Radiolysis has been used to synthesize NCPs by $\gamma$-irradiation under ambient temperature and pressure. This approach possesses some advantages over other methods such as, absence of foreign matter, polymerization at room temperature, reaction uniformly by $\gamma$-irradiation and easy control of reaction rate [6]. Pillalamarri et al. [84] developed the radiolytic synthesis of PANI nanofibers $(50-100 \mathrm{~nm}$ in diameter and $1-3 \mu \mathrm{m}$ in length) and nanorods $(250-500 \mathrm{~nm}$ in diameter and $5-10 \mu \mathrm{m}$ in length) by $\gamma$-ray irradiated aqueous solutions of aniline in the presence of initiator. The obtained nanofibers can be extracted after washing cycles and the polymer can be doped with acids such as $\mathrm{HCl}, \mathrm{HClO}_{4}$, etc. Lee et al. [85] reported the synthesis of highly uniform PPy particles $(100 \sim 500 \mathrm{~nm}$ in diameter) with a good electrical property by in-situ $\gamma$-irradiation/induced chemical oxidative polymerization method. Remita et al. [86,87] did a systematical investigation on radiolytic synthesis of PEDOT nanostructures and related mechanism.

Electrochemical nanowire assembly, which has been employed to grow metal nanowires, can also produce and control the morphology of CPs nanostructures [14]. Li et al. [88] reported a novel template-free process to synthesize PANI nanofibrils by controlled multi-potential electropolymerization. The nucleation sites of PANI were firstly generated on electrode at a higher potential and the nanofibrils were finally obtained at a lower potential. Kwon et al. [89] successfully fabricated PPy nanowires via cathodic electropolymerization from an aqueous solution without templates and chemical additives. The synthesized nanowires were directly deposited on the substrate with a nanoporous and interconnected network structure. The influence of time, monomer concentration and dopant concentration on the morphology of the PPy nanostructures has been well investigated. An innovative electrochemical approach was developed by extending directed electrochemical nanowire assembly to grow PPy $(560 \mathrm{~nm}$ in diameter) and PEDOT nanowires (340 $\mathrm{nm}$ in diameter) along the predicted pathway [90].

Soft lithography is another low-cost, high-resolution and high-throughput approach that can fabricate nanoscale patterns using a micro-mold [91-94]. Zhang et al. [95] reported PEDOT:PSS nanowires $(278-833 \mathrm{~nm}$ in diameter) were patterned by micromolding in capillaries on a glass or a Si wafer. The height of these grown nanowires can be controlled by applying sufficient force on stamp during micropatterning. A large $\mathrm{CP}$ nanowires array was fabricated by $\mathrm{Hu}$ and coworkers with internal preferential alignment of nanowires by simple residue free embossing protocol [96]. Another research group studied the direct patterning of functional CPs achieved by a nanoimprint lithography technique [97]. Recently, a technique based on nanoimprint lithography and a lift-off process for patterning CPs was proposed [98]. The patterned CPs from aqueous solutions or organic solvents at 
Table 2 Advantages and disadvantages of synthetic approaches

\begin{tabular}{|c|c|c|}
\hline Synthetic approaches & Advantages & Disadvantages \\
\hline Hard template & $\begin{array}{l}\text { Feasible for almost all CPs. The size and morphology } \\
\text { of CPs can be well controlled. }\end{array}$ & Additional process to remove the template is required. \\
\hline Soft template & $\begin{array}{c}\text { A simple and inexpensive method. Synthesize NCPs } \\
\text { in large quantities. }\end{array}$ & Weak control the size and morphology of NCPs. \\
\hline Interfacial & Simple and facile synthesis without template. & Restrict to certain precursors. \\
\hline Seeding & $\begin{array}{l}\text { Synthesize NCPs in one-step rapidly with bulk } \\
\text { quantities. The seeds play a dual role as both the } \\
\text { templates and the reactive oxidants. }\end{array}$ & Difficulty in fabricating hollow nanotubular structures. \\
\hline Electrospinning & Simple method to synthesize CP nanofibers. & Only available for soluble and thermoplastic CPs. \\
\hline Radiolysis & $\begin{array}{l}\text { Synthesize NCPs at room temperature and in } \\
\text { ambient pressure. The process is easily controlled } \\
\text { and adaptable without inducing impurities. }\end{array}$ & $\begin{array}{c}\text { Weak control on the size and morphology of NCPs. } \\
\text { Precise control of dose rate and time of radiolysis is } \\
\text { required. }\end{array}$ \\
\hline Electrochemical assembly & $\begin{array}{l}\text { The size and morphology of NCPs can be } \\
\text { well controlled. }\end{array}$ & $\begin{array}{c}\text { Lacks a precise control in the morphologies and } \\
\text { dimensions of NCPs. }\end{array}$ \\
\hline Soft lithography & Low-cost, high-resolution and high-throughput. & Expensive facilities are required. \\
\hline
\end{tabular}

Partially reproduced from references $[9,39]$.

nanoscale make it possible to use these materials in flexible optoelectronic devices.

In summary, CPs with different nanostructures can be synthesized by many approaches as discussed above. According to our knowledge and discussions of other scientists, the distinct definitions of various methods are not quite clear, such as "template-free", "self-assembly" or "soft template" [9]. Each approach has its advantages and disadvantages as listed in Table 2. The preparation steps and the ability of the technique determine the size, morphology, properties of final CPs. For example, the solid template is necessary for hard template which mainly determines the morphology of CPs, while it is not necessary for soft template in which the morphology of the CPs can be varied by changing synthetic conditions. Electrospinning process is assumed as the best method to obtain long nanofibers. However, some non-conducting polymers (i.e., PEO) usually are used as assistant to tune the viscosity of the mixture. How to select the approach is according to many factors, such as the requirement of size and morphology of final CPs, the physical and chemical properties, the initial raw materials, the amount of $\mathrm{CPs}$ and the current experimental conditions.

\section{STRATEGIES TO FABRICATE ADVANCED FUNCTIONAL NANOCOMPOSITES}

Recently, CP based nanocomposites with high surface area, controlled morphology and tunable electric properties have achieved superior performance and fascinated many researchers because of their usefulness in many applications. The properties and performances of $\mathrm{CP}$ based nanocomposites not only rely on the quality and morphology of each component, but also highly depend on the fabrication approach selected.

\section{$\mathrm{CP} /$ metal nanocomposites}

NCP composites with metal nanoparticles take advantage of organic and inorganic components, which possess the combined properties other material does not have. This combination provides an attractive route to reinforce the electronic interaction between the two components by morphological modification and structural rebuilding. This strong electronic interaction increases the electrochemical and electrocatalytic activities and sensing capabilities of the nanocomposites, compared to pure CPs [25,99-101]. Different designed morphologies require different starting materials and fabrication methods, as listed in Table 3. Although it is a challenge to develop CP/ metal nanocomposites with a complex architecture, including 3D network, core-shell and multilayered heterostructures, they have been successfully developed by common approaches such as, oxidative polymerization, chemical reaction, electrochemical deposition and electrospinning techniques [31,102]. The in situ oxidative polymerization is a facile method that mixes metal particles with monomers and certain oxidizing agent with different molar ratio [103]. The principle of chemical method is to reduce metal ions from their salt chemicals, such as $\mathrm{HAuCl}_{4}, \mathrm{H}_{2} \mathrm{PdCl}_{4}, \mathrm{H}_{2} \mathrm{PtCl}_{6}, \mathrm{AgNO}_{3}$ at the interface of $\mathrm{CPs}$ and salt solution while polymerization occurred simultaneously with the reduction of metal ions. The obtained metal nanoparticles will be formed on the surface of CPs or integrated with NCPs. Electrochemical synthesis approach involves the direct deposition of metal 
Table 3 Synthesis and applications of selected CP/metal nanocomposites

\begin{tabular}{|c|c|c|c|c|c|}
\hline $\begin{array}{l}\text { Conducting } \\
\text { polymer }\end{array}$ & Metal & Preparation method & Morphology & $\begin{array}{l}\text { Properties and } \\
\text { application }\end{array}$ & Ref \\
\hline PANI & $\mathrm{Au}$ & $\begin{array}{l}\text { In situ oxidative polymerization of aniline } \\
\text { with gold nanoparticles }\end{array}$ & Nanocomposite fibers & Ammonia sensing & [103] \\
\hline PANI & $\mathrm{Au}$ & $\begin{array}{l}\text { One-pot oxidation using chloroauric acid } \\
\text { as the oxidant }\end{array}$ & $\begin{array}{l}\text { Pseudo-spherical } \\
\text { structure }\end{array}$ & Immunosensor & [100] \\
\hline PANI & $\mathrm{Au}$ & $\begin{array}{l}\text { Water/toluene biphasic system using } \mathrm{AuCl}_{4} \\
\text { as an oxidant }\end{array}$ & $\begin{array}{l}\text { Rodlike AuNPs embedded } \\
\text { in polymer }\end{array}$ & $\begin{array}{l}\text { Electrocatalytic } \\
\text { performance }\end{array}$ & [104] \\
\hline PANI & $\mathrm{Au}$ & $\begin{array}{l}\text { PANI shell grown on gold nanoparticles } \\
\text { via in-situ polymerization }\end{array}$ & $\begin{array}{l}\text { Core-shell structure } \\
\text { nanoparticles }\end{array}$ & $\begin{array}{l}\text { Asymmetric superca- } \\
\text { pacitor device }\end{array}$ & [153] \\
\hline PANI & $\mathrm{Fe}^{0}$ & $\begin{array}{l}\text { Reductive deposition of nano- } \mathrm{Fe}^{0} \text { onto } \\
\text { the PANI nanofibers }\end{array}$ & $\begin{array}{l}\text { Nanofibers with a } \\
\text { rough surface }\end{array}$ & $\begin{array}{l}\text { Adsorbent for } \\
\text { removal of arsenic }\end{array}$ & {$[154]$} \\
\hline PANI & $\mathrm{Fe}$ & $\begin{array}{l}\text { Fe was modified by silane and aniline was } \\
\text { polymerized }\end{array}$ & $\begin{array}{l}\text { Core-shell structure } \\
\text { nanoparticles }\end{array}$ & $\begin{array}{l}\text { Exhibit excellent } \\
\text { dielectric properties }\end{array}$ & [155] \\
\hline PANI & $\mathrm{Cu}$ & $\begin{array}{l}\text { In situ polymerization method to produce } \\
\text { polymer and metal }\end{array}$ & $\begin{array}{l}\text { Multibranching } \\
\text { tree-like form }\end{array}$ & $\begin{array}{l}\text { High antimicrobial } \\
\text { efficacy }\end{array}$ & [156] \\
\hline PANI & $\mathrm{Pd}$ & Layer-by-layer electrodeposition & $\begin{array}{l}\text { Sandwich-structured } \\
\text { nanotube array }\end{array}$ & Electrocatalysts & [157] \\
\hline PANI & $\mathrm{Pd}$ & $\begin{array}{c}\text { Drop ascorbic acid in } \mathrm{K}_{2} \mathrm{PdCl}_{4} / \mathrm{DMF} \text { with } \\
\text { PANI/DMF solution }\end{array}$ & $\begin{array}{l}\text { Core-shell structure } \\
\text { nanoparticles }\end{array}$ & Selective catalysts & [158] \\
\hline PPy & $\mathrm{Au}$ & $\begin{array}{l}\text { Polymerize PPy hydrogel and } \\
\text { electrodeposited AuNPs }\end{array}$ & AuNPs in 3D PPy hydrogel & $\begin{array}{l}\text { Sensitive ampero- } \\
\text { metric biosensor }\end{array}$ & {$[106]$} \\
\hline PPy & $\mathrm{Au}$ & $\begin{array}{c}\text { Electro-polymerizing pyrrole on the } \\
\text { nanoporous gold }\end{array}$ & $\begin{array}{l}\text { PPy coated on } \\
\text { bicontinuous AuNPs }\end{array}$ & $\begin{array}{l}\text { Hybrid nanomaterial } \\
\text { for actuation }\end{array}$ & [159] \\
\hline PPy & $\mathrm{Ag}$ & $\begin{array}{l}\text { Coat the incipient network via wet } \\
\text { chemical route }\end{array}$ & $\begin{array}{l}\text { Coaxial nanowire } \\
\text { aero-sponges }\end{array}$ & $\begin{array}{l}\text { Stress sensing and } \\
\text { joule heating }\end{array}$ & [160] \\
\hline PPy & $\mathrm{Ag}$ & $\begin{array}{l}\text { One-pot UV-induced } \\
\text { photopolymerization }\end{array}$ & $\begin{array}{l}\text { Dense structures in } \\
\text { the film plane }\end{array}$ & l & [161] \\
\hline PPy & $\mathrm{Pt}$ & $\begin{array}{l}\text { Polyvinylpyrrolidone assist the } \\
\text { self-assembly }\end{array}$ & $\begin{array}{l}\text { Intercalated } \\
\text { non-woven mesh }\end{array}$ & $\begin{array}{l}\text { Electrocatalyst for } \\
\text { biosensing }\end{array}$ & [111] \\
\hline PEDOT:PSS & $\mathrm{Au}$ & $\begin{array}{l}\text { One-step microplasma assisted } \\
\text { fabrication process }\end{array}$ & Core-shell structures & $\begin{array}{l}\text { Fuel cell electrocata- } \\
\text { lytic application }\end{array}$ & [162] \\
\hline PEDOT:PSS & Ag & Inkjet printing & $\begin{array}{l}\text { Ag grid on } \\
\text { PEDOT:PSS layer }\end{array}$ & $\begin{array}{l}\text { Inkjet-printed } \\
\text { supercapacitors }\end{array}$ & [163] \\
\hline POT & $\mathrm{Au} / \mathrm{Cu}$ & $\begin{array}{l}\text { Seeding polymerization reaction and } \\
\text { a redox/complexation }\end{array}$ & $\begin{array}{l}\text { Web-like structure } \\
\text { of pot with } \mathrm{Au} / \mathrm{Cu}\end{array}$ & $\begin{array}{l}\text { Non-enzymatic } \\
\text { glucose sensors }\end{array}$ & {$[109]$} \\
\hline
\end{tabular}

nanoparticles from metal salts, while depositing CPs simultaneously. The obtained nanocomposite can be formed with metal nanoparticle embedded in CPs matrix or on the surface of formed CPs or inside the CPs nanotubes. Some researchers used the hard template such as porous aluminum oxide or AAO membranes to obtain nanocomposites in nanowires or nanotubes [102]. Bogdanović and co-workers prepared PANI/Au nanocomposite by an interfacial polymerization method [104]. The formation of PANI/Au nanocomposite can be controlled by varying the ratio of initial $\mathrm{Au}^{+}$ions and aniline concentrations. The electrical conductivity of the nanocomposite was significantly higher than that of the polymer. This $\mathrm{CP} /$ metal nanocomposite showed an excellent electrocatalytic performance towards oxygen re- duction reaction. Dutt et al. [105] fabricated a $\mathrm{PANI}_{\text {shell }} /$ $\mathrm{Au}_{\text {core }}$ nanocomposite by pouring the mesophase containing gold chloride over the mesophase solution that contains aniline. The polymerization can be completed in 72 hours and the nanocomposite can be easily extracted from the mesophase. Network nanostructured PPy hydrogel/Au composite was prepared by electrochemical deposition of $\mathrm{Au}$ nanoparticles (AuNPs) on the prepared PPy hydrogel/glassy carbon electrode (GCE) [106]. This 3D PPy hydrogel network provided an augmented effective surface area for biomolecules immobilization, and improved the ionic and electronic transport.

Seeding approach has been recently considered as one of the widely selected techniques to synthesize $\mathrm{CP} /$ metal nanocomposite materials [25,107]. This approach can 


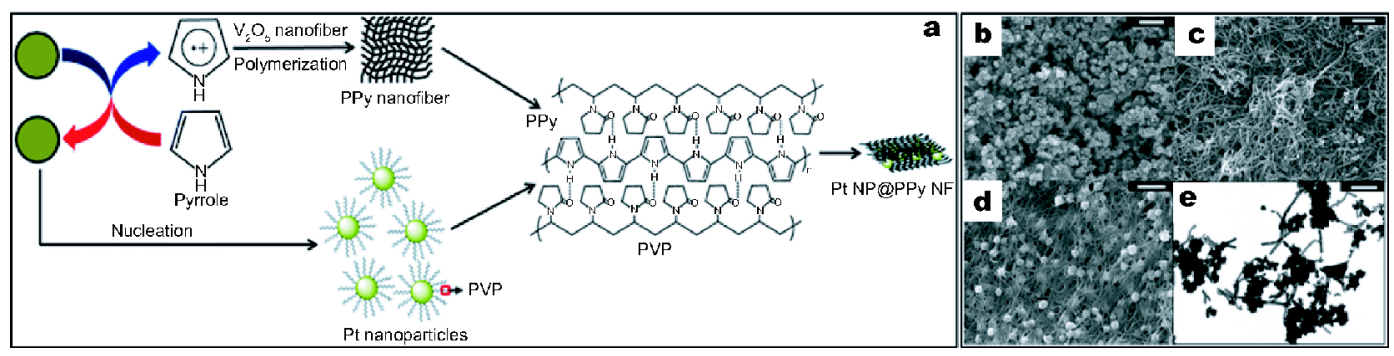

Figure 8 (a) Formation mechanism of the Pt NP@PPy NF structure. Reprinted with permission from Ref. [111] (Copyright 2013, Royal Society of Chemistry). SEM images of (b) PPy granules oxidized by $\mathrm{PtCl}_{2}$ without $\mathrm{V}_{2} \mathrm{O}_{5}$ seeds, (c) PPy/Au nanofiber composites from the $\mathrm{V}_{2} \mathrm{O}_{5} / \mathrm{pyrrole} / \mathrm{AuCl}$ system, (d) PPy/Pt nanofiber composites from the $\mathrm{V}_{2} \mathrm{O}_{5} /$ pyrrole/ $\mathrm{PtCl}_{4}$ system, and (e) TEM image of PPy/Pt nanofiber composites from $\mathrm{V}_{2} \mathrm{O}_{5} / \mathrm{Pyrrole}$ $\mathrm{PtCl}_{4}$ (scale bar, $500 \mathrm{~nm}$ ). Reprinted with permission from Ref. [108] (Copyright 2011, Royal Society of Chemistry).

simultaneously control the morphologies of both conducting polymers and noble metal, without the assistance of other templates or capping agents [108]. For $\mathrm{CP} /$ metal network, Zhang et al. [109,110] first demonstrated a facile and one-step approach to develop PPy/noble metal nanocomposites starting from the monomer and noble metal salts. This method can be used to synthesize other CPs network deposited with noble metal nanoparticles which can be converted to nanocarbon/noble metal nanocomposites by rapid microwave heating. For example, $\mathrm{V}_{2} \mathrm{O}_{5}$ nanofibers were added into aqueous noble metal salt solutions (i.e., $\mathrm{AuCl}, \mathrm{HAuCl}_{4} \cdot 3 \mathrm{H}_{2} \mathrm{O}, \mathrm{PtCl}_{2}$ and $\mathrm{PtCl}_{4}$ ). The pyrrole monomer was added into the mixture to initiate the polymerization reaction. $\mathrm{V}_{2} \mathrm{O}_{5}$ assisted the formation of PPy nanofibers by directing monomer into its nanofibril oligomer form and simultaneously reducing noble metal to nanocrystals. As shown in Fig. 8, the diameter of the PPy nanofibers was in the range of $15-30 \mathrm{~nm}$, and the size of nanoparticles of metals is around $80-100 \mathrm{~nm}$. Many studies have been reported on the synthesizs of CP/ metal nanocomposite based on this approach called " $\mathrm{V}_{2} \mathrm{O}_{5}$ nanofiber seeded polymerization technique" [111], including poly (o-toluidine) $(\mathrm{POT}) / \mathrm{Au} / \mathrm{Cu}[109], \mathrm{PPy} / \mathrm{Ag}$ [112].

\section{$\mathrm{CP} /$ metal oxides nanocomposites}

Many metal oxides have been used in various application areas. They played different roles when used in combination with CPs. Typically, high surface area is desired from both inorganic species and CPs to achieve superior performance with high conductivity. There are many synthesis methods for fabricating $\mathrm{CP} /$ metal oxides nanocomposites but mostly, two synthetic strategies have been employed to prepare the hybrids of CPs coupled with metal oxides: i) preparing nanostructured metal oxides in the presence of CPs by chemical reactions, and ii) polymerizing monomer in the presence of magnetic metal oxides. In both strategies, different approaches have been involved, including hydrothermal method [113115], solvothermal method [116], calcination of $\mathrm{M}(\mathrm{OH})_{x}$ (M: metal) nanoparticles [117], self-assembly method [118], thermal treatments, solution phase growth [119], electrodeposition [120], photopolymerization [121] and electropolymerization. For example, Table 4 shows the synthesis and applications of selected conducting polymer based nanocomposites with metal oxides. The nanotube array, core-shell nanostructure and 3D porous hybrids may result in excellent electronic and electrochemical activity due to fully utilizing the synergistic properties between the metal oxides and CPs. Besides metal oxides, other inorganic species have been used in CP-based nanocomposites for special applications, which have similar preparation process as $\mathrm{CP} / \mathrm{metal}$ oxides composites. The synthesis and applications of CPs with other inorganic compounds are also listed in Table 4.

In the first strategy, nanostructured metal oxides are prepared in the presence of $\mathrm{CPs}$, which means the first step is to synthesize CPs or directly use CPs as templates. In this strategy, the reaction of metal oxides should not influence the properties and morphology of CPs. Xia et al. [122] fabricated $\mathrm{PANI} / \mathrm{RuO}_{2}$ core-shell nanofiber arrays on carbon cloth (CC) as pseudocapacitor materials. As shown in Fig. 9a and b, a thin layer of $\mathrm{RuO}_{2}$ was grown by atomic layer deposition (ALD) on PANI nanofibers. Properties of samples with different ALD cycles of $\mathrm{RuO}_{2}$ have been studied, which showed that $\mathrm{RuO}_{2}$ layer played a crucial role in stabilizing the PANI pseudocapacitors and improving the energy density. For core-shell nanostructures of composites such as PANI/ $/ \mathrm{MoO}_{3}, \mathrm{PPy} / \mathrm{MoO}_{3}$, $\mathrm{PPy} / \mathrm{VO}_{2}, \mathrm{PPy} / \mathrm{SnO}_{2}$ PEDOT:PSS $/ \mathrm{V}_{2} \mathrm{O}_{5}$ and other composites have been synthesized by hydrothermal method [113-115], transmission electron microscope can be used 
Table 4 Synthesis and applications of selected CP based nanocomposites with metal oxides and other inorganic compounds

\begin{tabular}{|c|c|c|c|c|c|}
\hline $\begin{array}{l}\text { Conducting } \\
\text { polymer }\end{array}$ & $\begin{array}{l}\text { Inorganic } \\
\text { compounds }\end{array}$ & Preparation method & Morphology & $\begin{array}{l}\text { Properties and } \\
\text { application }\end{array}$ & Ref \\
\hline PANI & $\mathrm{TiO}_{2}$ & $\begin{array}{l}\text { Hydrothermal and } \\
\text { electropolymerization }\end{array}$ & Core-shell nanorod array & Electrochromic material & {$[114]$} \\
\hline PANI & $\mathrm{ZnO}$ & $\begin{array}{l}\text { Precipitation followed by } \\
\text { sonication process }\end{array}$ & $\begin{array}{l}\mathrm{ZnO} \text { embedded in } \\
\text { PANI matrix }\end{array}$ & Visible light photocatalytic & {$[164]$} \\
\hline PANI & $\mathrm{CdO}$ & $\begin{array}{l}\text { In diethylene glycol solution by } \\
\text { oxidative polymerization }\end{array}$ & $\begin{array}{l}\text { Spherical and elliptical } \\
\text { nanoparticles }\end{array}$ & Photocatalytical activity & {$[117]$} \\
\hline PANI & $\mathrm{RuO}_{2}$ & Atomic layer deposition & $\begin{array}{l}\text { Core-shell nanofiber } \\
\text { arrays }\end{array}$ & $\begin{array}{l}\text { Highly stable } \\
\text { pseudocapacitors }\end{array}$ & {$[122]$} \\
\hline PANI & $\mathrm{Fe}_{3} \mathrm{O}_{4} / \mathrm{MnO}_{2}$ & $\begin{array}{l}\text { Solvothermal method and } \\
\text { polymerization }\end{array}$ & Core-shell hybrids & $\begin{array}{l}\text { Adsorbents for heavy } \\
\text { metal ions }\end{array}$ & {$[116]$} \\
\hline PANI & $\mathrm{NiO} / \mathrm{CuO}$ & $\begin{array}{l}\text { Electrodeposition and } \\
\text { electrochemical oxidation }\end{array}$ & $\begin{array}{l}\text { Nanoparticles and } \\
\text { nanofibers }\end{array}$ & Non-enzymatic sensor & {$[165]$} \\
\hline PANI & $\mathrm{NiCo}_{2} \mathrm{O}_{4}$ & $\begin{array}{l}\text { Hydrothermal treatment and } \\
\text { in situ polymerization }\end{array}$ & Core-shell structure & $\begin{array}{l}\text { Sensitive determination of } \\
\text { glucose }\end{array}$ & {$[166]$} \\
\hline PANI & Hydrogen titanate & $\begin{array}{c}\text { A simple oxidative } \\
\text { polymerization method }\end{array}$ & $\begin{array}{l}\text { 1D core-shell structured } \\
\text { composites }\end{array}$ & $\begin{array}{l}\mathrm{Cr}(\mathrm{VI}) \text { and humic acid } \\
\text { removal }\end{array}$ & {$[118]$} \\
\hline PANI & $\mathrm{MnFe}_{2} \mathrm{O}_{4}$ & $\begin{array}{l}\text { Incorporating } \mathrm{MnFe}_{2} \mathrm{O}_{4} \text { during } \\
\text { polymerization of aniline }\end{array}$ & Fiber-like network structure & Microbial fuel cell & {$[167]$} \\
\hline PPy & $\mathrm{CuO}$ & $\begin{array}{l}\text { Polymerization of pyrrole with } \\
\mathrm{CuO} \text { as wire templates }\end{array}$ & Core-shell structures & Lithium batteries & [119] \\
\hline PPy & $\mathrm{TiO}_{2}$ & $\begin{array}{l}\text { Pulsed-light and pulsed-potential } \\
\text { methods }\end{array}$ & $\begin{array}{l}\text { Highly ordered } \\
\text { nanotube arrays }\end{array}$ & l & {$[120]$} \\
\hline PPy & $\mathrm{TiO}_{2}$ & Density functional theory simulation & l & An efficient photocatalyst & {$[168]$} \\
\hline PPy & $\mathrm{SnO}_{2}$ & Vapor phase polymerization & Nanosheets and nanofibers & $\begin{array}{l}\text { Highly sensitive } \mathrm{NH}_{3} \text { gas } \\
\text { sensors }\end{array}$ & [169] \\
\hline PPy & $\mathrm{NiO}$ & Solvothermal reduction & Needle-like structures & $\begin{array}{l}\text { Non-enzymatic detection of } \\
\text { glucose }\end{array}$ & {$[170]$} \\
\hline PPy & $\mathrm{CoO}$ & $\begin{array}{c}\text { CoO grown on } 3 \mathrm{D} \text { nickel foam } \\
\text { with PPy }\end{array}$ & Well-aligned $\mathrm{CoO}$ nanowire & $\begin{array}{c}\text { Asymmetric } \\
\text { supercapacitors }\end{array}$ & {$[171]$} \\
\hline PPy & $\mathrm{WO}_{3}$ & In situ photopolymerization & $\begin{array}{l}\text { Uniform granular } \\
\text { morphology }\end{array}$ & $\mathrm{H}_{2} \mathrm{~S}$ gas sensor & {$[121]$} \\
\hline PPy & $\mathrm{Fe}_{2} \mathrm{O}_{3}$ & $\begin{array}{l}\text { Hydrothermal and electrochemical } \\
\text { polymerization }\end{array}$ & $\begin{array}{l}\text { 3D honeycomb-like } \\
\text { nanoflakes/leaves }\end{array}$ & $\begin{array}{l}\text { Asymmetric } \\
\text { supercapacitors }\end{array}$ & {$[123]$} \\
\hline PPy & $\mathrm{ZnCo}_{2} \mathrm{O}_{4}$ & Chemical polymerization method & $\begin{array}{l}\text { Mesoporous } \mathrm{ZnCO}_{2} \mathrm{O}_{4} \\
\text { with } \mathrm{PPy}\end{array}$ & $\begin{array}{l}\text { Anode for lithium-ion } \\
\text { batteries }\end{array}$ & {$[172]$} \\
\hline PPy & $\mathrm{LiV}_{3} \mathrm{O}_{8}$ & $\begin{array}{l}\text { Low-temperature in situ oxidative } \\
\text { polymerization route }\end{array}$ & Nanorods & $\begin{array}{l}\text { Rechargeable lithium } \\
\text { batteries }\end{array}$ & {$[173]$} \\
\hline PEDOT & $\mathrm{V}_{2} \mathrm{O}_{5}$ & $\begin{array}{l}\text { Cocoon-to-silk fiber reeling } \\
\text { process }\end{array}$ & $\begin{array}{c}\text { Layered } \mathrm{V}_{2} \mathrm{O}_{5} / \mathrm{PEDOT} \\
\text { nanobelts }\end{array}$ & Planar perovskite solar cells & {$[174]$} \\
\hline PEDOT & $\mathrm{Fe}_{2} \mathrm{O}_{3}$ & $\begin{array}{l}\text { Spin-casted and in situ } \\
\text { polyreaction }\end{array}$ & $\begin{array}{l}\text { Composite films with } \\
\text { rough surface }\end{array}$ & Dye sensitized solar cells & {$[175]$} \\
\hline PEDOT:PSS & $\mathrm{V}_{2} \mathrm{O}_{5}$ & $\begin{array}{l}\text { Hydrothermal method } \\
\text { and spin-coating }\end{array}$ & $\begin{array}{l}\text { Double-decked } \\
\text { buffer layer }\end{array}$ & Photovoltaic cells & {$[115]$} \\
\hline PEDOT:PSS & $\mathrm{Mn}_{2} \mathrm{O}_{3}$ & $\begin{array}{l}\text { Hydrothermal method and mix } \\
\text { with PEDOT:PSS }\end{array}$ & Nanowires & Lithium ion battery anodes & {$[176]$} \\
\hline PEDOT & $\mathrm{NiO} / \mathrm{Ni}(\mathrm{OH})_{2}$ & Mild electrochemical route & Flowerlike porous arrays & $\begin{array}{l}\text { Flexible asymmetric } \\
\text { supercapacitors }\end{array}$ & {$[177]$} \\
\hline
\end{tabular}

to characterize and verify the formation of core-shell structure, and to show the core phase of metal oxide and the amorphous CPs shell.

In the second strategy where monomers are polymerized in the presence of magnetic metal oxides, Fig. 9c and d, showed a 3D honeycomb-like hematite nanoflakes/ branched PPy nanoleaves heterostructures [123]. The core-branch heterostructures facilitated the combination of inorganic metal oxides and CPs. The $\mathrm{MnO}_{2}$ nanosheets were first synthesized by a cathode electrodeposition 


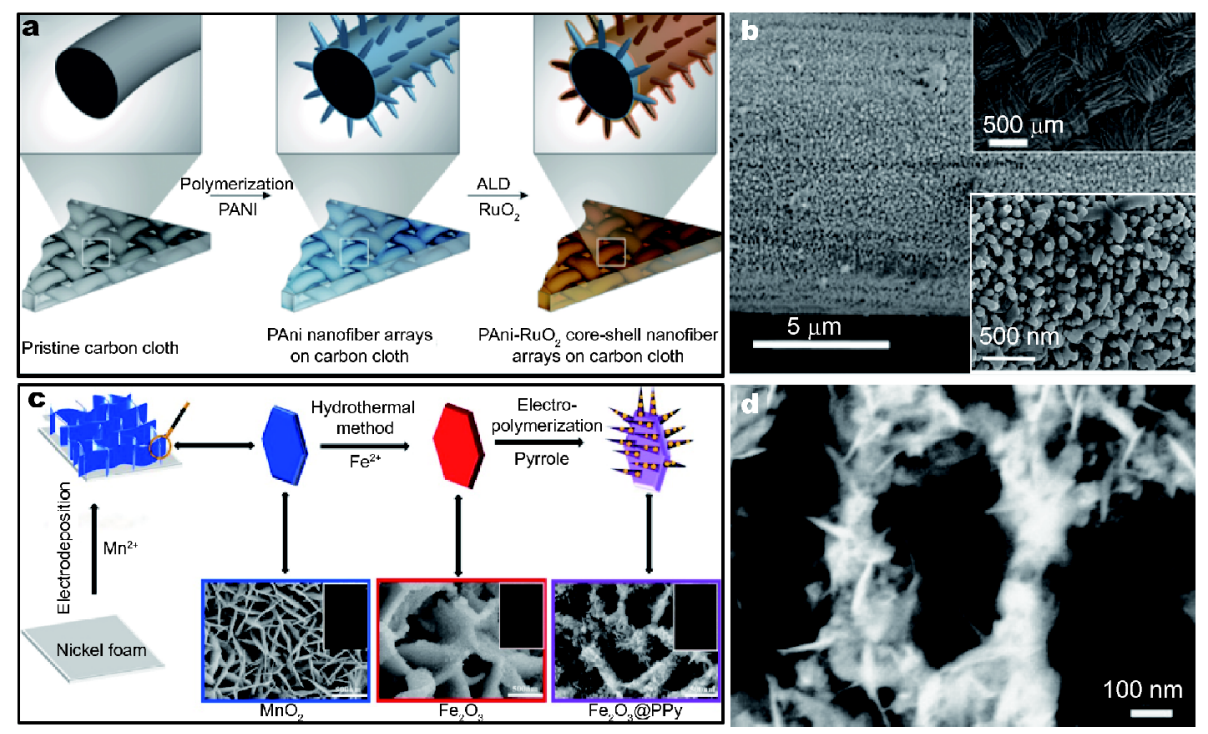

Figure 9 (a) Schematic of the design process of $\mathrm{PANI} / \mathrm{RuO}_{2}$ core-shell nanofiber arrays on carbon cloth and (b) $\mathrm{PANI} / \mathrm{RuO} \mathrm{O}_{2}$ core-shell nanofiber arrays with $500 \mathrm{ALD}$ cycles of $\mathrm{RuO}_{2}$. Reprinted with permission from Ref. [122] (Copyright 2015, WILEY-VCH Verlag GmbH \& Co. KGaA, Weinheim). (c) Fabrication process of core-branch $\mathrm{Fe}_{2} \mathrm{O}_{3} @ P P y$ heterostructures, and (d) SEM image of honeycomb-like $\mathrm{Fe}_{2} \mathrm{O}_{3}$ nanoflakes@PPy nanoleaves. Reprinted with permission from Ref. [123] (Copyright 2016, Elsevier).

technology, and then the obtained $\mathrm{MnO}_{2}$ nanosheets were employed as the sacrificed template to synthesize the honeycomb-like $\mathrm{Fe}_{2} \mathrm{O}_{3}$ nanoflakes by hydrothermal method. Afterwards, PPy nanoleaves were electrodeposited on the $\mathrm{Fe}_{2} \mathrm{O}_{3}$ nanoflakes. Compared with $0 \mathrm{D}-$ 2D nanostructure, 3D branched nanoarchitectures possess extraordinary advantages such as larger surface areas, direct electron and ion transport pathways. The self-assembly method, discussed previously in CPs synthesis, is also a facile and versatile technique to nanocomposites. In the preparation of $1 \mathrm{D} \mathrm{PANI} / \mathrm{TiO}_{2}$ nanocomposites, $\mathrm{TiO}_{2}$ nanoparticles can be well dispersed in a $\beta$-naphthalene sulfonic acid solution prior to the polymerization of aniline monomer. $\mathrm{TiO}_{2}$ nanoparticles surrounded in micelles with aniline can be considered as a soft template to form PANI. In PANI coated protonic titanate nanobelt composites, titanate nanobelt precursors were synthesized through an alkaline hydrothermal treatment process, and PANI was coated as shell by self-assembly approach [118].

\section{$\mathrm{CP} /$ metal chalcogenides nanocomposites}

During the past decades, ultrathin 2D nanostructured metal chalcogenides (MCs) have attracted significant attention because of their distinctive compositional and unique features [124]. MCs consist of a variety of materials $\left(\mathrm{MX}_{2}: \mathrm{M}=\mathrm{W}, \mathrm{Mo}, \mathrm{Sn}, \mathrm{Ti}, \mathrm{Re}, \mathrm{Nb}, \mathrm{Ta}, \mathrm{Hf}, \mathrm{Zr}\right.$ and $\mathrm{X}=$ $\mathrm{S}, \mathrm{Se})$ and exhibit outstanding properties in diverse ap- plications such as energy conversion and storage, sensor, thermoelectric devices, memory devices and biomedical devices [125]. However, the tremendous investigation and achievement on MCs do not only rely on their inherent material properties, also largely depend on their adjustable properties with other nanomaterials [124]. Due to outstanding electrical properties of CPs, the combination of CPs with ultrathin MCs hybrid nanostructures becomes the focus of enormous research for both fundamental properties and various kinds of applications. Varieties of synthetic approaches for CP/MCs nanocomposites with various morphologies, structures and properties have been developed to satisfy the requirements arising from different applications [126].

In situ polymerization synthesis is a widely used method to fabricate $\mathrm{CP} / \mathrm{MCs}$ hybrid nanomaterials with a variety of morphologies [125]. During the synthesis, CP monomers and MCs are added into the host dispersion and polymerization initiates on the addition of oxidant solution and $\mathrm{CP} / \mathrm{MC}$ nanocomposites can be obtained after purification treatment. There are several parameters that can alter the final morphology of nanocomposite such as concentration of monomer, dopant and oxidant, molar ratio of oxidant to monomer, temperature and reaction time. Zhu et al. [127] demonstrated a facile strategy via an ice-reaction process to construct the architecture by coupling PANI nanoneedle arrays with $\mathrm{MoS}_{2}$ thin nanosheets. Typically, $\mathrm{MoS}_{2}$ nanosheets were obtained by 


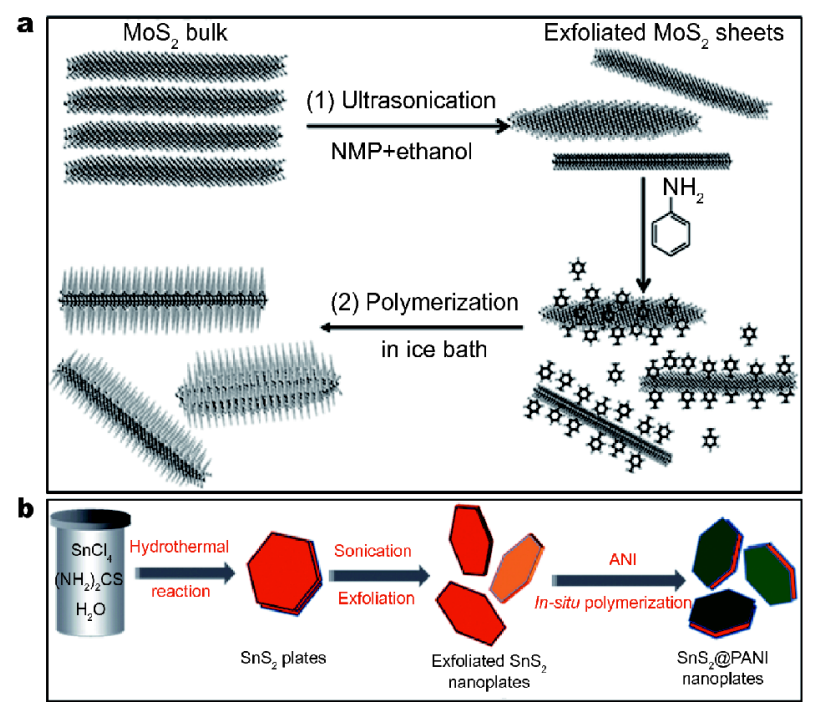

Figure 10 Schematic illustration of the fabrication of: (a) MoS @PANI architectures. Reprinted with permission from Ref. [127] (Copyright 2015 WILEY-VCH Verlag GmbH \& Co. KGaA, Weinheim) and (b) SnS 2 PANI nanoplates. Reprinted with permission from Ref. [128] (Copyright 2014, Royal Society of Chemistry).

ultrasonication of bulk $\mathrm{MoS}_{2}$, and these nanosheets serve as a substrate for in situ growth PANI nanoneedles via ice-reaction as shown in Fig. 10a. Wang et al. [128] proposed a synthetic procedure for $\mathrm{SnS}_{2} @ P A N I$ nanoplates involving three facile steps shown in Fig. 10b: i) hydrothermal synthesis of $\mathrm{SnS}_{2}$ plates, ii) exfoliation of $\mathrm{SnS}_{2}$ plates by ultrasonication and iii) in situ coating of PANI. Many other groups have also fabricated ternary nanocomposite adding reduced graphene oxide (rGO) with PANI and MCs for high performance supercapacitors. $[129,130]$.

Solution mixing is another method widely used for the preparation of $\mathrm{CP} / \mathrm{MC}$ nanocomposites [131]. This method typically involves dispersion of CPs and MCs nanosheets separately in solvent using stirring or ultrasonication followed by mixing and filtration. For example, the counter electrode for dye-sensitized solar cells was prepared by depositing the composite of PEDOT: $\mathrm{PSS} / \mathrm{MoSe}_{2}$ by drop coating on different substrates [132]. PEDOT:PSS/MoSe ${ }_{2}$ composite could replace Pt owing to its low-cost and good catalytic ability, that offers an opportunity for fabrication of flexible Pt-free dye-sensitized solar cells. PEDOT:PSS, being an excellent water-soluble conducting polymer binder, provides multiple electron transfer pathways between the MCs and the substrate. Similar approach can be adopted for other metals such as Mo, Sn composite with PEDOT:PSS for applications in different areas such as thermoelectric, anode materials for lithium-ion batteries etc. [133,134]. Another research group reported the exfoliation of $\mathrm{MoS}_{2}$ nanosheet in PEDOT:PSS solution by sonication mixing [135]. The PEDOT:PSS/MoS ${ }_{2}$ composite thin films were then fabricated through direct vacuum filtration using PVDF membrane.

One-pot synthesis is considered as a facile methodology for the fabrication of different types of nanocomposites $[136,137]$. Lei et al. [138] proposed a template-free onepot synthetic route to prepare algae-like $\mathrm{PPy} / \mathrm{MoS}_{2}$ nanocomposite through a redox reaction between ammonium tetrathiomolybdate $\left[\left(\mathrm{NH}_{4}\right)_{2} \mathrm{MoS}_{4}\right]$ and pyrrole monomer under a hydrothermal condition. The as-prepared unique algae-like $\mathrm{PPy} / \mathrm{MoS}_{2}$ nanocomposites were composed of few layers of $\mathrm{MoS}_{2}$ nanosheets covered with PPy. During the reaction, ammonium tetrathiomolybdate was reduced to $\mathrm{MoS}_{2}$ and pyrrole underwent an in situ chemical oxidative polymerization and $\mathrm{MoS}_{2} / \mathrm{PPy}$ composite was obtained into a $3 \mathrm{D}$ architecture. The as-prepared nanocomposites exhibited excellent catalytic activity and provided a facile strategy for high sensitivity detection of $\mathrm{H}_{2} \mathrm{O}_{2}$. Recently, fullerene-like MCs with PPy fibers have been synthesized by ultrafast microwave nanomanufacturing [139], which showed a single-step and energy-efficient method to obtain $\mathrm{MoS}_{2}$ and $\mathrm{WS}_{2}$.

\section{$\mathrm{CP} /$ carbon nanocomposites}

Hybridization of CPs with carbon nanomaterials can integrate the redox reaction of CPs and high conductivity with large surface area of carbon nanomaterials, which 
Table 5 Synthesis and applications of selected CP based nanocomposites with carbon materials

\begin{tabular}{|c|c|c|c|c|c|}
\hline $\begin{array}{l}\text { Conducting } \\
\text { polymer }\end{array}$ & Carbon & Preparation method & Morphology & Properties and application & Ref \\
\hline PANI & CNTs & Electrospinning & $\begin{array}{l}\text { Porous interconnected } \\
\text { network }\end{array}$ & Supercapacitor electrodes & {$[178]$} \\
\hline PANI & CNTs & $\begin{array}{l}\text { Oxidative polymerization } \\
\text { process }\end{array}$ & $\begin{array}{l}\text { Nanotube network } \\
\text { with carbon cloth }\end{array}$ & Flexible supercapacitors & [143] \\
\hline PANI & DWCNTs & Drop-casting solution & Thin film & $\begin{array}{c}\text { Thermoelectric organic } \\
\text { composites }\end{array}$ & {$[179]$} \\
\hline PANI & $\mathrm{CNT}-\mathrm{COOH}$ & $\begin{array}{l}\text { Chemical oxidative } \\
\text { polymerization }\end{array}$ & Coaxial structure & Supercapacitor & {$[144]$} \\
\hline PANI & Graphene & $\begin{array}{l}\text { Chemical reduction and } \\
\text { electropolymerization }\end{array}$ & $\begin{array}{l}\text { Flexible paper with } \\
\text { nanorod }\end{array}$ & $\begin{array}{l}\text { High-performance } \\
\text { supercapacitor }\end{array}$ & {$[146]$} \\
\hline PANI & Graphene & $\begin{array}{l}\text { One-step electrochemical } \\
\text { co-deposition }\end{array}$ & $\begin{array}{l}\text { PANI nanowires on } \\
\text { nanosheets }\end{array}$ & Flexible supercapacitors & {$[180]$} \\
\hline PANI & Graphene & $\begin{array}{l}\text { In-situ oxidative } \\
\text { polymerization }\end{array}$ & $\begin{array}{l}\text { Flaky wrinkled and folded } \\
\text { sheet-like }\end{array}$ & $\begin{array}{l}\text { Electrodes and } \\
\text { hydrophobicity }\end{array}$ & {$[181]$} \\
\hline PANI & $3 \mathrm{D}-\mathrm{rGO}$ & $\begin{array}{l}\text { One step hydrothermal } \\
\text { method }\end{array}$ & $\begin{array}{c}\text { Interconnected porous } 3 \mathrm{D} \\
\text { network }\end{array}$ & Supercapacitors & {$[182]$} \\
\hline PPy & SWCNTs & $\begin{array}{l}\text { Convenient physical mixing } \\
\text { and vacuum filtration }\end{array}$ & $\begin{array}{l}\text { Unique layer with } \\
\text { nanosheets }\end{array}$ & Thermoelectric performance & {$[183]$} \\
\hline PPy & Graphene & $\begin{array}{l}\text { Coating and electrochemical } \\
\text { reduction }\end{array}$ & $\begin{array}{l}\text { One-dimensional } \\
\text { nanostructure }\end{array}$ & $\begin{array}{l}\text { Supercapacitor and } \\
\text { biosensor }\end{array}$ & {$[184]$} \\
\hline PPy & Graphene & Physical synthesis route & $\begin{array}{c}\text { 3D hybrid } \\
\text { nanoarchitecture }\end{array}$ & $\begin{array}{l}\text { Solid-state flexible } \\
\text { capacitor }\end{array}$ & {$[185]$} \\
\hline PPy & Graphene & Chemical polymerization & $\begin{array}{l}\text { Multilayered nanoarchitec- } \\
\text { ture }\end{array}$ & Supercapacitors & {$[186]$} \\
\hline PPy & $\mathrm{rGO}$ & Chemical polymerization & $\begin{array}{c}\text { Nanotubes and rGO } \\
\text { nanosheets }\end{array}$ & $\begin{array}{l}\text { All-solid-state } \\
\text { supercapacitors }\end{array}$ & [187] \\
\hline PEDOT:PSS & MWCNTs & Physical mixture & Thin film & Humidity sensor & {$[188]$} \\
\hline PEDOT:PSS & MWCNTs & Electropolymerization & $\begin{array}{l}\text { Core-shell and } 3 \mathrm{D} \\
\text { network }\end{array}$ & Electrochemical capacitors & [141] \\
\hline PEDOT:PSS & G/SCNT & Blend and spin-coating & Film with nanosheets & $\begin{array}{c}\text { Transparent conductive } \\
\text { electrodes }\end{array}$ & {$[189]$} \\
\hline PEDOT:PSS & $\mathrm{rGO}$ & Reduce GO to rGO & Hollow hybrid fiber & Fiber supercapacitor & {$[145]$} \\
\hline PEDOT & Carbon & $\begin{array}{l}\text { Pulsed current electro- } \\
\text { polymerization technique }\end{array}$ & $\begin{array}{l}\text { Carbon nanofoam- } \\
\text { fibrous PEDOT }\end{array}$ & Supercapacitor & [190] \\
\hline PEDOT & GO & Electropolymerization & Ridge & Dopamine detection & [191] \\
\hline
\end{tabular}

G/SCNT: graphene dispersion assisted by sulfonated carbon nanotube.

exhibits excellent electronic performance [22]. Carbon nanomaterials including carbon nanofibers, carbon nanotubes (CNTs), graphene, graphene oxide (GO) and rGO are potential components for CP-based nanocomposites (Table 5).

CNTs, exhibiting high mechanical strength, good chemical stability and excellent electrical conductivity, have been widely studied and used in different nanodevices $[31,140]$. However, there are a few limitations for CNTs, such as poor processability and lack of chemical properties. Therefore, CP/CNT nanocomposites would provide a meaningful aspect to improve or extend properties of both nanomaterials. For example, the electron/hole transport will be improved due to the strong interactions.
Many researchers tried to investigate effective methods to synthesize CP/CNT nanocomposites. Electrochemical polymerization is a convenient approach to fabricate $\mathrm{CP} /$ CNT nanocomposites because the morphology and properties of the nanocomposites can be well controlled by the electropolymerization conditions [31]. Zhou et al. [141] used electrochemical polymerization method to synthesize PEDOT:PSS/multiwalled carbon nanotubes (MWCNTs) core-shell composites with 3D porous nanonetwork microstructure. The core-shell nanostructure can significantly reduce the ions diffusion distance, and the $3 \mathrm{D}$ porous nano-network microstructure can effectively increase the electrode/electrolyte interface. Besides the core-shell nanostructures, other nanostructures using 

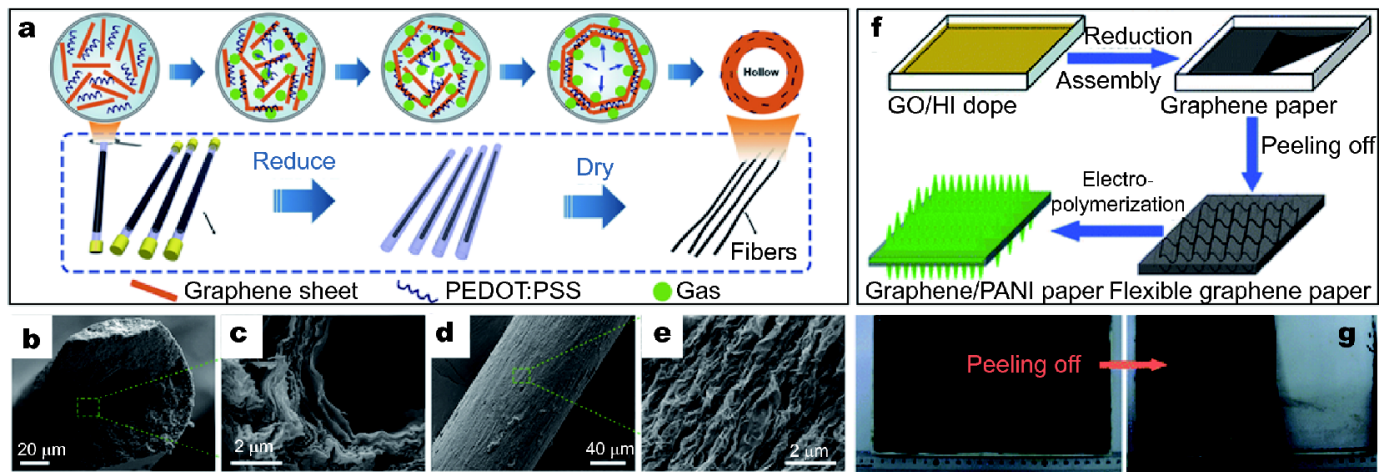

Figure 11 (a) Schematic illustration of preparation of hollow composite fibers and formation of hollow structures, (b) and (c) cross-sectional SEM images of the hollow composite fibers at low and high magnifications, respectively, (d) and (e) SEM images of the hollow composite fibers by a side view at low and high magnifications, respectively. Reprinted with permission from Ref. [145] (Copyright 2016, WILEY-VCH Verlag GmbH \& Co. $\mathrm{KGaA}$, Weinheim). (f) Schematic illustrations of the formation process of PANI/graphene paper, (g) photograph of a piece of the peeling-off graphene paper fabricated in a Teflon substrate. Reprinted with permission from Ref. [146] (Copyright 2013, Royal Society of Chemistry).

CNTs as fillers and CPs as matrix can be prepared by a template-directed electropolymerization method [142]. Chemical polymerization is also widely used for preparation of $1 \mathrm{D} \mathrm{CP} / \mathrm{CNT}[143,144]$. However, due to the poor interactions between $\mathrm{CPs}$ and CNTs, covalent bonding agents were introduced to enhance the interactions, such as p-phenylenediamine, chlorosulfonic acid, poly(aminobenzene sulfonic acid) and other agents [31]. A uniform core-sheath structure and a thick homogeneous coating of CPs can be achieved.

$2 D$ carbon nanomaterials, especially graphene, exhibit high electrical and thermal conductivities, mechanical strength and specific surface area. Many studies have used $\mathrm{GO}$ or rGO with CPs, as listed in Table 5. For some CPs, the swelling/shrinkage during the insertion/deinsertion process of the counter ions causes volume changes and destroys the backbone of $\mathrm{CP}$ itself resulting in smaller charge-discharge cycle. It is necessary to construct $\mathrm{CP} /$ graphene nanocomposites to achieve an optimum supercapacitor electrode for better charge-discharge cycles. In the area of the working electrode in supercapacitor, a binder was always used to stick the active materials onto metal foil, which might make procedures more complex and impair the electrical conductivity, and therefore, many researchers fabricated freestanding composites for capacitance testing. For example, Qu et al. [145] fabricated novel and high-performance supercapacitors with hollow fiber electrodes including hollow $\mathrm{CP} / \mathrm{rGO}$ composite fibers, which exhibited high flexibility and electrical conductivity. The mixture of PEDOT:PSS, graphene oxide, and vitamin $\mathrm{C}$ was injected into a glass pipe to reduce $\mathrm{GO}$ to $\mathrm{rGO}$ in the mold pipe, then dried and reduced to synthesize the hollow composite fiber as shown in Fig. 11. Cong et al. [146] prepared a flexible PANI/graphene paper by electropolymerization of PANI nanorods on the graphene paper. As shown in Fig. 11f, g, graphene oxide sheets were prepared according to the modified Hummers method and aniline was electropolymerized on the graphene paper in $1 \mathrm{~mol} \mathrm{~L}^{-1} \mathrm{H}_{2} \mathrm{SO}_{4}$ solution. Another efficient way to synthesize $\mathrm{CPs}$ with graphene is exfoliation of graphite. Choi et al. [147] reported the fabrication of free-standing flexible PANI/ graphene multilayered nanostructures by sonication of the graphite flakes in an organic solvent to form continuous films with PANI. The PANI was reported to be able to intercalate between graphene layers, without damaging graphene structures.

\section{Ternary and multi-component nanocomposites}

Recently, ternary nanocomposites which combined three components from CPs, inorganic materials (metal, metal oxides, etc.) and carbon nanomaterials have attracted the attention of many researchers due to their excellent performance over binary systems. In ternary architecture design, various synergistic effects were observed in their application as the electrode material for supercapacitors. The extraordinary electrochemical performance of ternary nanocomposites will be discussed in the section of supercapacitors. Here, we focus on the synthesis aspect of ternary system, which usually involves two-steps synthesis or two different methods. Representative examples of ternary CP nanohybrids with their fabrications and highlighted applications are listed in Table 6. For example, in hierarchical nanocomposites of PANI/graphene/Au, binary graphene/Au hybrid was formed by hydrothermal process and PANI was coated on the sur- 
Table 6 Synthesis and applications of selected CP based ternary and multi-component nanocomposites

\begin{tabular}{|c|c|c|c|c|c|c|c|}
\hline $\begin{array}{l}\text { Conducting } \\
\text { polymer }\end{array}$ & Metal & Metal oxides & $\begin{array}{l}\text { Carbon } \\
\text { materials }\end{array}$ & $\begin{array}{l}\text { Other } \\
\text { materials }\end{array}$ & Preparation method & Properties and applications & Ref \\
\hline PANI & $\mathrm{Au}$ & / & MWCNTs & l & $\begin{array}{l}\text { Twisting two fibers coated } \\
\text { with PANI@Au@CNT }\end{array}$ & $\begin{array}{l}\text { Highly stretchable } \\
\text { supercapacitors }\end{array}$ & {$[192]$} \\
\hline PANI & $\mathrm{Au}$ & l & Graphene & I & $\begin{array}{l}\text { Hydrothermal method and } \\
\text { in situ polymerization } \\
\text { process }\end{array}$ & $\begin{array}{l}\text { Improved performance } \\
\text { for supercapacitors }\end{array}$ & {$[148]$} \\
\hline PANI & $\mathrm{Fe}$ & I & CNTs & l & $\begin{array}{c}\text { Reducing } \mathrm{FeCl}_{3} \text { in the } \\
\text { solution of aniline } \\
\text { and CNT }\end{array}$ & $\begin{array}{l}\text { Catalysts with high oxygen } \\
\text { reduction reaction }\end{array}$ & {$[193]$} \\
\hline PANI & $\mathrm{Pd}$ & / & $\mathrm{rGO}$ & l & $\begin{array}{l}\text { One-step electrodeposition } \\
\text { technique }\end{array}$ & $\begin{array}{l}\text { Electrocatalyst for alcohol } \\
\text { oxidation reaction }\end{array}$ & {$[194]$} \\
\hline PANI & Ag & / & MWCNTs & / & $\begin{array}{c}\text { Chemical polymerization of } \\
\text { PANI }\end{array}$ & $\begin{array}{l}\text { Supercapacitors with out- } \\
\text { standing energy density }\end{array}$ & {$[195]$} \\
\hline PANI & $\mathrm{Au}$ & $\mathrm{Fe}_{3} \mathrm{O}_{4}$ & MWCNT & I & Layer-by-layer technique & $\begin{array}{l}\text { High-performance } \\
\text { electromagnetic absorption }\end{array}$ & {$[196]$} \\
\hline PANI & / & $\mathrm{SnO}_{2}$ & $\mathrm{rGO}$ & l & $\begin{array}{l}\text { Microwave irradiation } \\
\text { and in situ polymerization }\end{array}$ & $\begin{array}{l}\text { Active electrode material } \\
\text { for supercapacitors }\end{array}$ & {$[197]$} \\
\hline PANI & l & $\mathrm{Fe}_{3} \mathrm{O}_{4}$ & $\mathrm{rGO}$ & l & $\begin{array}{l}\text { One-pot solvothermal } \\
\text { method and polymerization }\end{array}$ & $\begin{array}{l}\text { Excellent microwave } \\
\text { absorption properties }\end{array}$ & [198] \\
\hline PANI & l & $\mathrm{Fe}_{3} \mathrm{O}_{4}$ & l & Attapulgite & $\begin{array}{l}\text { One-pot process using } \\
\text { Fe(III) as the oxidant } \\
\text { for aniline }\end{array}$ & $\begin{array}{l}\text { Served as an adsorbent } \\
\text { and catalyst support }\end{array}$ & [199] \\
\hline PANI & I & $\mathrm{Co}_{3} \mathrm{O}_{4}$ & / & Chitosan & $\begin{array}{l}\text { In situ polymerization of } \\
\text { aniline in } \mathrm{CS} \text { and } \mathrm{Co}_{3} \mathrm{O}_{4}\end{array}$ & Core/double shell structure & {$[200]$} \\
\hline PANI & / & / & rGO & $\mathrm{NiFe}_{2} \mathrm{O}_{4}$ & $\begin{array}{l}\text { Reduction, doping and in } \\
\text { situ chemical polymerization }\end{array}$ & $\begin{array}{l}\text { High-performance } \\
\text { supercapacitors }\end{array}$ & {$[201]$} \\
\hline PANI & I & / & $\begin{array}{l}\text { Graphene } \\
\text { oxide }\end{array}$ & $\mathrm{S}$ & $\begin{array}{l}\text { Modified Hummers method } \\
\text { and layer-by-layer assembly }\end{array}$ & Lithium-sulfur batteries & {$[202]$} \\
\hline PANI & l & l & $\mathrm{C}$ & $\mathrm{TiN}$ & $\begin{array}{l}\text { Stepwise deposition and } \\
\text { coating process }\end{array}$ & Flexible supercapacitors & {$[203]$} \\
\hline PPy & $\mathrm{Ag}$ & l & CNTs & / & $\begin{array}{l}\text { Oxidative polymerization of } \\
\text { pyrrole with silver nitrate }\end{array}$ & $\begin{array}{l}\text { Effective towards } E \text {. coli } \\
\text { for water disinfection }\end{array}$ & {$[152]$} \\
\hline PPy & I & $\mathrm{Fe}_{2} \mathrm{O}_{3}$ & $\mathrm{rGO}$ & / & $\begin{array}{l}\text { Hydrothermal synthesis and } \\
\text { oxidative polymerization }\end{array}$ & $\begin{array}{l}\text { Electrode with excellent } \\
\text { capacitance retention }\end{array}$ & [149] \\
\hline PPy & / & $\mathrm{TiO}_{2}$ & Graphene & l & $\begin{array}{l}\text { Directly mixing/drying, } \\
\text { reduction, and heat } \\
\text { treatment }\end{array}$ & $\begin{array}{l}\text { High capacitance for } \\
\text { supercapacitors }\end{array}$ & {$[204]$} \\
\hline PPy & / & $\mathrm{TiO}_{2}$ & CNTs & / & $\begin{array}{l}\text { Chemical preparation and in } \\
\text { situ polymerization }\end{array}$ & $\begin{array}{l}\text { Improved electrochemical } \\
\text { response }\end{array}$ & {$[205]$} \\
\hline PPy & $\mathrm{Ag}$ & $\mathrm{ZnO}$ & / & l & $\begin{array}{l}\text { Polymerize pyrrole with } \\
\text { silver-ammonia complex }\end{array}$ & $\begin{array}{c}\text { Anode material for } \\
\text { zinc-based secondary cell }\end{array}$ & {$[206]$} \\
\hline PPy & $\mathrm{Pt} / \mathrm{Pd}$ & $\mathrm{MoO}_{3}$ & / & I & $\begin{array}{l}\text { Polymerize pyrrole } \\
\text { with } \mathrm{MoO}_{3}\end{array}$ & $\begin{array}{l}\text { Electrocatalysis of ethanol } \\
\text { in acid media }\end{array}$ & {$[207]$} \\
\hline PEDOT & $\mathrm{Ti}$ & $\mathrm{Fe}_{2} \mathrm{O}_{3}$ & l & l & $\begin{array}{l}\text { Hydrothermal method and } \\
\text { electrodeposition }\end{array}$ & $\begin{array}{l}\text { High-energy asymmetric } \\
\text { supercapacitors }\end{array}$ & [208] \\
\hline PEDOT:PSS & l & $\mathrm{MnO}_{2}$ & CNTs & / & $\begin{array}{l}\text { Vacuum filtration and } \\
\text { electrochemical deposition }\end{array}$ & $\begin{array}{l}\text { Supercapacitors with high } \\
\text { energy density }\end{array}$ & {$[150]$} \\
\hline PEDOT:PSS & / & $\mathrm{RuO}_{2}$ & Graphene & l & Electrostatic stabilization & $\begin{array}{l}\text { Screen-printing ink for } \\
\text { supercapacitor }\end{array}$ & {$[209]$} \\
\hline PEDOT:PSS & / & / & MWCNT & $\mathrm{Ni}(\mathrm{OH})_{2}$ & $\begin{array}{l}\text { Coordinating etching and } \\
\text { precipitating method }\end{array}$ & $\begin{array}{l}\text { Pseudocapacitive materials } \\
\text { for supercapacitors }\end{array}$ & {$[210]$} \\
\hline
\end{tabular}

face of graphene/Au sheets by in situ polymerization strategy [148]. In the nanocomposites of $\mathrm{PPy} / \mathrm{Fe}_{2} \mathrm{O}_{3} / \mathrm{rGO}$, the first step is to use hydrothermal synthesis to produce the binary metals or metal oxides with carbon materials, and the second step is oxidative polymerization of PPy [149]. In the system of PEDOT:PSS/ $\mathrm{MnO}_{2} / \mathrm{CNTs}$, PED- 
OT:PSS wrapped MWNT electrode was fabricated by a simple vacuum filtration method first, and then $\mathrm{MnO}_{2}$ were electrochemically deposited on the surface of PEDOT:PSS/CNTs composites [150].

Ternary nanocomposites have also been used in other systems such as metal-organic frameworks (MOFs), which are the form of the coordination of metal ions and organic ligands, and have become popular templates for preparing porous carbon compounds. A novel low-cost and highly efficient hydrazine sensor has been synthesized based on nitrogen-doped carbon nanopolyhedra (CNP), Prussian blue (PB) and PPy [151]. PB is loaded on CNP support due to its porous texture and CNP can promote the synthesis of $\mathrm{PB}$. PPy is to provide high conductivity and good environment stability. The electrode modified with $\mathrm{PB} / \mathrm{CNP} / \mathrm{PPy}$ exhibits an excellent activity for the electrocatalytic oxidation of hydrazine. In pathogenic bacteria detection, nanocomposites of PPy/ CNTs/Ag nanoparticles have been fabricated because they were efficient towards $E$. coli with $100 \%$ removal [152]. This design of ternary system fully utilized the high affinity of silver nanoparticles towards sulfur-containing amino acids and phosphor, and the ability of CNT for effectively killing bacteria by causing perturbation and/or disruption of the cell membrane via oxidation.

\section{APPLICATIONS OF CONDUCTING POLYMER NANOCOMPOSITES}

As discussed in previous section, NCPs and their composites, synthesized using various kinds of methods and strategies, have been under intensive investigation because of the unique combination of large surface area, high electrical conductivity, mechanical flexibility, selfhealing, facile production, easy nano-structuring and low cost. In this section, the applications of nanocomposites in many fields are discussed such as energy storage devices, sensors, energy harvesting devices, corrosion protection, antistatic agent, electromagnetic interference shielding and other important applications $[10,11,25,31,211]$.

\section{Energy storage and conversion devices}

\section{Supercapacitors}

Nowadays, supercapacitors have attracted extensive attention because they can traverse the gap of specific energy and specific power between batteries and dielectric capacitors by instantaneously transport high power within a very short period and have promising applications such as power sources of electric vehicles and stand- by power systems $[15,20]$. With the development of microelectromechanical systems, on-chip energy storage devices that can compatibly integrate with miniaturized electronic systems are highly desired. It is of interest to explore small scale supercapacitors with high power densities and longer cycle lifetimes that can compensate the limitation involved in batteries [212]. Currently, the most widely investigated supercapacitors are carbon based electrical double layer capacitors (EDLCs), including monolithic carbide derived carbon [213], onion-like carbon [214], CNTs [215] and graphene [216]. On the other hand, CPs have been extensively studied for pseudocapacitance behavior because of multiple oxidation states of these polymers. They are considered to have significantly better electrochemical performance than carbon based materials.

PANI has been widely used for supercapacitors due to the tunable pseudocapacitive performance owing to its various oxidation states. The recent study demonstrated that shorter diffusion paths and high surface area for ordered PANI structures are the key factors for enhancing electrochemical performance such as power density [217]. Many PANI-based composites with different carbon materials have been studied such as $1 \mathrm{D}$ carbon nanotubes/nanofibers and 2D graphene. The high aspect ratio of PANI chains forms the disordered network that makes ion diffusion sluggish within the active material. Therefore, it is imperative to incorporate ordered nanomaterial that provides better accessibility to redox sites and rapid diffusion through the network. This ordered network enhances the electrochemical accessibility of a material in one direction [218,219]. Fig. 12 illustrated a smart nano-architectural 3D core-shell structure to overcome the stacking problem during electrochemical cycling. This is due to the controlled synergy between physicochemical properties of nanoporous carbon and PANI, which resulted in high performance electrochemical energy storage device. [220]. These carbonPANI nanocomposites achieved a high specific capacitance of $300-1100 \mathrm{Fg} \mathrm{g}^{-1}$, high specific energy of $21 \mathrm{~W} \mathrm{~h} \mathrm{~kg}^{-1}$, high specific power of $12 \mathrm{~kW} \mathrm{~kg}^{-1}$, and capacitance retention of $86 \%$ after 20,000 cycles which is superior to previous reported work. New core-shell architectures with different conductive polymers may have potential for even higher performance and improved stabilities, that can be investigated in future research.

There are many CPs applications can be found in flexible supercapacitors owing to their high degree of flexibility and good affinity [221]. Anothumakkool et al. [222] reported a novel synthetic strategy for the pre- 


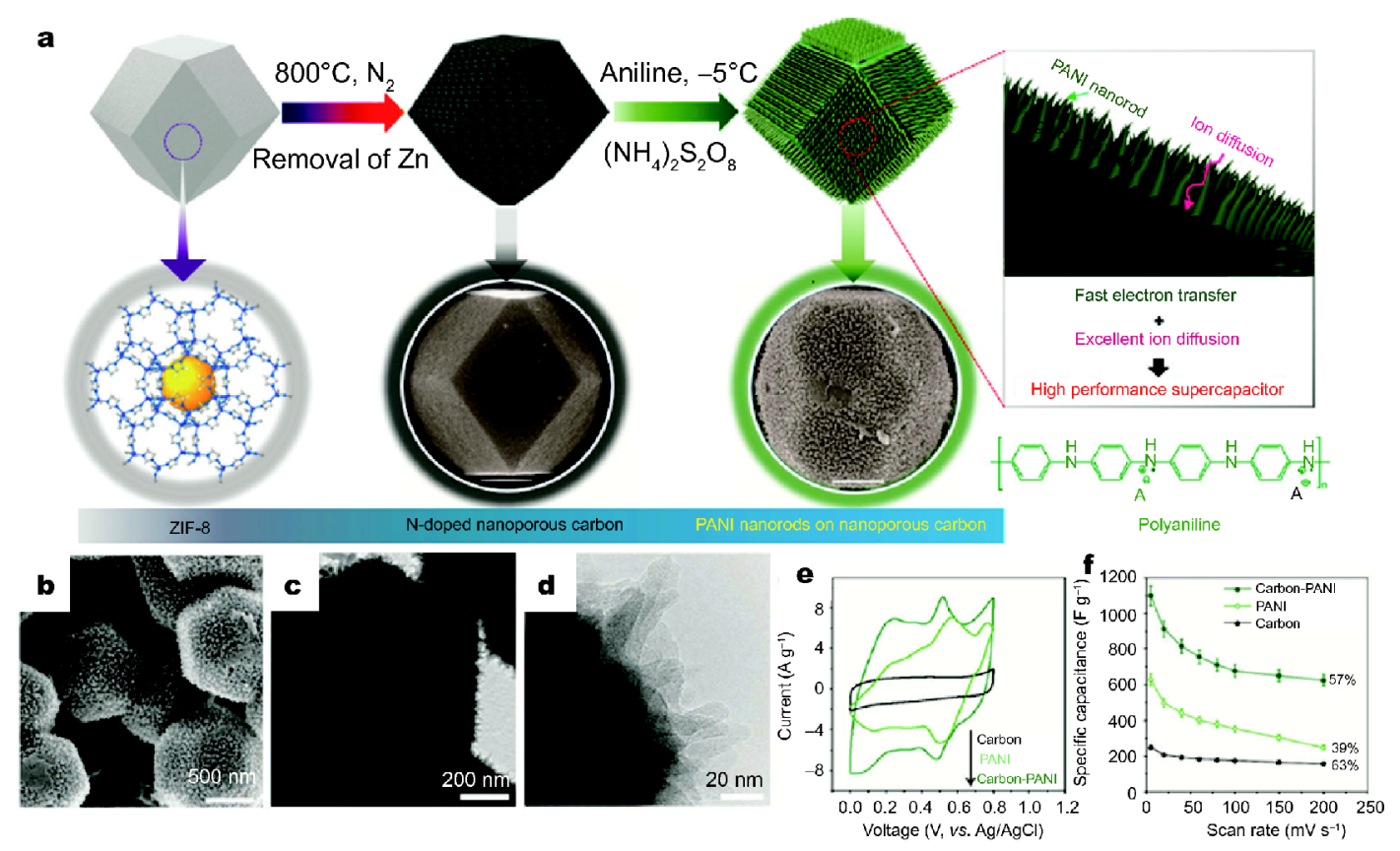

Figure 12 (a) Schematic illustration of the synthesis process for nano porous carbon-PANI core-shell nanocomposite materials starting from a rhombic dodecahedron of ZIF-8. (b) SEM image of a carbon-PANI composite. (c) and (d) Transmission electron microscope (TEM) images of the carbon-PANI composite. (e) Comparative cyclic voltammetry studies of carbon, PANI, and carbon-PANI. (f) Variation of capacitance with scan rate for carbon, PANI and the carbon-PANI nanocomposite. Reprinted with permission from Ref. [220] (Copyright 2016, Royal Society of Chemistry).

paration of a highly conducting PEDOT phase on flexible cellulose paper, which stabilized the counter-ions by hydrogen bonding. This flexible device showed conductivity as high as $375 \mathrm{~S} \mathrm{~cm}^{-1}$ with low sheet resistance and a

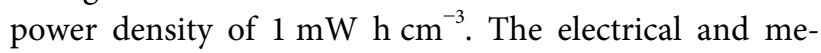
chanical properties are stable under flexing and bending conditions over around 4,000 cycles of charge-discharge. Wang et al. [223] reported a fast solution-based approach for the fabrication of flexible nanostructured PEDOT/ cellulose hybrid composite. The PEDOT was coated as a thin layer on nano cellulose fibers with large surface area and the composite displayed high specific capacitance $\left(90 \mathrm{~F} \mathrm{~g}^{-1}\right)$ with low equivalent series resistance $(1.7 \Omega)$, excellent cycling stability ( $93 \%$ capacitance retention after 15,000 cycles), high volumetric energy $\left(1.5 \mathrm{~mW} \mathrm{~h} \mathrm{~cm}^{-3}\right)$ and high power density $\left(1470 \mathrm{~mW} \mathrm{~cm}^{-3}\right)$.

In a recent study, researchers found that ternary composites or even multi-component nanocomposites consisting of CPs, carbon materials and metal oxides exhibited much higher capacitance and better cycling stability than binary systems. Noble metal nanoparticles possess excellent electron conductivity and thermal stability. Transition metal oxides such as $\mathrm{Co}_{3} \mathrm{O}_{4}, \mathrm{NiO}, \mathrm{RuO}_{2}$, $\mathrm{SnO}_{2}$ and $\mathrm{MnO}_{2}$ showed large surface area, short conduction lengths and electrochemical pseudocapacitive properties [150]. Carbon nanomaterials have high accessible surface area, high conductivity and good charge transfer channels. Especially, graphene is an excellent substrate to host the active polymer [148]. More examples of ternary CP nanohybrids for supercapacitors are listed in Table 6. For example, Xu and co-workers [192] proposed a novel flexible and stretchable supercapacitors using Au nanograins decorated aligned CNT sheet with the deposition of PANI. The structure took the form of a two-ply structure consisting of two identical single fibers by scrolling PANI@Au@CNT sheet. In this design, Au nanograins increased the roughness of linear electrode to increase the utilization rate of PANI, and simultaneously, Au nanograins embedded in the PANI/CNT layers can increase the electrical conductivity. The supercapacitor showed excellent volumetric capacitance of $6 \mathrm{~F} \mathrm{~cm}^{-3}$ at a scan rate of $10 \mathrm{~V} \mathrm{~s}^{-1}$. The developed stretchable wireshaped supercapacitors exhibited a high volumetric capacitance of $0.2 \mathrm{~F} \mathrm{~cm}^{-3}$ at a strain of $400 \%$. Jiang et al. [210] synthesized the coaxial ternary hybrid material with MWCNTs as a core, and thin layer $(<5 \mathrm{~nm})$ of amorphous $\mathrm{Ni}(\mathrm{OH})_{2}$ and PEDOT:PSS as a shell. The high pseudocapacitance and excellent rate capability were achieved due to the amorphous $\mathrm{Ni}(\mathrm{OH})_{2}$ that increases the probability of redox reactions to occur on or near the 
surface of the electrode. This ternary hybrid showed more than $3,250 \mathrm{~F} \mathrm{~g}^{-1}$ of gravimetric capacitance in basic electrolyte and retained $71.9 \%$ of its initial value. Zeng et al. [208] designed an anode based on PEDOT/Ti/ $/ \mathrm{Fe}_{2} \mathrm{O}_{3}$ coreshell nanorod arrays grown on flexible carbon cloth. In this structure, the donor density of $\mathrm{Fe}_{2} \mathrm{O}_{3}$ was intensely enhanced with Ti doping to boost its capacitive performance. PEDOT improved the conductivity of nanomaterials and act as a protective layer to prevent the integrity of the electrode structure. This ternary nanocomposite structure showed noteworthy energy density of $0.89 \mathrm{~mW} \mathrm{~h} \mathrm{~cm}^{-3}$ and can be used as a high-performance electrode material for asymmetric supercapacitor devices.

\section{Rechargeable Li-ion batteries}

The high energy density is an important factor for rechargeable batteries used for electronic devices, power supply, grid-scale energy storage and electric vehicles [224-226]. It is known that Li-ion batteries have the highest energy density among other rechargeable batteries $[227,228]$. The high capacity, fast charge-discharge rate and longer cycle life are the key parameters for a battery that are associated with many other factors. However, there are still many limiting factors which influence the battery performance in many ways [14,31,229]. The major limitation is to develop high capacity cathodes material with high energy density. One of the materials that have been extensively studied was sulfur due to its abundance, low material cost, higher capacity and energy density than Li-ion batteries. It can be used in elemental form or can be used as pre-lithiated sulfur $\left(\mathrm{Li}_{2} \mathrm{~S}\right)$. However, low electrical conductivity of sulfur results relatively low capacity, thus limiting its use for commercial application [14]. Another parameter limits its use is polysulfide, which are the discharge products that leach out of the electrode and cover the cathode causing poor rechargeability and low capacity. The long chain polysulfides diffuse and migrate to anode through electrolyte and react with lithium resulting in consumption of anode material that decreases the open circuit potential and discharge capacity. Many strategies have been adopted to overcome these challenges such as using carbon materials to form the network. However, the escape of polysulfides is inevitable from the electrode. Anode is another area of research that has been broadly studied for Li-ion batteries to increase the charge capacity. Commercially, lithiated graphite has displayed excellent electrochemical performance. However, graphite showed much lower capacity as compared to highest theoretical capacity of $\mathrm{Li}$ $\left(4,000 \mathrm{~mA} \mathrm{~h} \mathrm{~g}^{-1}\right)$.
A recent study showed silicon as suitable replacement for graphite as the anode material due to its high specific capacity, low discharge potential and environmental friendliness. In recent years, the design and fabrication of electrodes has gained much attention in applications of rechargeable batteries. Li-ion batteries based on organicinorganic hybrid composites have been widely studied due to electrical conductivity and high coulombic efficiency and long cycling lifetime with negligible degradation. Inorganic compounds possess good lithium storage but have low electrical conductivity and cyclability. CPs form an effective electrode with inorganic materials that can overcome these limitations of electrode lifetime, rate capabilities and mechanical stability [230].

To improve the entrapment of polysulfide, Cui et al. [231] used encapsulated carbon/sulfur particles with PEDOT:PSS which are thermally stable and moderately rigid in the electrochemical environment as shown in Fig. $13 \mathrm{a}$ and $\mathrm{b}$. This work provided an effective way to trap polysulfides and minimize the dissolution of polysulfides from cathodes. The discharge capacity remained over $600 \mathrm{~mA} \mathrm{~h} \mathrm{~g}^{-1}$ at the $150^{\text {th }}$ cycle which was significantly improved. Chen et al. [232] used a membrane assisted precipitation technique to generate sulfur-coated PEDOT core/shell nanoparticles. The PEDOT provided the conductive matrix for electron transport and encapsulation shell to entrap polysulfides. The initial discharge capacity of $1,117 \mathrm{~mA} \mathrm{~h} \mathrm{~g}^{-1}$ and the capacity retention of $83 \%$ per 50 cycles can be achieved indicating excellent cycling durability and performance. The CPs have been utilized with $\mathrm{Si}$ anodes [233]. The polyfluorene-type polymers served as a conductive binder to overcome the volume expansion of Si during charge-discharge cycles. Cui et al. [234] incorporated a PANI hydrogel into the silicon anode to form a hierarchical hydrogel framework which bound the $\mathrm{Si}$ surface by crosslinking through hydrogen bonding with phytic acid or electrostatic interaction with the positively charged polymer. A high performance $\mathrm{Li}$ ion battery has been achieved with a cycle life of 5,000 cycles with over $90 \%$ capacity retention at current density of $6.0 \mathrm{~A} \mathrm{~g}^{-1}$ (Fig. 13c-e).

For real applications, high-rate and high-voltage materials are critical to reduce the charging time. Long-term cycling of an electrode is highly dependent on volume expansion and surface degradation of materials [235]. Chao et al. [236] fabricated a core-shell structure of PEDOT and $\mathrm{V}_{2} \mathrm{O}_{5}$ with graphite foam and were able to achieve ultra-fast stable Li-ion storage performance, high capacities and enhanced rate $\left(168 \mathrm{~mA} \mathrm{~h} \mathrm{~g}^{-1}\right.$ at $\left.60^{\circ} \mathrm{C}\right)$. Wang et al. [237] prepared $\mathrm{Fe}_{2} \mathrm{O}_{3} / \mathrm{PANI}$ composite which 


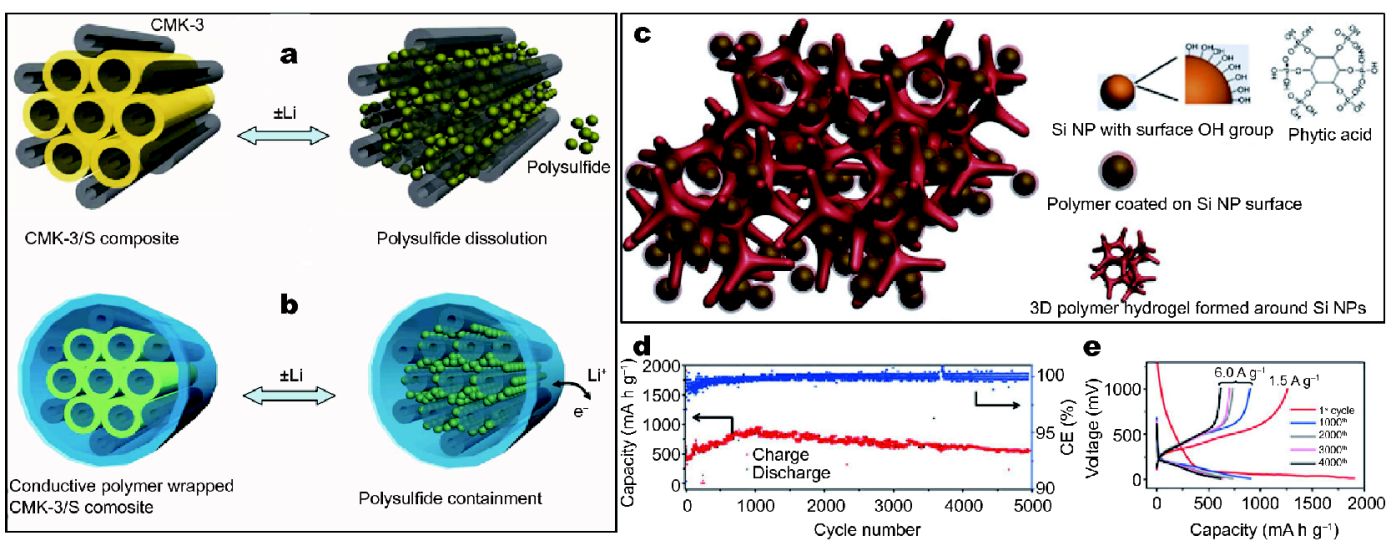

Figure 13 (a) Illustration of the encapsulation of carbon/sulfur particles with PEDOT:PSS for improving polysulfides encapsulation: carbon/sulfur particles without PEDOT:PSS coating and the polysulfides leak out of the carbon matrix during charge/discharge process. (b) With a PEDOT:PSS coating where the polysulfides are encapsulated within the composite and therefore lithium ions and electrons can move in and out. Reprinted with permission from Ref. [231] (Copyright 2011, American Chemical Society). (c) Schematic illustration of 3D porous SiNP/conductive polymer hydrogel composite electrodes. Each SiNP is encapsulated within a conductive polymer surface coating and is further connected to the highly porous hydrogel framework. (d) Lithiation/de-lithiation capacity and coulombic efficiency of SiNP-PANI electrode cycled at current density of $6 \mathrm{~A} \mathrm{~g} \mathrm{~g}^{-1}$ for 5,000 cycles. (e) Galvanostatic charge/discharge profiles plotted for the $1^{\text {st }}, 1000^{\text {th }}, 2000^{\text {th }}, 3000^{\text {th }}$ and $4000^{\text {th }}$ cycles. Reprinted with permission from Ref. [234] (Copyright 2013, Nature Publishing Group).

demonstrated a high rate capability and a high capacity of $778 \mathrm{~mA} \mathrm{~h} \mathrm{~g}^{-1}$ at higher current density of $1 \mathrm{~A} \mathrm{~g}^{-1}$. This is due to the improved electrical conductivity and effective ion transportation of the composite electrode and firm connection between the electrolyte and the electrode materials. $\mathrm{Xu}$ et al. [238] designed a PEDOT:PSS coated $\mathrm{ZnO} / \mathrm{C}$ hierarchical porous nanorods nanocomposite as anode through one-pot wet chemical reaction followed by thermal calcination. The produced nanostructured materials exhibited excellent electrochemical performance. The $\mathrm{ZnO} / \mathrm{C}$ with hierarchical structures helped accommodate the volumetric changes during charge/discharge; the porous structures facilitate the transportation of solvated lithium ions and highly conductive PEDOT-PSS coating layer greatly accelerated the electron transport. Cui et al. [239] first demonstrated a high-performance cathode material with $\mathrm{PPy} / \mathrm{Li}_{2} \mathrm{~S}$ composite in which $\mathrm{PPy}$ helped to facilitate electronic conduction. A high discharge capacity of $785 \mathrm{~mA} \mathrm{~h} \mathrm{~g}^{-1}$ of $\mathrm{Li}_{2} \mathrm{~S}$ was achieved with stable cycling over prolonged 400 charge/discharge cycles. Lawes et al. [240] reported inkjet-printed silicon in which $\mathrm{Si}$ nanoparticles with PEDOT:PSS binder were used as high performance anodes material for Li-ion batteries. The continuous conductive network formed by PEDOT: PSS allowed rapid electron transfer and its flexibility accommodates the large volume changes of SiNPs during charging and discharging. These anodes exhibit very high capacity of more than $1,700 \mathrm{~mA} \mathrm{~h} \mathrm{~g}^{-1}$ for 100 cycles and exhibited the stability during cycling performance over

\section{1,000 cycles.}

\section{Dielectric Capacitors}

With the requirement of high-power, high-efficiency and low-cost capacitive storage system, there is great need for the development of dielectric materials with a high dielectric permittivity, low loss and high energy density [241-245]. Compared to inorganic dielectric materials (i. e., ferroelectric ceramics) [246-249], polymer-based dielectric materials have received tremendous attentions because of their excellent mechanical properties, high electric breakdown field and ease of synthesis [250-254]. NCPs as a new class of conducting organic materials provided a unique opportunity as conducting fillers in polymer-based dielectric composites [255-263]. Different from other conductive fillers, NCPs exhibit two advantages: i) their electrical conductivity can be adjusted over a broad range by simple doping or de-doping process, which will give rise to unique dielectric/electric properties, and ii) their mechanical properties are similar to dielectric polymer matrix that offers excellent compatibility with the polymer matrix [264-268]. Huang and his coworkers [258] developed a PANI-based composites with dielectric permittivity $(>7,000)$ at $100 \mathrm{~Hz}$, which is approximately 90 times of the polymer matrix. This was achieved by dispersing PANI in a polymer matrix to fabricate all-organic composites. The composite possesses high flexibility and elastic modulus close to that of the insulated polymer matrix, which exhibited an elastic en- 

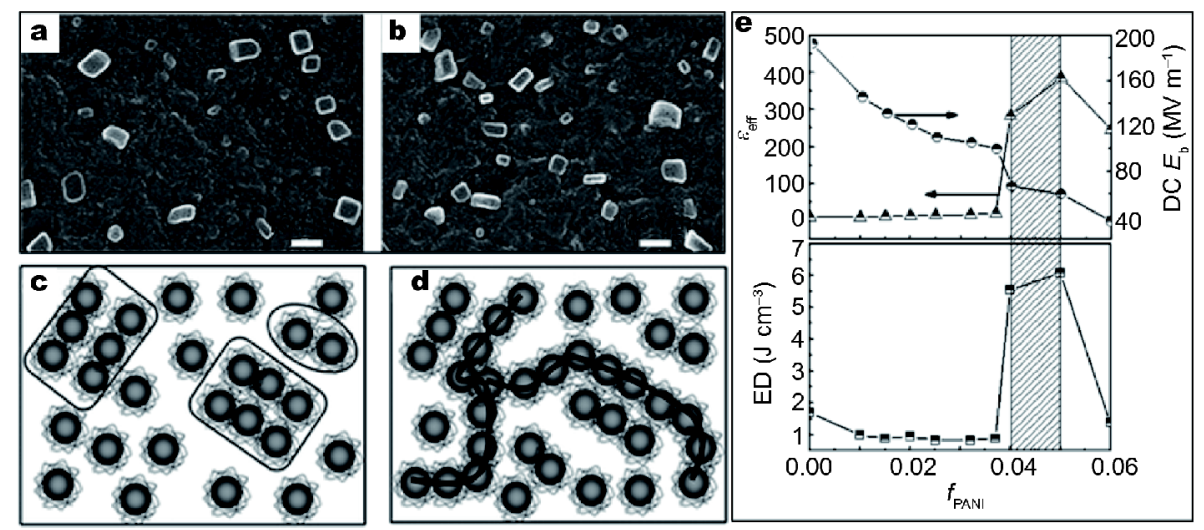

Figure 14 SEM images of PVDF films with (a) $f_{\mathrm{PANI}}=0.050$ and (b) $f_{\mathrm{PANI}}=0.060$. Schematic images of the microstructure of PANI/PVDF films with (c) $0.042<f_{\mathrm{PANI}} \leq 0.050$ and (d) $0.050<f_{\mathrm{PANI}} \leq 0.060$. (e) Dependence of dielectric permittivity and DC breakdown field at room temperature. (f) The energy density of the PANI/PVDF films varies with different volume fraction of PANI. Reprinted with permission from Ref. [259] (Copyright 2010, Royal Society of Chemistry).

ergy density of $0.18 \mathrm{~J} \mathrm{~cm}^{-3}$ under a field of $16 \mathrm{MV} \mathrm{m}^{-1}$. Yuan et al. [259] prepared high energy density nanocomposites with PANI-based fillers at lower filler loading. SEM images shown in Fig. 14a and $\mathrm{b}$ gave the morphologies of the PANI/PVDF nanohybrid films with 4 vol.\% and 5 vol.\%. The thickness of the insulation layer between PANI particulates decreased and microcapacitors can be formed. Finally, the conductive network was formed as illustrated in schematic images in Fig. 14c and $\mathrm{d}$. The percolation threshold was 4.2 vol.\% and the dielectric permittivity and loss exhibited a stable value in the frequency range from 1 to $10 \mathrm{kHz}$ below the percolation threshold. The nanocomposites showed the dielectric permittivity of 385 (with the volume fraction of 0.05 at $1 \mathrm{kHz}$ ), the breakdown strength of $160 \mathrm{MV} \mathrm{m}^{-1}$, and the energy storage density of $6.1 \mathrm{~J} \mathrm{~cm}^{-3}$. This method provided an effective route for fabricating a high energy density capacitor. In a recent study, the interfacial polymerization method and encapsulation technique were used to guarantee a uniform distribution of NCPs in an insulated polymer matrix. Wang et al. [255] and Shehzad et al. [256] both worked on further improvement of the compatibility of the PANI in the polymer matrix using an organic dopants such as dodecylbenzene sulfonic acid (DBSA) and perfluorosulfonic acid (PFSA). The dielectric permittivity at the percolation threshold of $2.9 \mathrm{wt} . \%$ fillers, were raised by 50 -fold compared to the polymer matrix at $100 \mathrm{~Hz}$. CNTs covered with PANI (PANI@CNTs) were synthesized as conducting fillers that showed good dispersibility in thermoplastic polyurethane [269]. PANI nanorods on poly(vinyl pyrrolidone) (PANI@PVP) were synthesized with uniform size and easily dispersed in the PVDF matrix. The nanocomposite with $9.5 \mathrm{wt} . \%$ of fillers exhibited a high dielectric permittivity of 174 and a suppressed loss of 0.17 at $100 \mathrm{~Hz}$ [262]. Alternatively, PANI can be treated as the outside layer in core-shell nanostructure to increase the interfacial polarization [270,271]. Good mechanical properties and high dielectric permittivity were obtained by these work which could be promising dielectric material for preparing film capacitors.

In a current study, the most used PANI fillers are particle-like or fiber-like, which limited the study on the all-organic composites [242,272]. Therefore, it is useful to synthesize CPs with different shape and size, for the development of high performance all-organic composites. Zhang et al. [261] fabricated an all-organic composite system using newly developed PPy nanoclips. Each nanoclip had a length of $1 \mu \mathrm{m}$, a width of $0.5 \mu \mathrm{m}$ with a thickness (diameter) of 50-70 $\mathrm{nm}$. The composites had a uniform microstructure by a unique and facile process that combined solution casting and hot pressing. The composites showed a very low percolation threshold (8 wt.\%) and exhibited a high dielectric permittivity of more than 1,000. More importantly, the dielectric loss of $\mathbf{1}$ is lower than the loss reported in most of conductor-dielectric composites using metallic particles and 1D conductive fillers. The loss observed in the composites at low temperatures is mainly determined by this relaxation process rather than the conductivity [273].

\section{Chemical sensors}

CPs have been considered as good candidates for chemical gas sensors because of their reversible electrical 
Table 7 Selected conducting polymer based nanocomposites as chemiresistive sensors

\begin{tabular}{|c|c|c|c|c|c|c|c|c|}
\hline Sensing materials & Structure & Sensing gas & Concentration & $\begin{array}{l}\text { Sensitivity or } \\
\text { response }\end{array}$ & Detection limit & $\begin{array}{l}\text { Response } \\
\text { time }\end{array}$ & $\begin{array}{l}\text { Recover } \\
\text { time }\end{array}$ & Ref \\
\hline $\mathrm{PANI} / \mathrm{Cu}$ & Thin film & $\mathrm{NH}_{3}$ & $50 \mathrm{ppm}$ & $86 \%$ & $1 \mathrm{ppm}$ & $7 \mathrm{~s}$ & $160 \mathrm{~s}$ & {$[278]$} \\
\hline $\mathrm{PANI} / \mathrm{Au}$ & Nanowires & $\mathrm{H}_{2} \mathrm{~S}$ & I & $13.8 \%$ & $0.1 \mathrm{ppb}$ & $<2 \min$ & $<5 \min$ & {$[279]$} \\
\hline $\mathrm{PANI} / \mathrm{Au}$ & Nanofibers & $\mathrm{CH}_{3} \mathrm{SH}$ & $1.5 \mathrm{ppm}$ & $30 \%$ & $1.5 \mathrm{ppm}$ & $\sim 500 \mathrm{~s}$ & l & [107] \\
\hline PANI/Ag & Nano-network & $\mathrm{NH}_{3}$ & $10 \mathrm{ppm}$ & $90 \%$ & $5 \mathrm{ppm}$ & $<3 \min$ & I & {$[280]$} \\
\hline $\mathrm{PANI} / \mathrm{CeO}_{2}$ & Core-shell NPs & $\mathrm{NH}_{3}$ & $50 \mathrm{ppm}$ & $650 \%$ & $2 \mathrm{ppm}$ & $57.6 \mathrm{~s}$ & I & {$[281]$} \\
\hline $\mathrm{PANI} / \mathrm{SnO}_{2}$ & Nanosheets & $\mathrm{NH}_{3}$ & $5 \mathrm{ppm}$ & $30 \%$ & $257 \mathrm{ppb}$ & $259 \mathrm{~s}$ & $468 \mathrm{~s}$ & [169] \\
\hline $\mathrm{PANI} / \mathrm{rGO}$ & Network film & $\mathrm{NH}_{3}$ & 100 ppm & $60 \%$ & $100 \mathrm{ppb}$ & $36 \mathrm{~s}$ & $18 \mathrm{~s}$ & {$[282]$} \\
\hline PANI/CNTs & Nanofibers & $\mathrm{NH}_{3}$ & $30 \mathrm{ppm}$ & $40 \%$ & $4 \mathrm{ppm}$ & $18 \mathrm{~s}$ & $46 \mathrm{~s}$ & {$[283]$} \\
\hline PANI/MWCNTs & Core-shell nanotubes & $\mathrm{NH}_{3}$ & $2 \mathrm{ppm}$ & $15.5 \%$ & / & $6 s$ & $35 \mathrm{~s}$ & {$[284]$} \\
\hline PANI/graphene & Meshed structure & $\mathrm{NH}_{3}$ & $20 \mathrm{ppm}$ & $360 \%$ & $1 \mathrm{ppm}$ & $50 \mathrm{~s}$ & $23 \mathrm{~s}$ & {$[285]$} \\
\hline PANI/(S,N:GQDs) & Nano-pores & $\mathrm{NH}_{3}$ & $100 \mathrm{ppm}$ & $42.3 \%$ & $1 \mathrm{ppm}$ & $115 \mathrm{~s}$ & $44 \mathrm{~s}$ & {$[286]$} \\
\hline $\mathrm{PPy} / \mathrm{Ag}$ & Nanowires & Ethanol & $80 \mathrm{ppm}$ & $54 \%$ & $10 \mathrm{ppm}$ & $<1 \mathrm{~min}$ & $500 \mathrm{~s}$ & {$[287]$} \\
\hline $\mathrm{PPy} / \mathrm{Pd}$ & Core-shell NPs & $\mathrm{NH}_{3}$ & $20 \mathrm{ppm}$ & $13.1 \%$ & / & $14 \mathrm{~s}$ & $148 \mathrm{~s}$ & {$[288]$} \\
\hline $\mathrm{PPy} / \mathrm{NiO}$ & Nanocomposite & $\mathrm{NO}_{2}$ & $100 \mathrm{ppm}$ & $47 \%$ & $10 \mathrm{ppm}$ & $49 \mathrm{~s}$ & $<5 \min$ & [289] \\
\hline $\mathrm{PPy} / \mathrm{WO}_{3}$ & Nanocomposites & $\mathrm{NO}_{2}$ & 100 ppm & $61 \%$ & $5 \mathrm{ppm}$ & / & l & {$[290]$} \\
\hline $\mathrm{PPy} / \mathrm{TiO}_{2} /$ graphene & Nanocomposites & $\mathrm{NH}_{3}$ & $50 \mathrm{ppm}$ & $102.2 \%$ & 1 & $36 \mathrm{~s}$ & $16 \mathrm{~s}$ & [291] \\
\hline PEDOT/Ag & Nanotubes & $\mathrm{NH}_{3}$ & $100 \mathrm{ppm}$ & $30 \%$ & $1 \mathrm{ppm}$ & $2 \mathrm{~s}$ & $7 \mathrm{~s}$ & {$[292]$} \\
\hline PEDOT:PSS/Cu(II) & Porous structure & $\mathrm{NH}_{3}$ & $50 \mathrm{ppm}$ & $8 \%$ & 1 & $138 \mathrm{~s}$ & $63 \mathrm{~s}$ & [293] \\
\hline PEDOT:PSS/Fe(II) & Thin film & $\mathrm{CO}$ & / & $150 \%$ & / & $30 \mathrm{~s}$ & $5 \mathrm{~s}$ & {$[294]$} \\
\hline PEDOT:PSS/GO & Thin film & $\mathrm{H}_{2}$ & $100 \mathrm{ppm}$ & $4.2 \%$ & / & $30 \mathrm{~s}$ & $25 \mathrm{~s}$ & {$[295]$} \\
\hline
\end{tabular}

Sensitivity or response includes $\Delta R / R_{0}$ and $R / R_{0}$.

properties that are related to the change of resistance, current, or electrochemical potential by reaction with chemicals [31,274]. PANI nanofibers as one of the most used NCPs, have been utilized as sensing materials to detect different chemical gases based on different mechanisms, such as $\mathrm{HCl}, \mathrm{NH}_{3}, \mathrm{~N}_{2} \mathrm{H}_{4}, \mathrm{CHCl}_{3}$ and $\mathrm{CH}_{3} \mathrm{OH}$ [275]. However, their application is limited by low sensitivity and poor selectivity. It can be enhanced by adding a second nanocomponent, including metal and metal oxide particles, carbon materials, insulating polymers, etc. to the $\mathrm{CP}$ nanostructures. For example, due to intrinsic electronic and electrochemical properties, metal NPs play a very important role in chemical gas sensing, which can exhibit excellent sensing performance when exposed to specific chemical molecules [16,25]. The limitations of metals themselves are their NP format, high operating temperatures and reduced long-term stability, which made a great challenge to use the metal particles for sensing platform alone. Therefore, to increase the sensitivity, integrating metals NPs with CPs has become an effective way due to their promising chemical specificities, high surface area, high electrical conductivities, shorter diffusion lengths and low temperature processa- bility $[28,276,277]$. NCP-based sensors, which transform a chemical reaction into an electrical response, have been successfully utilized for monitoring organic and inorganic gases, including alcohols, ethers, ammonia, nitrogen, $\mathrm{NO}_{x}, \mathrm{H}_{2}, \mathrm{H}_{2} \mathrm{~S}, \mathrm{SO}_{2}$ and $\mathrm{CO}$. Many research groups dedicated on CPs-based nanocomposites for chemical gas sensing and the information are listed in Table 7.

\section{Ammonia sensors}

Ammonia $\left(\mathrm{NH}_{3}\right)$ is one of the highly toxic gases and a key component of various industrial processes. It damages the skin, eyes and respiratory system of human when the concentration is higher than $25 \mathrm{ppm}$ in the air. Many researches have been focused on detection of ammonia for environmental monitoring, process control and health precautions. Various ammonia sensing technologies have been investigated, including electrolytic sensors, solid state sensors and spectroscopic techniques and conducting polymers [296]. Some drawbacks limit the commercial application of these sensors, such as low sensitivity, limited accuracy for electrolytic sensors, expensive spectroscopic sensors and poor selectivity for solid state devices. Most of $\mathrm{NH}_{3}$ sensors based on metals or metal 

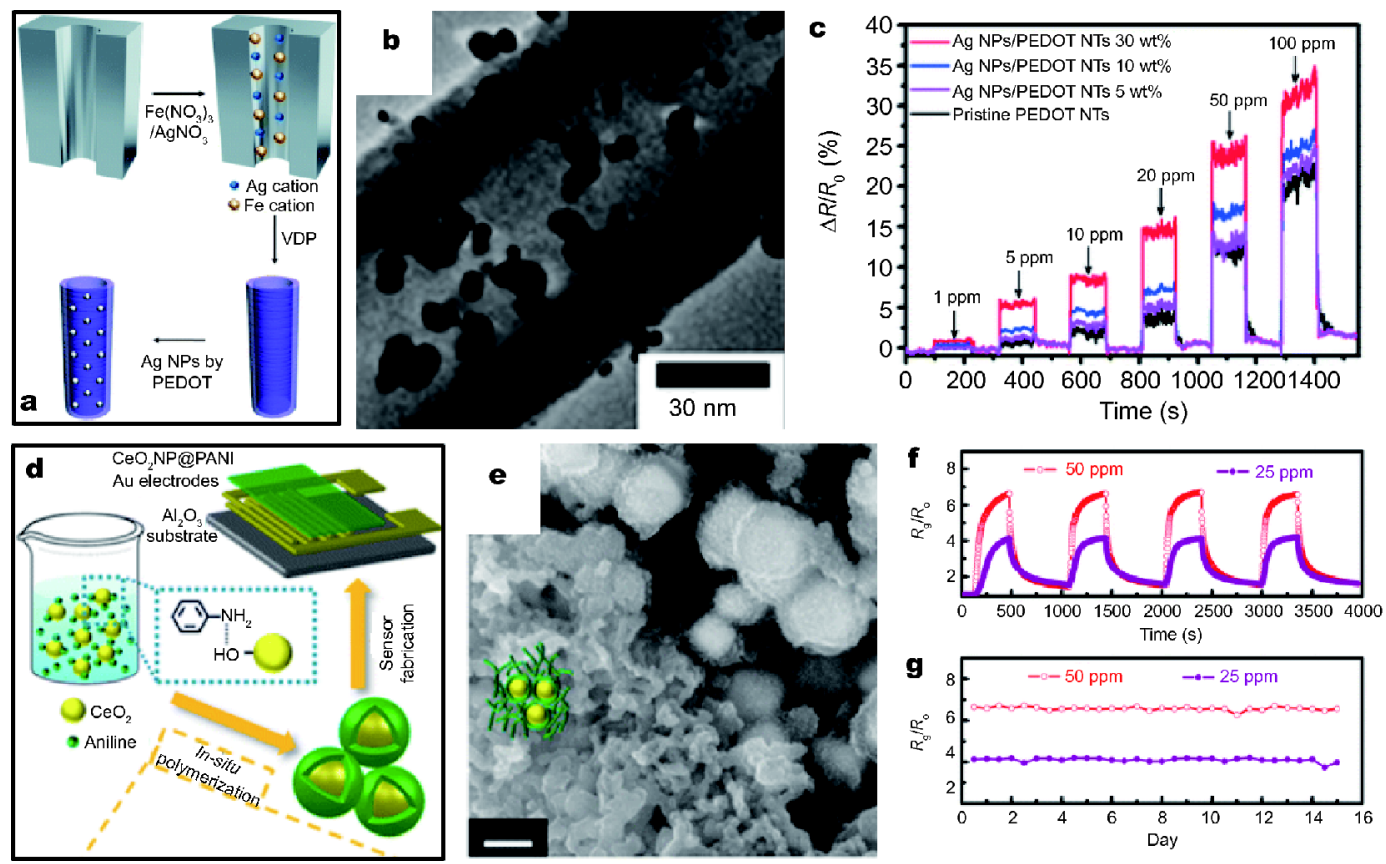

Figure 15 (a) Synthetic route to PEDOT/Ag. (b) TEM image of PEDOT/Ag with 30 wt.\% concentration of $\mathrm{AgNO}_{3}$. (c) The sensing performances and the sensitivity changes of pristine PEDOT NTs and Ag NPs/PEDOT NTs with 5, 10 and 30 wt.\%. Reprinted with permission from Ref. [292] (Copyright 2011, The Royal Society of Chemistry). (d) and (e) Schematic of preparation and SEM of core-shell CeO $/ 2 / \mathrm{PANI}$ particles. (f) Response curves of $\mathrm{CeO}_{2} / \mathrm{PANI}$ (CPA4) and PANI to $50 \mathrm{ppm}$ and $\mathrm{CeO}_{2}$ to $200 \mathrm{ppm}$ and $2 \%$ ammonia. (g) Sensor stability of $\mathrm{CeO}_{2} / \mathrm{PANI}$ at room temperature. Reprinted with permission from Ref. [281] (Copyright 2014, American Chemical Society).

oxides are expensive and are operated at high temperature that gives low response and short life time. Therefore, $\mathrm{CPs}$ has been widely investigated as $\mathrm{NH}_{3}$ sensors due to their fast response, low cost and operation at ambient conditions and metal nanoparticles can be incorporated in CPs without changing their properties to enhance the sensor performance [283]. For example, Patil et al. [278] fabricated a temperature ammonia sensor based on copper nanoparticle intercalated PANI nanocomposite thin films. The sensor showed a high sensitivity of detecting as low as $1 \mathrm{ppm}$ of $\mathrm{NH}_{3}$, with fast response and recovery times of 7 and $160 \mathrm{~s}$ and sensor response of $\sim 86 \%$. The enhanced response was attributed to the large surface area and improved charge transfer between $\mathrm{Cu}$ NPs and PANI matrix. Park and co-workers [292] decorated PEDOT nanotubes with $\mathrm{Ag}$ NPs using metal ion reductionmediated vapor deposition polymerization, where $\mathrm{Ag}^{+}$ was reduced to Ag NPs by PEDOT as shown in Fig. 15a, b. The sensitivity of PEDOT/Ag depends on the concentration of $\mathrm{AgNO}_{3}$ where increasing $\mathrm{AgNO}_{3}$ enhances the sensitivity of sensor. The fabricated sensor was more sensitive than pristine PEDOT that can only detect $5 \mathrm{ppm}$ of $\mathrm{NH}_{3}$ as compared to $1 \mathrm{ppm} \mathrm{NH}_{3}$ for the sensor.

Besides metal particles, other inorganic nanomaterials such as metal oxides can be used to improve sensing performance. For examples, as shown in Fig. 15d, roomtemperature $\mathrm{NH}_{3}$ gas sensor was fabricated using $\mathrm{CeO}_{2}$ NPs coated by cross-linked PANI hydrogel [281]. The nanohybrids showed enhanced response (6.5 to $50 \mathrm{ppm}$ of $\mathrm{NH}_{3}$ ) that exhibited excellent stability after 30 cycles in 15 days. This was due to formation of a p-n junction when $\mathrm{CeO}_{2}$ NPs and PANI come in contact. Similarly, PPy based high sensitivity, high selectivity $\mathrm{NH}_{3}$ sensor was prepared by making $\mathrm{SnO}_{2} / \mathrm{PPy}$ nanocomposite via vapor phase polymerization with detection limit of as low as $257 \mathrm{ppb}$ [169]. The sensing performance was attributed to following reasons: the $\mathrm{P} / \mathrm{N}$ junction at the interface of $\mathrm{SnO}_{2}$ nanosheets and PPy coating, high specific surface area and good ohmic contact between the substrate and the sensing material.

Currently, sensor films on a flexible substrate have become an interesting research topic in modern electronics. Polyethylene terephthalate (PET) is the widely used flexible substrate to fabricate organic electronic sensing devices. The main challenge in flexible devices is to keep flexibility while maintaining critical properties like sensitivity, stability, reproducibility at a desired level. Gavgani et al. [286] investigated a flexible sensor based on $S$ 
and $\mathrm{N}$ co-doped graphene quantum dots (S, N: GQDs)/ PANI hybrid thin film. They obtained a significant improvement of $\mathrm{NH}_{3}$ response ( $42 \%$ at $\left.100 \mathrm{ppm}\right)$, excellent selectivity and rapid response and recovery times (115 s) at room temperature. The synergistic effect between the $S$, $\mathrm{N}$ : GQDs and PANI of doping/de-doping process, charge carrier mobility and swelling process, was considered as a reason of enhanced sensing properties. Bandgar et al. [297] synthesized a flexible and low-temperature PANIbased sensor, which showed an optimum response of $26 \%$ to $100 \mathrm{ppm} \mathrm{NH}_{3}$ gas at $0^{\circ} \mathrm{C}$ with a fast response $(19 \mathrm{~s})$ as well as recovery time (36 s). In most of flexible devices, the resistance remains almost unchanged and the sensing performance was not affected during repetitive bending cycles, which demonstrated mechanical stability indicating the potential for soft/wearable electronic technology [298]. Jun et al. [299] fabricated novel radio frequency identification (RFID)-based wireless sensor systems using carboxyl group functionalized PPy (C-PPy) nanoparticles (NPs). The C-PPy nanoparticles with an average size of $60 \mathrm{~nm}$, were synthesized from a water-soluble polymer and highly monodispersed metal cations. The presence of the C-PPy NPs gave rise to a strong affinity between the PPy backbone and the $\mathrm{NH}_{3}$, which was detected by the RFID sensor.

\section{Hydrogen sulfide sensors}

Hydrogen sulfide $\left(\mathrm{H}_{2} \mathrm{~S}\right)$ is a toxic and flammable gas which is often generated from different industrial processes or by the degradation of organic matter such as rotten egg. The immediately dangerous to life or health (IDLH) concentration for $\mathrm{H}_{2} \mathrm{~S}$ is $100 \mathrm{ppm}$. Therefore, low cost $\mathrm{H}_{2} \mathrm{~S}$ sensors are of interest for food and packaging industry. $\mathrm{H}_{2} \mathrm{~S}$ is a weak acid which does not interact with PANI significantly. The incorporation of transition metal chlorides in PANI nanofibers can improve the response to $\mathrm{H}_{2} \mathrm{~S}$ compared to unmodified PANI nanofibers $\left(\mathrm{CuCl}_{2}-\right.$ PANI and $\mathrm{ZnCl}_{2}$-PANI) [300-302]. High sensitivity for high concentrations $(>20 \mathrm{ppm})$ was achieved but the recovery performance was limited. Shirsat et al. [279] reported a sensitive and selective chemiresistive sensor for $\mathrm{H}_{2} \mathrm{~S}$ detection, which consisted of PANI nanowires-Au NPs hybrid network between two gold microelectrodes. The sensor exhibited excellent selectivity by $\Delta R / R_{0}$ of $5 \%$ upon exposure to $50 \mathrm{ppm} \mathrm{NH}_{3}$, which was significantly lower than the response to $0.1 \mathrm{ppb} \mathrm{H}_{2} \mathrm{~S}$. In recent work, electrospun PANI nanofibers were used to fabricate $\mathrm{H}_{2} \mathrm{~S}$ gas sensor that were written directly on the paper and polyimide substrates [303]. The sensor exhibited high sensitivity (1 ppm), quick recovery (250 s) and high se- lectivity towards $\mathrm{H}_{2} \mathrm{~S}$ among $\mathrm{H}_{2} \mathrm{~S}, \mathrm{NO}_{2}$ and acetone. The formation of high quality nanofibers is the key to good recovery and repeatability.

In summary, the possibility of adding functional fillers into the polymer matrix greatly broadens the use of $\mathrm{CP}$ sensors. It is a challenge to develop low cost nanostructured sensor devices on a large scale. High selectivity for specific target species is another critical subject for real sensing applications. Sensor array with statistical tools such as principal component analysis for data processing are utilized to evaluate the selectivity of the sensor.

\section{Biosensors}

CPs have attracted intensive interest in the development of biosensors because they are excellent materials for immobilization of biomolecules and rapid electron transfer for the fabrication of efficient biosensors [29,304-307]. Various biomolecule targets with specific properties determined the parameters of CPs based biosensors, such as sensitivity, selectivity, especially response time, which is of crucial importance [308]. The sensing signals, including conductivity, current, impedance data, are strongly associated with the number and mobility of charge carriers [29]. CPs combined with metal, metal oxide and carbon nanomaterials exhibited enhanced electrochemical properties for the following reasons: (1) the amount of nanomaterials loaded on electrode surface was increased; (2) the electron transfer during the reaction was accelerated; (3) distribution of nanomaterials became more uniform; and (4) the electrocatalytic activity and stability was much improved [309]. Many research groups dedicated on CPs-based nanocomposites as biosensors and the information are listed in Table 8.

\section{Hydrogen peroxide sensors}

Hydrogen peroxide $\left(\mathrm{H}_{2} \mathrm{O}_{2}\right)$, as a reactive oxygen species, has wide applications in industrial process and environmental and biological reactions. $\mathrm{H}_{2} \mathrm{O}_{2}$ is also related to several diseases; therefore it is very important to develop a reliable, rapid and economical detection method for healthcare and biological monitoring. As biosensors, the detection of $\mathrm{H}_{2} \mathrm{O}_{2}$ is important because it is often a product in enzymatic reactions. In the past decades, many methods including chemiluminescence, chromatography, and electrochemistry have been used to determine the $\mathrm{H}_{2} \mathrm{O}_{2}$ concentration [320]. Among these techniques, electrochemical sensor acted as the most promising sensing method and offered an inexpensive and effective way for $\mathrm{H}_{2} \mathrm{O}_{2}$ detection [25]. The experimental results in most 
Table 8 Selected conducting polymer based nanocomposites as biosensors

\begin{tabular}{|c|c|c|c|c|c|c|c|}
\hline $\begin{array}{c}\text { Electrode } \\
\text { configuration }\end{array}$ & Analyte & $\begin{array}{c}\mathrm{LOD} \\
\left.(\mu \mathrm{mol} \mathrm{L})^{-1}\right)\end{array}$ & $\left.\begin{array}{l}\text { Linear range } \\
(\mathrm{mmol} \mathrm{L}\end{array}\right)$ & $\begin{array}{c}\text { Working } \\
\text { potential }(\mathrm{V})\end{array}$ & $\begin{array}{l}\text { Response time } \\
\text { (s) }\end{array}$ & $\begin{array}{c}\text { Sensitivity } \\
\left(\mu \mathrm{A} \mathrm{mmol}{ }^{-1} \mathrm{~L} \mathrm{~cm}^{-2}\right)\end{array}$ & Ref \\
\hline $\mathrm{PPy} / \mathrm{Ag} / \mathrm{GCE}$ & $\mathrm{H}_{2} \mathrm{O}_{2}$ & 0.68 & $0.005-0.1$ & -0.25 & $<5$ & 9,701 & [310] \\
\hline $\mathrm{PPy} / \mathrm{CuNPs}$ & $\mathrm{H}_{2} \mathrm{O}_{2}$ & 0.9 & $0.2-1$ & -0.85 & $<3$ & I & [311] \\
\hline $\mathrm{PPy} / \mathrm{Ag} / \mathrm{Fe}_{3} \mathrm{O}_{4} / \mathrm{GCE}$ & $\mathrm{H}_{2} \mathrm{O}_{2}$ & 1.7 & $0.00-11.5$ & -0.2 & l & I & [312] \\
\hline PEDOT:PSS/MB & $\mathrm{H}_{2} \mathrm{O}_{2}$ & 0.1 & $0.0001-0.12$ & -0.15 & l & 353.9 & [313] \\
\hline PANI/PtNPs & Glucose & 0.7 & $0.01-8$ & -0.56 & 3 & 96.1 & [314] \\
\hline $\mathrm{PANI} / \mathrm{NiCo}_{2} \mathrm{O}_{4}$ & Glucose & 0.38 & $0.015-4.735$ & 0.5 & I & 4,550 & [166] \\
\hline PANI/AuNPs/CC & Glucose & 3.08 & $0.0126-10.0$ & 1 & I & 150 & [315] \\
\hline $\begin{array}{c}\mathrm{PANI} / \mathrm{Pt} / \mathrm{GOx} / \mathrm{PU} / \\
\mathrm{E}-\mathrm{PU}\end{array}$ & Glucose & I & $0-20$ & 0.6 & I & 1.34 & [316] \\
\hline $\mathrm{NiO} / \mathrm{PANI} / \mathrm{GO} / \mathrm{GCE}$ & Glucose & 0.5 & $0.002-5.560$ & 0.6 & I & 376.22 & [317] \\
\hline $\mathrm{PPy} / \mathrm{NiO}$ & Glucose & 0.33 & $0.01-0.5$ & 0.53 & l & $1,094.80$ & [170] \\
\hline $\mathrm{POT} / \mathrm{Au} / \mathrm{Cu}$ & Glucose & 0.027 & $1-30$ & 0.1 & l & 37 & [109] \\
\hline $\mathrm{PPy} / \mathrm{PB} / \mathrm{CNP}$ & Hydrazine & 0.29 & $0.0075-1.653$ & 0.25 & $<3$ & I & [151] \\
\hline PANI/Nafion/Cu & Urea & 0.5 & $0.001-0.1$ & -0.35 & 15 & 112 & [318] \\
\hline PANI/Nafion/Cu & Creatinine & 0.5 & $0.001-0.1$ & -0.35 & 15 & 85 & [318] \\
\hline $\begin{array}{l}\text { PANI/MWCNT/ } \\
\text { Basillus sp./GA }\end{array}$ & Paracetamol & 2.9 & $0.005-0.63$ & 0.5 & $<2$ & I & [319] \\
\hline
\end{tabular}

LOD: S/N=3, GCE: glassy carbon electrode, PU: polyurethane, E-PU: epoxy-enhanced polyurethane, GOx: glucose oxidase, CC: carbon cloth, GA: glutaraldehyde, PB: Prussian blue, MB: Meldola blue, CNP: carbon nanopolyhedra.

of metal/CP electrodes have been summarized in our previous work, which illustrated metal/CP nanocomposites have relatively low detection limit, high current sensitivity, fast response time and linear regions covered wide determination range [25]. For example, Mahmoudian et al. [310] synthesized PPy coated silver nanostrip bundles (Ag NSBs-PPy) by a facile method of direct reduction of $\mathrm{Ag}$ cations in the presence of the pyrrole monomer in an aqueous solution of $\mathrm{AgNO}_{3}$ and $\mathrm{NaOH}$. The glassy carbon electrode (GCE) modified with $\mathrm{Ag}$ NSBs-PPy in an electrochemical system showed remarkable catalytic performance for $\mathrm{H}_{2} \mathrm{O}_{2}$ detection. The enlarged surface area resulted in the improvement of the ability of the modified electrode and fast response for reaction with $\mathrm{H}_{2} \mathrm{O}_{2}$. The detection limit for the range of low and high concentration is estimated as $0.68 \mu \mathrm{mol} \mathrm{L}{ }^{-1}$ and $13.10 \mu \mathrm{mol} \mathrm{L}^{-1}$, respectively. Yang et al. [321] fabricated an enzymeless electrochemical sensor based on highly ordered polyoxometalate (POM)-doped PANI nanopillar films for the detection of hydrogen peroxide. The sensing performance was attributed to the large surface area of the 1D nanostructure and the multiple redox reactions of POMs.

Some $\mathrm{CP} /$ metal nanocomposites have been widely employed for both catalytic and biosensing applications [30]. For instance, Au/PANI nanocomposites have been fabricated by depositing Au nanoparticles on the surface of PANI nanofibers. The product exhibited excellent catalytic properties for the reduction of nitro-compounds in the presence of $\mathrm{NaBH}_{4}$ with shorter adsorption time and faster reaction rate using smaller $\mathrm{Au}$ nanoparticles [322]. Lu and coworkers [323-325] reported a series of promising research achievements on $\mathrm{CP} /$ noble metal nanocomposites for catalytic properties. $\mathrm{CP} /$ noble metal nanorings were fabricated by an one-pot fabrication using facile soft-template method, which was the first time to use (CTA) $)_{2} \mathrm{PdBr}_{4}$ as a template [323]. For instance, the experimental results showed enhanced catalytic activity of $\mathrm{PPy} / \mathrm{Pd}$ nanorings for the reduction of $\mathrm{p}$-nitrophenol into p-aminophenol by $\mathrm{NaBH}_{4}$ in aqueous solution, owing to following two factors: (i) PPy was used to immobilize Pd nanoparticles in good dispersion and enhance the electron transfer between PPy and Pd, and (ii) stable ring-like structure provided the process stability. PANI/Au nanorices were prepared by the similar method in which $\mathrm{HAuCl}_{4}$-(3-aminopropyl)triethoxysilane (APTES) acted as both a soft template and an oxidant [324]. The nanocomposites exhibited an enhanced peroxidase-like catalytic activity compared with the individual component, which was used as enzyme mimics toward the oxidation of tetramethylbenzidine (TMB). Some ternary nanocomposites have been also prepared for $\mathrm{H}_{2} \mathrm{O}_{2}$ detection 
[326,327]. Lu et al. [326] reported the synthesis of PPy/ $\mathrm{CuFe}_{2} \mathrm{O}_{4} / \mathrm{Cu}_{9} \mathrm{~S}_{8}$ nanotubes as an efficient peroxidase mi$\mathrm{mic}$ by the combination of electrospinning process, annealing treatment and hydrothermal reaction. The results indicated $\mathrm{H}_{2} \mathrm{O}_{2}$ could be well detected in the linear range from 0 to $20 \mu \mathrm{mol} \mathrm{L}{ }^{-1}$ and the detection limit was estimated to be about $0.688 \mu \mathrm{mol} \mathrm{L}^{-1}(\mathrm{~S} / \mathrm{N}=3)$. This work offered a simple method to fabricate a high performance peroxidase-like catalyst for biosensors and environmental monitoring.

\section{Glucose sensors}

Glucose is one of the essential substances in human's living and an important component of food, drugs and industrial products. Glucose detection is important in biomedical applications and ecological approaches, specially of clinical importance [306]. The quantitative monitoring of blood glucose has become crucial and can greatly reduce the risks of diabetes mellitus-induced heart disease, kidney failure, or blindness, etc. In previous studies, the most common glucose biosensors based on GOx and other enzymes have attracted wide interest owing to their high selectivity and biocompatibility. Miao et al. [328] fabricated a glucose sensor based on AuNPs/ polyvinylpyrrolidone/PANI nanocomposites for enzyme immobilization and biosensor construction. The sensor exhibited fast amperometric response, good stability and reproducibility, and excellent electrocatalytic activity towards glucose in real serum samples without common interference. However, there are limitations of enzymebased biosensors such as high cost, easily deactivated and tedious modification steps. In recent work, non-enzymatic glucose sensors with CP-based nanocomposites are becoming new hotspots. Xu et al. [315] synthesized a flexible electrochemical sensor based on AuNPs/PANI arrays/CC electrode. The flexible carbon cloth was employed as base electrode, PANI arrays were directly grown on CC electrode, and large number of Au nanoparticles were electrodeposited on the surface. High sensing performance towards glucose detection was achieved that includes a wide linear range from $10.26 \mu \mathrm{mol} \mathrm{L}^{-1}$ to $10 \mathrm{mmol} \mathrm{L}^{-1}$, a high sensitivity of $150 \mu \mathrm{A} \mathrm{mmol}^{-1} \mathrm{~L} \mathrm{~cm}^{-2}$, and a low detection limit of $3.08 \mu \mathrm{mol} \mathrm{L}^{-1}$. Poyraz et al. [109] fabricated networks of POT nanofibers and $\mathrm{Au} / \mathrm{Cu}$ nanoparticles NPs via one-step seeding polymerization reaction and a redox/complexation process. High sensitivity for glucose, a wide linear operation range and high selectivity in the presence of uric acid (UA) and L-ascorbic acid (AA) at their physiological levels were achieved. Zheng et al. [329] developed a highly sensitive non-enzymatic glucose sensor based on $\mathrm{Cu} / \mathrm{PANI} /$ graphene nanocomposite. This system showed high selectivity to glucose oxidation but no signal from interferents such as ascorbic acid and dopamine. This indicates its great potential as a non-enzymatic glucose sensor. Among many metal oxides, nickel oxide (NiO) nanostructure has been widely used in non-enzymatic glucose sensors owing to their excellent electrocatalytic properties and chemical stability. Zhuang et al. [317] fabricated a 3D nickel oxide NPs/PANI nanowire/graphene oxide hybrid composite. The resulting sensor displayed high sensitivity, good reproducibility and a detection limit of $0.11 \mu \mathrm{mol} \mathrm{L}{ }^{-1}$. Besides individual metal oxides, $\mathrm{Yu}$ et al. [166] investigated a core-shell structure of $\mathrm{NiCo}_{2} \mathrm{O}_{4} @$ PANI nanocomposite for electrocatalytic properties using simple and reliable strategy. $\mathrm{NiCo}_{2} \mathrm{O}_{4}$ provides more catalytically active sites and offer numerous effective electrolyte-accessible channels for ion transportation. PANI coating on the outer walls, serving as conductive substrate, is one of the strategies to improve the conductivity of $\mathrm{NiCo}_{2} \mathrm{O}_{4}$.

\section{Other biomolecules sensors}

Other biomolecules such as DNA sensor are equally important for minimizing any damage in DNA molecule to prevent from serious diseases. Wei et al. [330] used PEDOT:PSS membrane in an electrokinetic microfluidic device based on ion concentration polarization (ICP) for the detection of low-abundance DNA samples. Such device performed fast and more efficient hybridization reaction, which was able to detect DNA target in the subnanomolar concentration regimes. These devices can be directly applied to complex biological samples. PANI can be used to modify the biosensor surface that can further enhance the sensing performance by improving the charge transfer. This was achieved by polymerizing aniline in emulsion with dinonylnaphthalene sulfonic acid (DNNSA) yielding highly processible mixture for biosensor surface modification [331,332]. Zhang et al. fabricated a potentiometric immunosensor for the detection of a cardiac biomarker-Troponin I-T-C with PANI/ DNNSA as a transducing layer. Different from traditional potentiometric sensors based on potentiometric response from analyte binding [333,334], this sensor depends on enzymatic redox reaction catalyzed on the sensing surface. It has a significantly low limit of detection $\left(5 \mathrm{pg} \mathrm{mL}^{-1}\right.$ or $\left.56 \mathrm{fmol} \mathrm{L}^{-1}\right)$ and a wide dynamic range $(6$ orders of magnitudes), making it an ideal substitute for conventional immunoassays currently used in clinical settings [335]. Rong and co-workers [106] fabricated new 
network nanocomposite composed of PPy hydrogel loaded with gold nanoparticles for a sensitive label-free amperometric immunosensor. For carcinoembryonic antigen (CEA) detection, the immunosensor exhibited a wide linear detection range from $1 \mathrm{fg} \mathrm{mL}^{-1}$ to $200 \mathrm{ng} \mathrm{mL}^{-1}$ with an ultralow limit of detection of $0.16 \mathrm{fg} \mathrm{mL}^{-1}$.

\section{Energy harvesting devices}

\section{Actuators}

Electroactive polymers (EAPs), including piezoelectric polymers and electrostrictive polymers, are considered as the most suitable materials for energy harvesting devices due to their high flexibility, low cost, easy synthesis and compatibility with any desired shape [258,336,337]. Piezoelectricity gives a linear relationship between the strain and the electric field whereas electrostriction has quadratic dependence of strain on the electric field. To improve the capability of electromechanical response, it is necessary to increase the dielectric constant while maintaining low Young's modulus. As discussed in Section "Dielectric capacitors", the development of polymeric composites filled with conductive loading is most promising way to increase the dielectric permittivity and modify the electrical properties. In a recent study, researchers found that polymer composites with $\mathrm{CP}$ as the filler can keep high conversion efficiency and good strain capability [338]. PANI-based composites were developed that possessed an elastic modulus close to that of the insulation polymer matrix [339]. The developed composite exhibited a strain of $2.65 \%$ with an elastic energy density of $0.18 \mathrm{~J} \mathrm{~cm}^{-3}$ under a field of $16 \mathrm{MV} \mathrm{m}^{-1}$ [258]. Jaaoh et al. [340] studied the power output of fabricated polyurethane (PU)/PANI composites with various PANI contents by solution casting giving maximum power with 2 wt.\% of PANI. Putson et al. [341] modified the PU as matrix with different oxidation states of PANI (emeraldine base, EB and emeraldine salt, ES) as filler. The film containing PANI-ES has three times larger dielectric constant than PU matrix. This large dielectric permittivity was further increased to 142.6 at $1 \mathrm{kHz}$ by the addition of $\mathrm{HCl}$ (PU/PANI-ES-HCl) to increase the interfacial area.

\section{Triboelectric nanogenerator}

Triboelectric nanogenerator (TENG), invented by Wang and co-workers in 2012, has drawn widespread attention as a novel mechanical energy harvesting device [342]. The working principle of TENG is based on the coupling effect of triboelectrification and electrostatic induction when two triboelectrode materials with opposite tribo- electric polarities have friction between them [343]. Since TENG relies on the surface charging effect, it is critical to select and develop the triboelectrode materials with excellent triboelectric properties. In recent work, PPy was considered as the promising triboelectrode material for a high output TENG due to its numerous advantages over other materials such as semiconductor properties, flexibility, high specific capacitance, rapid charge storage, difficult to be oxidized or degraded in harsh environments, and easy to fabricate in $1 \mathrm{D}$ nanostructures. The first PPy based TENG was reported by Wang et al. $[344,345]$ to have outstanding performance of self-powered synthesis of PPy and self-charging powering system (Fig. 16). The device can power a digital temperaturehumidity meter and can power as many as 40 reactors. Cui et al. [49] proposed a novel TENG constructed with PPy nanowires prepared by an electrochemical polymerization method using AAO as a template. The synthesized PPy based TENG showed excellent durability and high output performance with a short circuit current density of $23.4 \mathrm{~mA} \mathrm{~m}^{-2}$ and output voltage of $351 \mathrm{~V}$. The smart device can be used to power a cathodic protection system to protect metals from corrosion. CPs can improve the overall performance of flexible piezoelectric nanogenerators (FPNGs) and other energy harvesting nanodevices. Sultana et al. [346] proposed the presence of PANI in nanogenerator makes it suitable for portable, wearable flexible electronic devices that have large electrical throughput. The CPs nanocomposites can be exploited in many other energy harvesting devices for their flexibility, ease of synthesis and adjustable electrical properties.

\section{Thermoelectric devices}

Thermoelectric (TE) devices/systems directly convert thermal energy (temperature difference) into electrical energy, are attractive for applications from civilian (such as waste heat recovery) to military and aerospace purposes [347]. Typical module consists of two different materials connected at two points. When the two conjunct points are placed at different temperature, there is an electrical potential generated between the two conjunct points (i.e., Seebeck effect). The conversion efficiency of a TE device is dependent on the material used. A figure-of-merit ( $Z$-factor or power factor), defined as $Z T=S^{2} \sigma T / \kappa$, is widely used to represent the characteristics of the TE materials. The other widely used parameter to characterize the energy conversion efficiency is $Z$ $\times T$, where $S$ is the Seebeck coefficient, $\sigma$ is the electrical conductivity, $\kappa$ is the thermal conductivity, and $T$ is the 


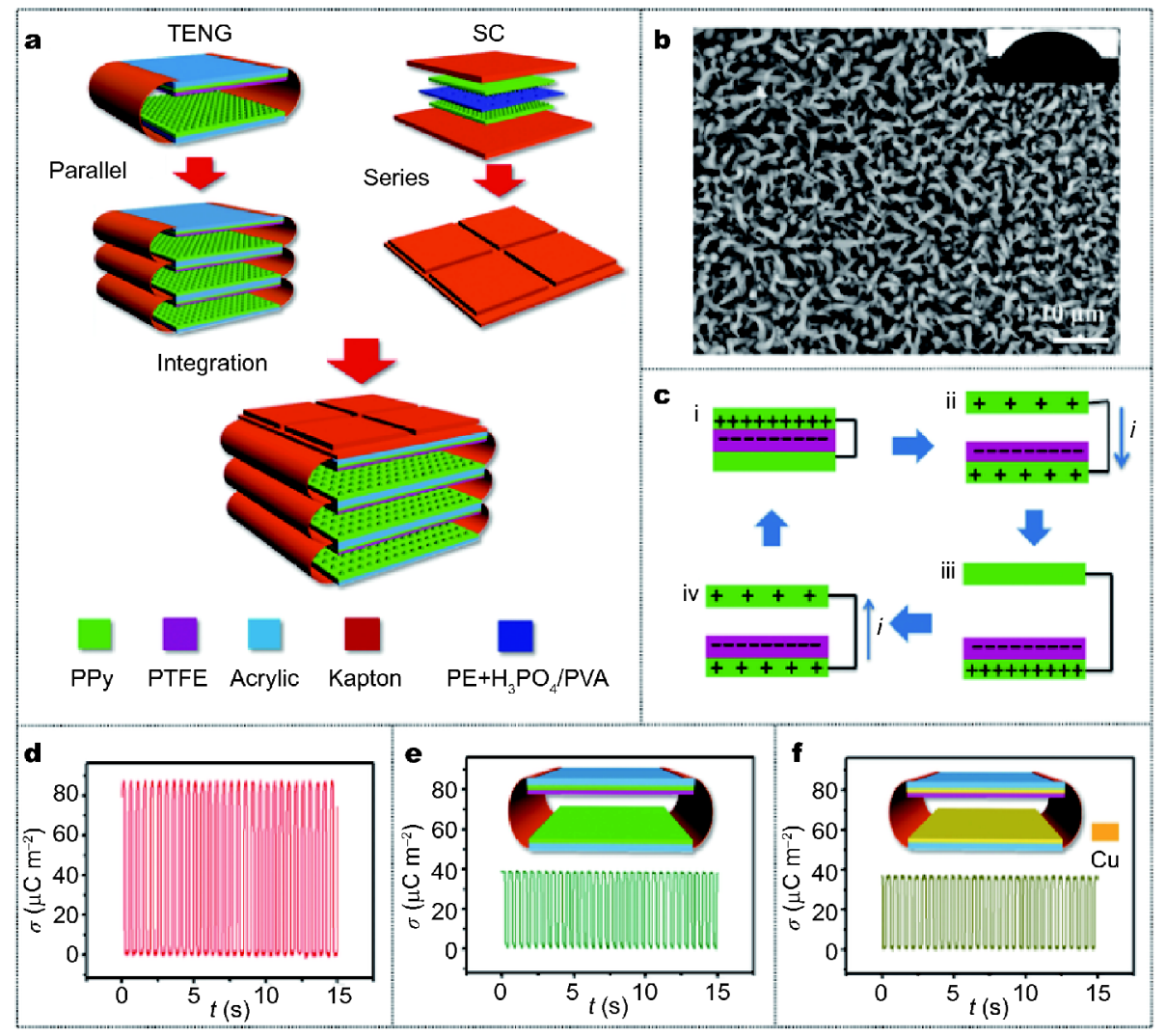

Figure 16 Overview of the all-plastic-materials based self-charging power system. (a) Schedule of the integrated self-charging power system from 3parallel TENG and 4-series supercapacitors (SC). (b) SEM image of hPPy, which is used as triboelectric electrode of TENG and electrode active material of supercapacitors, with its water-contacting angle shown in the up-right corner. (c) Brief mechanism of the TENG. Reprinted with permission from Ref. [345] (Copyright 2015, WILEY-VCH Verlag GmbH \& Co. KGaA, Weinheim).

absolute temperature, respectively, and $S^{2} \sigma$ is the power factor. Inorganic semiconductors, such as tellurium, lead, bismuth, are most efficient for thermoelectricity. Many nanostructured TE materials were developed, such as 1D (nanowires) and 2D (quantum wells and superlattices) materials, nanocomposites $\left(\mathrm{Bi}_{2} \mathrm{Te}_{3}, \mathrm{PbTe}\right.$ and $\mathrm{SiGe}$ based) and other new materials [348]. However, there are limitations for these materials to be used because they are heavy, brittle, toxic, expensive and sparsely available. Organic thermoelectric materials showed excellent response due to their low cost, mechanical flexibility, nontoxic and low processing temperature. The intrinsically low thermal conductivity of CPs makes them ideal for high-performance thermoelectric materials, but their relatively poor electrical conductivity and the Seebeck coefficient could be a limitation [349]. As one of the widely used organic thermoelectric materials, PANI exhibited very small thermoelectric power factors $\left(S^{2} \sigma\right)$. It was found that electrical conductivity and Seebeck coefficient are strongly correlated. This indicates the difficulty in enhancing both the parameters simultaneously in one material.

To overcome these limitations, increasing attention has been paid to CP-based nanocomposites to utilize both advantages of inorganic fillers and CPs [350,351,361], as listed in Table 9. Wang et al. [352] carefully controlled the polymer conformation and interfaces between PANI and Te nanorods, as shown in Fig. 17a, b. The high-speed carrier-moving channel, obtained by conformation of PANI chains, increased the electrical conductivity while preserving the low thermal conductivity. Recent studies have reported that $\mathrm{CPs}$ with carbon-based nanomaterials (CNTs, graphene and graphene nanoplates) can effectively increase the power factor [179,353,355-357]. For example, nanointerfaces between the PANI and CNTs can enhance the size-dependent energy-filtering effect [362] and the $\pi-\pi$ conjugation interactions between the PANI and CNTs would increase carrier mobility [354]. They both result in enhancement of electrical conductivity and Seebeck coefficient simultaneously. Gra- 
Table 9 The room-temperature TE properties of the conducting polymer based hybrid nanocomposite

\begin{tabular}{|c|c|c|c|c|c|c|}
\hline $\begin{array}{c}\text { CPs-based } \\
\text { nanocomposites }\end{array}$ & $\begin{array}{l}\text { Conductivity } \\
(\sigma)\left(\mathrm{S} \mathrm{cm}^{-1}\right)\end{array}$ & $\begin{array}{l}\text { Seebeck coefficient } \\
\qquad(S)\left(\mu \mathrm{V} \mathrm{K}^{-1}\right)\end{array}$ & $\begin{array}{c}\text { Power factors } \\
\left(S^{2} \sigma\right)\left(\mu \mathrm{W} \mathrm{m}{ }^{-1} \mathrm{~K}^{-2}\right)\end{array}$ & 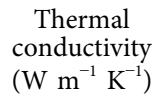 & $\begin{array}{c}Z T \\
\left(S^{2} \sigma T \kappa^{-1}\right)\end{array}$ & Ref \\
\hline PEDOT:PSS/Te nanorods & 19.3 & $163( \pm 4)$ & 70.9 & $0.22-0.3$ & 0.1 & [350] \\
\hline PEDOT:PSS/Te nanorods & 2 & 1400 & 42 & I & I & [351] \\
\hline PANI/Te nanorods (70 wt.\%) & 102 & $102( \pm 5)$ & 105 & 0.21 & 0.156 & {$[352]$} \\
\hline PEDOT:PSS/SWNTs & 400 & 25 & 25 & 0.4 & I & [353] \\
\hline PANI/SWCNT & 125 & 40 & 20 & I & 0.004 & {$[354]$} \\
\hline PANI/graphene & 130 & 15 & 3.6 & I & 0.008 & [355] \\
\hline PANI/graphene & 856 & 15 & 19 & l & I & [356] \\
\hline PANI/graphene/PANI/DWNT & 1,080 & 130 & 1,825 & l & I & [357] \\
\hline PANI/DWNT (30 wt.\%) & 610 & $\sim 61$ & $\sim 220$ & l & I & [179] \\
\hline $\mathrm{PPy} / \mathrm{rGO}$ & 75.1 & 33.8 & 8.56 & I & I & [358] \\
\hline PPy/SWCNT & $803( \pm 29)$ & $41( \pm 2)$ & 21.7 & I & I & [183] \\
\hline PPy/Graphene/PANI & 500 & 32.4 & 52.5 & I & I & [359] \\
\hline $\mathrm{PANI} / \mathrm{SWNT} / \mathrm{Te}$ & 345 & 54 & 101 & 0.3 & l & [360] \\
\hline
\end{tabular}

phene possesses similar chemical bonding with CNTs but has more $\pi$ bonds and larger surface area than CNTs [356]. However, researcher found the TE properties of PANI/graphene composites were still at a low level compared with PANI/CNT composites. This is due to the structural defects, impurity content and easy aggregation of graphene [356,363,364]. Wang et al. [356] prepared three different types of PANI/graphene nanocomposite films by solution-assistant dispersing method. The high electrical conductivity of $856 \mathrm{~S} \mathrm{~cm}^{-1}$ and power factor of $19 \mu \mathrm{W} \mathrm{m}{ }^{-1} \mathrm{~K}^{-2}$ were achieved. Cho et al. [357] prepared $\mathrm{PANI} /$ graphene/PANI/double-walled nanotubes (DWNTs) nanocomposites with ordered molecular structure. The maximum achieved power factor of $1,825 \mu \mathrm{W} \mathrm{m} \mathrm{K}^{-1}$ is the highest power ever reported for a completely organic material. The 3D conjugated network with PANI-covered DWNT bridging the gaps between graphene sheets increases the electrical conductivity and Seebeck coefficient. Recently, ternary systems have developed with uniform structures and high TE properties [359,360]. As shown in Fig. 17c and d, PPy/graphene/ PANI ternary nanocomposite has been prepared by the combination of in situ polymerization and solution process [359]. This ternary nanocomposite exhibited higher thermoelectric power factor than PPy, PANI and other binary systems. An abnormally high Seebeck coefficient was obtained in PANI/SWNT/Te nanocomposites, because of the energy filtering effect at both interfaces of $\mathrm{PANI} / \mathrm{SWNT}$ s and PANI/Te, while the electrical con- ductivity was still high [360].

\section{Corrosion protection}

Metal corrosion protection technology plays an extremely important role in the development of the national economy $[365,366]$. To prevent or mitigate corrosion, is not only a technical problem, but also related to the resources, energy, environmental protection and major strategic tasks. Therefore, effective corrosion protection plays a great strategic significance in future [365]. There are many anti-corrosion coating technologies present to reduce the loss of corrosion including electrochemical protection, coating, metal alloying, metal plating, etc. Among these technologies, coating technology has been widely adopted in a wide range of areas from large bridge, drilling platforms to small bikes and cans, etc., because the coatings can be easily repaired. Due to limitations of traditional coating material properties and process, coating may contain toxic substances such as lead or chromate, causing hazardous environment to the surroundings. Therefore, the development of a low cost coating material with green technology became one of the main objectives in the field of corrosion protection. Deberry et al. [367] and Mengoli et al. [368] first reported the application of conducting polymer in the field of corrosion protection. Since then, CPs have been extensively researched on corrosion protection due to easy preparation, thermal stability in air, redox behavior, low cost and versatile processability. Many research groups 


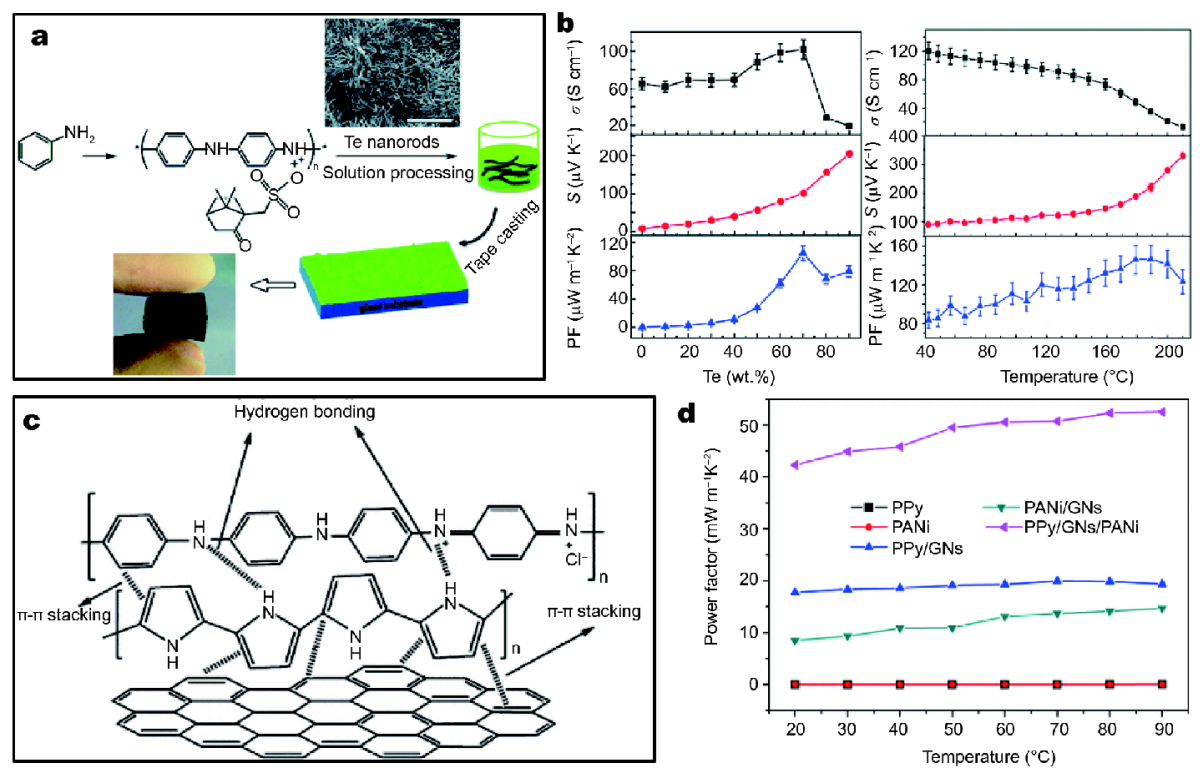

Figure 17 (a) Schematic illustration of the PANI/Te hybrid film processing, (b) electrical conductivity, Seebeck coefficient, and power factor of PANI/Te films changing with different Te content at room temperature and changing with temperature with Te content 70 wt.\%. Reprinted with permission from Ref. [352] (Copyright 2016, Royal Society of Chemistry). (c) Diagram of interactions in PPy/graphene/PANI composite, (d) Power factor of pure PPy, PANI, PPy/graphene composite, PANI/graphene composite, and PPy/graphene/PANI composite with 32 wt.\% graphene at different temperatures. Reprinted with permission from Ref. [359] (Copyright 2017, American Chemical Society).

have systematically investigated the synthesis of $\mathrm{CP}$ coatings on different metals such as copper, aluminum, iron, mild steel and stainless steel for corrosion protection [36]. In 1996, Ahmad and MacDiarmid [369] studied that conducting polymer can be applied chemically on the surface of steel, providing anodic protection by passivating the steel surface. Camalat et al. [370] reported the protection of steel by PANI coating in acidic medium. Ferreira et al. [371] investigated that PPy provides corrosion protection for easily oxidizable metals such as iron, aluminum and zinc. Nautiyal et al. [372] studied the influence of different types of dopants on passivation of carbon steel, electrodeposition of PPy coating and their effect on anti-corrosion performance. Because of the different methods of preparation, doping, corrosive media and different research methods involved, the mechanism of conducting polymer for corrosion protection is still under study [373-375].

In a recent study, experimental results indicated that it's a great challenge for a single conducting polymer to provide perfect corrosion protection. Charge stored in the polymer layer (used to oxidize base metal and to produce passive layer) can be irreversibly consumed during the system's redox reactions. Consequently, protective properties of the polymer coating may be lost with time. Further, porosity and anion exchange properties of $\mathrm{CPs}$ could be detrimental, particularly pitting corrosion caused by small aggressive anions (e.g., chlorides). An interesting alternative is to consider $\mathrm{CP}$ based composite systems to address the problems involved with conducting polymer coating [365]. Lighter weight and improved corrosion resistance makes composite materials as a good choice. The use of CPs with polymeric blends as corrosion protection coatings has shown significant protection for iron and its alloys. Polyvinyl chloride (PVC) and poly (methylmethacrylate) (PMMA) with good mechanical characteristics and high chemical resistance possessed attractive properties for use as corrosion protection coatings [376,377]. Besides the polymeric blends, the combination of $\mathrm{CP}$ with other nanostructured materials nanocomposites has also attracted considerable attention due to unique nanostructures, outstanding physicochemical and electro-optical properties, and a wide range of potential uses.

$\mathrm{CP} /$ metal oxide system uses nano-sized oxide fillers in $\mathrm{CP}$-based composites, and it had played very important role in improving the corrosion resistance and mechanical properties for anti-corrosive coating [378]. There are numerous reports on improvement of coatings performance in corrosive environments, using nanoparticles as reinforcement such as $\mathrm{TiO}_{2}, \mathrm{SiO}_{2}, \mathrm{ZnO}$ and $\mathrm{Fe}_{2} \mathrm{O}_{3}$. $\mathrm{TiO}_{2} /$ $\mathrm{CP}$ nanocomposites have been widely investigated be- 
cause the corrosion resistance was enhanced due to the presence of $\mathrm{TiO}_{2}$ particles in the coating system. They can form better dispersion for paint formulation which provides barrier properties in the coatings [379-381]. Recently, Pagotto et al. [382] reported multilayers of PANI/ $\mathrm{n}-\mathrm{TiO}_{2}\left(\mathrm{TiO}_{2}\right.$ nanotubes$)$ on carbon steel and welded carbon steel for corrosion protection. The addition of $\mathrm{TiO}_{2}$ nanotubes to PANI coatings inhibits the degradation of carbon steel by mechanical effect. The multilayer $\mathrm{PANI} / \mathrm{n}-\mathrm{TiO}_{2}$ enhances the adhesion and anticorrosive behavior. Bhandari et al. [383] studied the mild steel coated with $\mathrm{PANI} / \mathrm{SiO}_{2}$ (PSC) nanocomposites with dimension of $1 \mathrm{~cm} \times 1 \mathrm{~cm}$ to carry out the corrosion studies. The chronoamperometric response method was used for analysis in the corrosion protection and found significant drop in corrosion current for PSC compared with bare steel and PANI coating without $\mathrm{SiO}_{2}$ nanoparticles. The protection efficiency of composite coating was calculated at $99.3 \%$, indicating the suppressed corrosion of mild steel when coated with PSC composite coating.

$\mathrm{CP} /$ carbon materials are considered as ideal for anticorrosion and are preferred to meet different environmental needs among many multifunctional materials as anticorrosive fillers. Bai et al. [384] physically introduced carbon black into the model coating of PEDOT/polyvinyl butyral (PVB) binder to solve the problem of Fermi-level misalignment at the polymer/metal interface. The amount of electrochemically active PEDOT in the coating was successfully increased by the addition of carbon black. The composite coating applied on a zinc substrate provides effective inhibition of delamination. Qiu et al. [385] proposed a novel PANI/CNT brush-like nanostructures through in situ oxidative polymerization. It was found that nanobrush coating offers excellent corrosion protection of steel over a wide $\mathrm{pH}$ range by providing good barrier to the corrosive environment. It was more environmentally friendly than traditional heavy metal and their oxide coatings. Recently, graphene has been reported to be an excellent anticorrosion material due to its unique characteristics of chemical inertness, excellent thermal and chemical stability, remarkable flexibility and impermeable to molecules [386-388]. Jafari et al. [386] electrochemically synthesized adherent PANI/graphene nanocomposite coatings on $\mathrm{Cu}$ substrates. The coating exhibited excellent corrosion resistance in aggressive environments. The morphology of PANI/graphene nanocomposite remained integrated and defect-free after immersion in 5,000 ppm $\mathrm{NaCl}$ solution for $120 \mathrm{~min}$. Some researchers found that GO has a larger band gap and fully passivated surface. It has good solubility in polar solvents and is expected to provide better corrosion resistance than pristine graphene [389,390]. Qiu et al. [389] fabricated PANI/GO composite coated on 316 stainless steel by a pulse current technology. High hydrophobicity and lower porosity of the coating was found to be able to protect the steel from different corrosive medium $\left(\mathrm{H}_{2} \mathrm{O}\right.$, $\mathrm{O}_{2}, \mathrm{Cl}^{-}$, etc.), resulting in a better corrosion resistance.

Many other nanomaterials have been widely employed to boost the protective performance of coatings [365]. For example, He et al. [391] studied PANI grafted basalt plates (BPs) for enhanced corrosion protective performance of epoxy coatings. The results showed coating containing 10\% PANI-g-BPs exhibited the best protective performance with an impedance of about $1.2 \times$ $10^{10} \Omega \mathrm{cm}^{2}$ at $0.01 \mathrm{~Hz}$ after immersion for 80 days. Although CP-based coating has proved to have a good corrosion resistance, current study on its mechanism of corrosion is still limited. With the use of different test methods, corrosion resistance mechanism of polymer coatings can be fully and more accurately evaluated. With the continuous development of the theory and technology, it is believed that there will be more effective and sophisticated research methods for in-depth study of the electrochemical corrosion coatings.

\section{Antistatic agent}

It is well known that static charge is easily produced due to the insulator friction in dry air. Electrostatic attraction, repulsion, electric shock and the discharge machining caused by static charge can be of great harm and can have serious consequence to the life of the material [392]. Many important areas are in need of avoiding the accumulation of static electricity, such as the electronics industry, that includes a variety of static-sensitive components of production, transportation, storage, packaging [383,393]. The main role of the antistatic agent is to inhibit the generation of electrostatic charge and the promotion of charge leakage [383,393]. The most used methods for improving the antistatic performance are to reduce the surface resistivity or increase conductivity of the surface and to reduce the generation of triboelectric charge. For antistatic materials, the surface resistivity $\left(\rho_{\mathrm{s}}\right)$ should remain between $10^{9}$ and $10^{14} \Omega \mathrm{sq}^{-1}$ defined by military handbook and $10^{5}$ to $10^{12} \Omega \mathrm{sq}^{-1}$ defined by industry standards $[394,395]$. Another method to determine antistatic materials is to record the antistatic charge decay time, where a voltage is applied on the surface of the material (usually $5 \mathrm{kV}$ ) and the time required to decay to $10 \%$ of its initial strength is recorded. This time is known 
as $10 \%$ cut-off limit and the corresponding $50 \%$ discharge is referred as $50 \%$ cut-off limits. The material, which has good antistatic properties, should show $10 \%$ cut-off decay time in less than $2.0 \mathrm{~s}$.

The effect of surfactant antistatic agents is strongly dependent on the environment of material processing and the humidity when used. The requirements of new antistatic agents are inexpensive, transparent, less affected by air humidity, without heavy metals and easy to prepare in aqueous solution. Conventionally, amphiphilic surfactant was usually introduced into polymers as the antistatic material but the antistatic property is not permanent [396]. Like dielectric nanocomposites, different kinds of conductive fillers including metal nanoparticles, metal oxide whiskers, carbon black, carbon nanotubes, ionic liquids and graphene, have been added into the polymer matrix to obtain excellent antistatic property and economic results [397-399]. But poor dispersion of the filler and compatibility with polymer matrix results in poor antistatic performance.

Recently, many studies have been focused on CP-based composites as antistatic agents [393]. However, poor stability, rigidity, insolubility and infusible properties limit their direct use as antistatic agent [400]. Commonly, $\mathrm{CPs}$ blended with other polymer matrices have been widely used as a composite for anti-static application $[9,401]$. The main function of the antistatic agent is to promote a conductive channel. This kind of anti-static polymer composite has a good compatibility and better lasting. Soto-Oviedo et al. [401] reported PANI/organoclay nanocomposites and propylene-ethylidene-norbornene rubber antistatic agent prepared by melt blending using an internal mixer. The composites exhibit high conductivities up to $10^{-3} \mathrm{~S} \mathrm{~cm}^{-1}$ for $40 \mathrm{wt}$.\% of conducting nanocomposites, which can also be used for electromagnetic shielding applications. Xu et al. [402] introduced PANI as a conductive agent into polypropylene (PP) matrix, the composites showed significant improvement in volume resistivity of the composite. Shi et al. [403] studied the PANI/cellulose composite fibers with good antistatic properties. The composite was successfully spun from hydrophobic PANI and hydrophilic cellulose complex solution in aqueous media, containing 7 wt.\% $\mathrm{NaOH} / 12$ wt.\% urea, as solvent by wet-spinning. It was noted that the resistivity was as low as $10^{6} \Omega \mathrm{cm}$ with 2 wt.\% of PANI loading. The time for initial surface voltage decay to $10 \%$ were 0.34 and $0.21 \mathrm{~s}$, respectively, indicating the antistatic property of the fibers. The results also indicated that composite fiber with low PANI content had satisfactory values of decay time and good antistatic properties. Wang et al. [395] reported high-density polyethylene (HDPE) nanocomposites with graphene nanoplatelets (GNP) coated PANI as filler synthesized by in situ polymerization. The surface resistivity and volume resistivity $\left(\rho_{v}\right)$ decreased sharply with addition of $10 \mathrm{wt} . \%$ GNP@PANI. The significant improvement of the antistatic property of the nanocomposites is mainly due to the conductive network formed inside composites. Recently, many other nanocomposites have been synthesized for antistatic application, such as graphene-based PANI nanocomposites [404], MWCNT and silver nanoparticle decorated polypyrrole in epoxy matrix [405], and polyacrylonitrile/PANI composite nanofiber webs [406].

CP-based antistatic composites will become the main area of future research and development due to their advantages of corrosion resistance, ease of processing and lightweight towards antistatic applications. Because nanomaterials exhibit special properties over bulk, it is believed that with rapid development of nanotechnology and nanomaterials, novel CP-based nanocomposites would be a good prospect of antistatic materials. New conductive polymer materials and environmentally friendly conductive polymer nanocomposites research and development will bring great opportunities.

\section{Electromagnetic interference shielding}

With increasing demands of electronic devices and wireless communication, electromagnetic interference (EMI), generated by electrical devices, radio, television signals and magnetic devices, has become a serious issue which can cause degradation of system or equipment [35]. EMI has strong influence on human health such as the symptoms of languidness, insomnia, nervousness, headache, etc. Therefore, shielding of EMI is very critical for telecommunication signals, electronic device performance, industries operation and human life. Effective EMI shielding must have two functions of reducing undesirable emissions and protecting the component from stray external signals [407-409]. EMI shielding effectiveness (SE) is an important parameter to evaluate the absolute effectiveness of shielding materials and is strongly dependent on electrical conductivity and thickness of the shielding materials [410]. Materials with high electrical conductivity such as metals, carbon materials and CPs, have been widely used as EMI shielding materials [31,411-413]. Metals have limited applications due to their high mass density, poor flexibility and susceptibility to corrosion. CPs and their nanocomposites have become attractive materials for EMI shielding recently because of their high conductivity, environmental stability, me- 
Table 10 Study on CPs-based composites for EMI shielding in recent three years

\begin{tabular}{|c|c|c|c|c|c|c|}
\hline CPs-based nanocomposites & Preparation & $\begin{array}{l}\text { Conductivity } \\
\left(\mathrm{S} \mathrm{cm}^{-1}\right)\end{array}$ & $\begin{array}{l}\text { SE } \\
(\mathrm{dB})\end{array}$ & $\begin{array}{l}\text { Thickness } \\
(\mathrm{mm})\end{array}$ & $\begin{array}{c}\mathrm{SSE} \\
\left(\mathrm{dB} \mathrm{cm}^{2} \mathrm{~g}^{-1}\right)\end{array}$ & Ref \\
\hline PANI/Ag nanowire & Two-step casting & 5,300 & 50 & 0.013 & - & {$[415]$} \\
\hline PANI/amine-CNT & In situ polymerization & 3,009 & 50.2 & 0.005 & 74,900 & {$[416]$} \\
\hline PANI/amine-CNT & In situ polymerization & 3,009 & 74.9 & 0.029 & 19,300 & {$[416]$} \\
\hline PANI/graphite & $\begin{array}{l}\text { In situ polymerization and } \\
\text { ball milling }\end{array}$ & 24 & 83-89 & 1 & - & {$[417]$} \\
\hline PANI/graphite & $\begin{array}{l}\text { In situ polymerization and } \\
\text { ball milling }\end{array}$ & 24 & 17 & 0.005 & - & {$[417]$} \\
\hline PANI/graphene & Solution intercalation & 116 & 42 & 0.005 & - & {$[418]$} \\
\hline PANI/Bagasse fiber & In situ polymerization & 2 & 28.8 & 0.4 & & [419] \\
\hline PANI-aramid & Mixture and spin coating & 300 & 30 & 0.007 & - & {$[420]$} \\
\hline $\mathrm{PANI} / \mathrm{Co} / \mathrm{Ni}$ & Electroless deposition & - & $34-46$ & - & - & {$[421]$} \\
\hline PPy/MWCNT & In situ polymerization & 52 & 108 & 3 & - & {$[422]$} \\
\hline $\mathrm{PPy} /$ sawdust & $\begin{array}{l}\text { In-situ polymerization and } \\
\text { mixture }\end{array}$ & 1 & 20 & 0.01 & - & {$[423]$} \\
\hline PEDOT:PSS/rGO & In situ polymerization & 6.84 & 70 & 0.8 & 841.3 & {$[424]$} \\
\hline PEDOT:PSS/graphene foam & Drop coating & 43.2 & 91.9 & 1.5 & 20,800 & {$[425]$} \\
\hline PEDOT:PSS/WPU & Mixture and drop-casting & 77 & 62 & 0.15 & 4133 & {$[426]$} \\
\hline
\end{tabular}

WPU: waterborne polyurethane.

chanical flexibility, lightweight and low cost [414].

CP-based composites with carbon materials such as CNT, graphene etc. have been widely investigated and attracted enormous attention for EMI shielding applications due to the combination of unique structures and high electrical conductivities of CPs and CNTs, that form a network and conduct charges through $\pi-\pi$ hopping between them [411,427]. PANI is the most promising candidate for nanocomposites as shielding material due to its facile synthesis, environmental stability and high conductivity. Li et al. [416] fabricated lightweight flexible nanocomposites using oxidative polymerization of aniline on CNTs, to enhance the interactions between PANI and amine-functionalized CNT. The composite exhibited the highest specific SE of $7.5 \times 10^{4} \mathrm{~dB} \mathrm{~cm}^{2} \mathrm{~g}^{-1}$ compared with previously reported work. Besides CNT, CPs reinforced with other conductive carbon materials also delivered outstanding SE depending on their intrinsic properties and nanostructures. Joseph et al. [417] proposed PANI nanofiber-graphite composite with thickness of $1 \mathrm{~mm}$ which exhibited average EMI SE of $83-89 \mathrm{~dB}$ in the frequency range of $8.2-18 \mathrm{GHz}$ attributed to $100 \%$ attenuation of electromagnetic radiation. When the screen printing method was used and the thickness was reduced to $50 \mu \mathrm{m}, \mathrm{SE}$ is about $13 \mathrm{~dB}$. Wu et al. [425] developed a graphene foam (GF)/PEDOT:PSS composite by drop coating of PEDOT:PSS aqueous solution on functiona- lized GFs. Excellent electrical conductivity of $43.2 \mathrm{~S} \mathrm{~cm}^{-1}$ and total EMI SE of over $90 \mathrm{~dB}$ were obtained. The information of CP-based composites for EMI shielding in recent three years is summarized in Table 10.

In the latest trends and future aspect, CP-based shielding composites with multi-layered stack frameworks have attracted wider consideration and will be the most used approach [428]. Fang et al. [415] designed freestanding layer-structured PANI/Ag nanowire composite films via a simple casting process, as shown in Fig. 18a. The composite film with 14 vol.\% Ag-NWs showed high electrical conductivity of $5,300 \mathrm{~S} \mathrm{~cm}^{-1}$, good mechanical strength of $44 \mathrm{MPa}$ and excellent SE of more than $50 \mathrm{~dB}$ over a wide bandwidth of $1.2 \mathrm{GHz}$. Lyu et al. [420] fabricated high strength PANI-aramid nanocomposite with hierarchical layering structure, as shown in Fig. 18c. This stable composite film with a thickness of $10-15 \mu \mathrm{m}$ displayed good shielding effectiveness of $30-35 \mathrm{~dB}$ with mechanical strength of $179 \mathrm{MPa}$. Zhao et al. [421] synthesized a layer-structured shielding composite prepared by the successive coating of PANI and magnetic alloy cobalt-nickel which showed relatively high SE of 34-46 dB. Similar work was also achieved on layered linen fabric/PPy/nickel (LF/PPy/Ni) composites. The mechanism of EMI SE " $1+1>2$ " enhancement phenomenon was also discussed [429]. From these recent studies, it was inferred that layered structure has superiority in terms of 

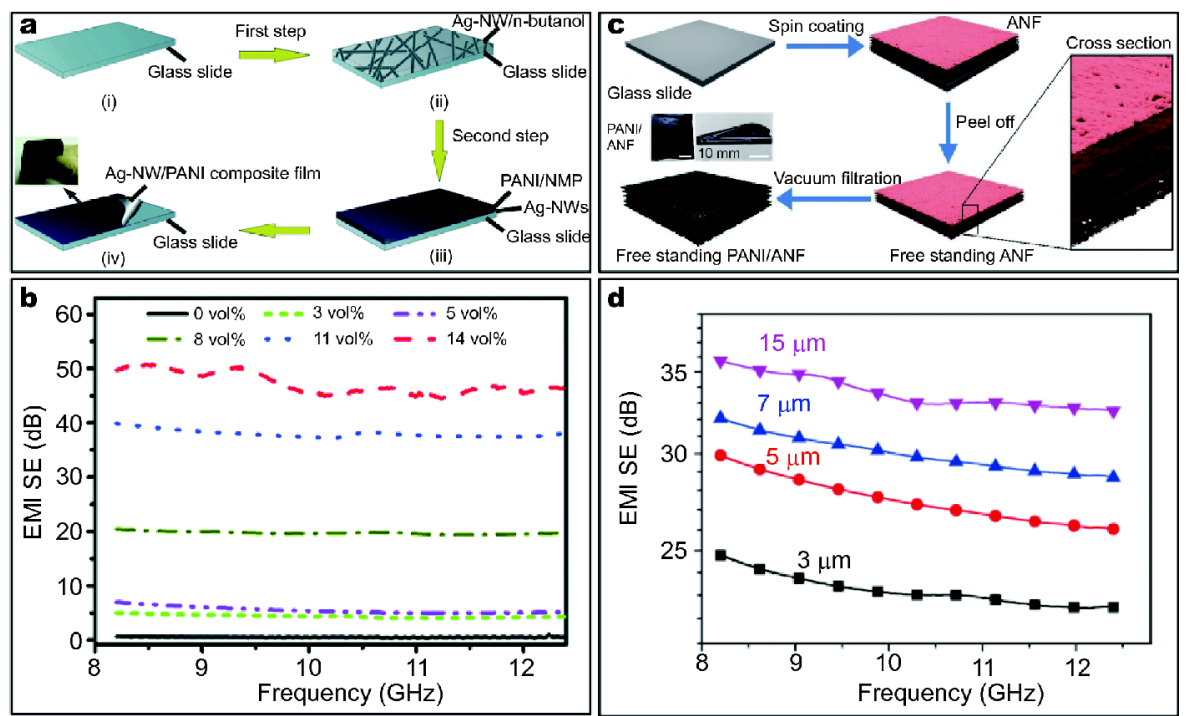

Figure 18 Layer-structured PANI/Ag-NW composite film: (a) the schematic of preparation and (b) the EMI SE in the X-band frequency range. Reprinted with permission from Ref. [415] (Copyright 2016, Royal Society of Chemistry). PANI-aramid nanocomposite with hierarchical layering structure: (c) the schematic of preparation and (d) the EMI SE in the X-band frequency range. Reprinted with permission from Ref. [420] (Copyright 2017, Elsevier).

shielding effectiveness in contrast to the single layer frameworks and embedded structures. The CPs keep the final film with ideal thickness and advanced mechanical properties. A new direction of the layer-structured composite films is promising for EMI shielding materials in the applications of electronic devices and radiation sources in near future.

\section{CONCLUSIONS AND FUTURE ASPECTS}

Ever since the discovery of highly conducting polyacetylene in 1970s and the Nobel Prize awarded in 2000, numerous researchers have dedicated their research on CPs and tremendous amount of research results have been reported in this area. The rapid growth of science and technology has enlightened the development of the $\mathrm{CPs}$ and their composite materials in nanoscale. In this review, we presented a comprehensive overview of the fabrication strategies of $\mathrm{CPs}$ and their nanocomposites, which offered extensive information on their advanced multifunctional properties for different applications. Many conventional and state-of-the-art synthetic approaches of CPs have been included, such as templatebased approaches (hard template and soft template) and template-free approaches (interfacial method, seeding, electrospinning, radiolysis, electrochemical assembly, soft lithography, etc.). The design and fabrication of CP based nanomaterials were also summarized, including CPs with metals, metal oxides, chalcogenides, nanocarbons with different morphologies, and CP based multi-component systems. Different synthetic approaches result in different morphologies and dimensions of nanocomposites for various applications, including electrochemical polymerization, seeding approach, interfacial polymerization, electrochemical deposition, rapid mixing method, hydrothermal method, spin-coating, and so on. With extraordinary electronic properties, functional $\mathrm{CP}$ based nanocomposites have been extensively explored in the applications of electronic nanodevices, energy storage devices (supercapacitors, batteries, dielectric capacitors), chemical and biological sensors, energy harvesting devices (actuators, triboelectric nanogenerator, thermoelectrics), and protection applications (anticorrosion agent, antistatic agent and electromagnetic interference shielding). After summarizing hundreds of reports in the literature on fabrication and application, future understanding and development are required.

For design and synthesis of pure CPs, the challenge is precise control of their electrical conductivity with different dimensions and morphologies. In future development, researchers should focus on providing novel synthetic methods and assembly processes that can produce CPs nanomaterials in a large quantity. It is known that high electrical conductivity can be obtained in CPs with high degree of structural order. It is necessary to propose effective methods to characterize and control the crystalline/amorphous ratio in $\mathrm{CP}$ structures. For fabri- 
cation strategies of CP based nanomaterials, the combination of CPs with other nanomaterials will continue to be a prospective research topic. The importance of the choice of CPs, combined with appropriate preparation techniques appear to be the key to develop promising nanocomposites. The systematic study on CPs with desirable sizes, nanostructures and properties in the composite could be very beneficial to this field in the future. Novel methods are needed to offer simple, efficient, scalable and inexpensive way for the nanomanufacturing of multi-component nanocomposites.

Great progress has been achieved in synthesis and application of CP based nanomaterials in supercapacitors, batteries, capacitors, and other energy storage devices. As an active component of supercapacitors, CPs suffered poor rate and cycling stability; however integrating them with different functional nanomaterials can effectively minimize the limitation of CPs and significantly improve the electrochemical performance. Based upon the studies surveyed in this review, the following aspects may deserve further investigation: (1) ternary composites with hybrid nanostructures could be more reliable for better-working supercapacitors, (2) flexible and stretchable supercapacitors will still be a hot research topic, which utilizes the advanced properties of CPs, including structural diversity, high flexibility and excellent durability and (3) it is critical to thoroughly understand energy storage mechanisms in different types of devices for the improvement of specific capacitance, energy density and power density. In dielectric capacitors, the current limitation of nanocomposites with conducting polymer filler is the simultaneous increase of dielectric loss and dielectric permittivity when the content of conducting polymer approaches the percolation threshold. The understanding of the breakdown strength mechanism of conductor-dielectric composites is still limited and further investigation on the application of this approach of dielectric capacitor is needed.

CPs have been widely used as the sensing layers of gas sensors due to low operating temperature, facile property adjustment, easy fabrication and excellent properties including high sensitivity and short response time. In future study, their limitation needs to be addressed: (1) stability for a long period is critical for sensors based on CPs for commercial applications. The performances of current sensors may dramatically decrease in air for a relatively longer time. This is due to the self-discharging phenomenon in CPs and degeneration by oxygen influence. (2) The reason of irreversibility is still not clear and needs to be studied. With sensing cycles increasing, the re- sponse of sensors gradually falls and is difficult to return to the original value. The interactions between gas and CPs need further investigations. (3) Selectivity has been an existing problem not only for CPs but also for other sensing materials. Furthermore, humidity has strong effect on sensing selectivity when detecting other gases in air. For biosensors, current studies using CP based nanocomposites have become key potential for bioanalytical techniques. Besides the problems mentioned for gas sensor, there is still room to improve the sensing performances in the following aspects: (1) integration of device nanomanufacturing, sensing arrays, signal preprocessing, pattern recognition in one microsystem, (2) improvement in the selectivity and sensitivity of nanocomposites and understanding the immobilization of biomolecule on sensing materials and the mechanism of reaction.

For protection applications, it is difficult to provide protection for a long period only using individual $\mathrm{CP}$ coating. In commercial application, the protection could be dramatically degenerated in aggressive environments. CP-based nanomaterials have demonstrated that they are the most promising alternative candidates for corrosion, antistatic and EMI shielding applications, because of adjustable conductivity, excellent shielding performance, corrosion resistance and good mechanical properties. Future investigations should focus on the synthetic paths of CP nanocomposites that exhibit more protective performance.

With all the discussions above, there are several critical points to be mentioned in terms of promoting CP-based nanocomposite research to the next level: (i) a reliable, large-scale manufacturing system needs to be developed in the future to assure the consistency of the nanocomposite properties and (ii) in-depth understanding of the interfaces between $\mathrm{CP}$ and other components in the nanocomposites will shed light to the future nanocomposite design and applications. Although quite a few applications have been discussed in this review, there is always more innovation that can be achieved with the development of new CP based nanomaterials. Further advances and deep insight in CPs will lead to new horizons in fabrication, characterization and applications. Evidently, CP based materials with high structural integrity and excellent multifunctional properties will make up the landscape of next-generation electronic devices.

Received 22 November 2017; accepted 3 January 2018; published online 30 January 2018 
1 Heeger AJ. Semiconducting and metallic polymers: the fourth generation of polymeric materials. J Phys Chem B, 2001, 105: 8475-8491

2 Kumar D, Sharma RC. Advances in conductive polymers. Eur Polymer J, 1998, 34: 1053-1060

3 Shirakawa H, Louis EJ, MacDiarmid AG, et al. Synthesis of electrically conducting organic polymers: halogen derivatives of polyacetylene, $(\mathrm{CH})_{x}$. J Chem Soc Chem Commun, 1977, 16: 578580

4 Chiang CK, Druy MA, Gau SC, et al. Synthesis of highly conducting films of derivatives of polyacetylene, $(\mathrm{CH})_{x}$. J Am Chem Soc, 1978, 100: 1013-1015

5 MacDiarmid AG. "Synthetic metals": a novel role for organic polymers (Nobel lecture). Angew Chem Int Ed, 2001, 40: 25812590

6 Ghosh S, Maiyalagan T, Basu RN. Nanostructured conducting polymers for energy applications: towards a sustainable platform. Nanoscale, 2016, 8: 6921-6947

7 Yin Z, Zheng Q. Controlled synthesis and energy applications of one-dimensional conducting polymer nanostructures: an overview. Adv Energy Mater, 2012, 2: 179-218

8 Pan L, Qiu H, Dou C, et al. Conducting polymer nanostructures: template synthesis and applications in energy storage. IJMS, 2010, 11: 2636-2657

9 Nguyen D, Yoon H. Recent advances in nanostructured conducting polymers: from synthesis to practical applications. Polymers, 2016, 8: 118

10 Inzelt G, Pineri M, Schultze JW, et al. Electron and proton conducting polymers: recent developments and prospects. Electrochim Acta, 2000, 45: 2403-2421

11 Mirabedini A, Foroughi J, Wallace GG. Developments in conducting polymer fibres: from established spinning methods toward advanced applications. RSC Adv, 2016, 6: 44687-44716

12 Kaur G, Adhikari R, Cass P, et al. Electrically conductive polymers and composites for biomedical applications. RSC Adv, 2015, 5: 37553-37567

13 Guimard NK, Gomez N, Schmidt CE. Conducting polymers in biomedical engineering. Prog Polymer Sci, 2007, 32: 876-921

14 Abdelhamid ME, O'Mullane AP, Snook GA. Storing energy in plastics: a review on conducting polymers \& their role in electrochemical energy storage. RSC Adv, 2015, 5: 11611-11626

15 Yang J, Liu Y, Liu S, et al. Conducting polymer composites: material synthesis and applications in electrochemical capacitive energy storage. Mater Chem Front, 2017, 1: 251-268

16 Baker CO, Huang X, Nelson W, et al. Polyaniline nanofibers: broadening applications for conducting polymers. Chem Soc Rev, 2017, 46: 1510-1525

17 Mastragostino M. Conducting polymers as electrode materials in supercapacitors. Solid State Ion, 2002, 148: 493-498

18 Snook GA, Kao P, Best AS. Conducting-polymer-based supercapacitor devices and electrodes. J Power Sources, 2011, 196: 1-12

19 Bryan AM, Santino LM, Lu Y, et al. Conducting polymers for pseudocapacitive energy storage. Chem Mater, 2016, 28: 59895998

20 Kim J, Lee J, You J, et al. Conductive polymers for next-generation energy storage systems: recent progress and new functions. Mater Horiz, 2016, 3: 517-535

21 Hagfeldt A, Boschloo G, Sun L, et al. Dye-sensitized solar cells. Chem Rev, 2010, 110: 6595-6663

22 Wang J, Wang J, Kong Z, et al. Conducting-polymer-based ma- terials for electrochemical energy conversion and storage. Adv Mater, 2017, 29: 1703044

23 Bai H, Shi G. Gas sensors based on conducting polymers. Sensors, 2007, 7: 267-307

24 Hatchett DW, Josowicz M. Composites of intrinsically conducting polymers as sensing nanomaterials. Chem Rev, 2008, 108: 746-769

25 Liu Z, Zhang L, Poyraz S, et al. Conducting polymer-metal nanocomposites synthesis and their sensory applications. Curr Org Chem, 2013, 17: 2256-2267

26 Zhang J, Liu X, Neri G, et al. Nanostructured materials for roomtemperature gas sensors. Adv Mater, 2016, 28: 795-831

27 Gerard M. Application of conducting polymers to biosensors. Biosens Bioelectron, 2002, 17: 345-359

28 Rajesh, Ahuja T, Kumar D. Recent progress in the development of nano-structured conducting polymers/nanocomposites for sensor applications. Sensors Actuators B-Chem, 2009, 136: 275286

29 Ates M. A review study of (bio)sensor systems based on conducting polymers. Mater Sci Eng-C, 2013, 33: 1853-1859

30 Han J, Wang M, Hu Y, et al. Conducting polymer-noble metal nanoparticle hybrids: Synthesis mechanism application. Prog Polymer Sci, 2017, 70: 52-91

31 Lu X, Zhang W, Wang C, et al. One-dimensional conducting polymer nanocomposites: Synthesis, properties and applications. Prog Polymer Sci, 2011, 36: 671-712

32 Zhan C, Yu G, Lu Y, et al. Conductive polymer nanocomposites: a critical review of modern advanced devices. J Mater Chem C, 2017, 5: 1569-1585

33 Tran HD, Li D, Kaner RB. One-dimensional conducting polymer nanostructures: bulk synthesis and applications. Adv Mater, 2009, 21: $1487-1499$

34 Zhao X, Zhan X. Electron transporting semiconducting polymers in organic electronics. Chem Soc Rev, 2011, 40: 3728-3743

35 Wang $\mathrm{Y}$, Jing $\mathrm{X}$. Intrinsically conducting polymers for electromagnetic interference shielding. Polym Adv Technol, 2005, 16: 344-351

36 Deshpande PP, Jadhav NG, Gelling VJ, et al. Conducting polymers for corrosion protection: a review. J Coat Technol Res, 2014, 11: 473-494

37 Muhammad Ekramul Mahmud HN, Huq AKO, Yahya R. The removal of heavy metal ions from wastewater/aqueous solution using polypyrrole-based adsorbents: a review. RSC Adv, 2016, 6: 14778-14791

38 Shahadat M, Khan MZ, Rupani PF, et al. A critical review on the prospect of polyaniline-grafted biodegradable nanocomposite. Adv Colloid Interface Sci, 2017, 249: 2-16

39 Long YZ, Li MM, Gu C, et al. Recent advances in synthesis, physical properties and applications of conducting polymer nanotubes and nanofibers. Prog Polymer Sci, 2011, 36: 1415-1442

40 Jackowska K, Bieguński AT, Tagowska M. Hard template synthesis of conducting polymers: a route to achieve nanostructures. J Solid State Electrochem, 2008, 12: 437-443

41 Fu GD, Zhao JP, Sun YM, et al. Conductive hollow nanospheres of polyaniline via surface-initiated atom transfer radical polymerization of 4-vinylaniline and oxidative graft copolymerization of aniline. Macromolecules, 2007, 40: 2271-2275

42 Martin CR, Van Dyke LS, Cai Z, et al. Template synthesis of organic microtubules. J Am Chem Soc, 1990, 112: 8976-8977

43 Luo SC, Yu H, Wan ACA, et al. A general synthesis for PEDOT- 
coated nonconductive materials and PEDOT hollow particles by aqueous chemical polymerization. Small, 2008, 4: 2051-2058

44 Zhang Z, Sui J, Zhang L, et al. Synthesis of polyaniline with a hollow, octahedral morphology by using a cuprous oxide template. Adv Mater, 2005, 17: 2854-2857

45 Martin CR. Nanomaterials: a membrane-based synthetic approach. Science, 1994, 266: 1961-1966

46 Cai Z, Martin CR. Electronically conductive polymer fibers with mesoscopic diameters show enhanced electronic conductivities. J Am Chem Soc, 1989, 111: 4138-4139

47 Martin CR. Template synthesis of electronically conductive polymer nanostructures. Acc Chem Res, 1995, 28: 61-68

48 Granström M, Inganäs O. Electrically conductive polymer fibres with mesoscopic diameters: 1 . Studies of structure and electrical properties. Polymer, 1995, 36: 2867-2872

49 Cui S, Zheng Y, Liang J, et al. Conducting polymer PPy nanowirebased triboelectric nanogenerator and its application for selfpowered electrochemical cathodic protection. Chem Sci, 2016, 7: 6477-6483

50 Cho SI, Lee SB. Fast electrochemistry of conductive polymer nanotubes: synthesis, mechanism, and application. Acc Chem Res, 2008, 41: 699-707

51 Duvail JL, Rétho P, Fernandez V, et al. Effects of the confined synthesis on conjugated polymer transport properties. J Phys Chem B, 2004, 108: 18552-18556

52 Zhang X, Zhang J, Liu Z, et al. Inorganic/organic mesostructure directed synthesis of wire/ribbon-like polypyrrole nanostructures. Chem Commun, 2004, 16: 1852-1853

53 Zhang X, Zhang J, Song W, et al. Controllable synthesis of conducting polypyrrole nanostructures. J Phys Chem B, 2006, 110: $1158-1165$

54 Jang J, Li XL, Oh JH. Facile fabrication of polymer and carbon nanocapsules using polypyrrole core/shell nanomaterials. Chem Commun, 2004, 7: 794-795

55 Jang J, Yoon H. Facile fabrication of polypyrrole nanotubes using reverse microemulsion polymerization. Chem Commun, 2003, 6: $720-721$

56 Yoon H, Chang M, Jang J. Formation of 1D poly(3,4-ethylenedioxythiophene) nanomaterials in reverse microemulsions and their application to chemical sensors. Adv Funct Mater, 2007, 17: 431-436

57 Jang J, Chang M, Yoon H. Chemical sensors based on highly conductive poly(3,4-ethylenedioxythiophene) nanorods. Adv Mater, 2005, 17: 1616-1620

58 Mao H, Liu X, Chao D, et al. Preparation of unique PEDOT nanorods with a couple of cuspate tips by reverse interfacial polymerization and their electrocatalytic application to detect nitrite. J Mater Chem, 2010, 20: 10277-10284

59 Zhang X, Lee JS, Lee GS, et al. Chemical synthesis of PEDOT nanotubes. Macromolecules, 2006, 39: 470-472

60 Liu Z, Zhang X, Poyraz S, et al. Oxidative template for conducting polymer nanoclips. J Am Chem Soc, 2010, 132: 13158-13159

$61 \mathrm{Li} \mathrm{G}, \mathrm{Li}$ Y, Li Y, et al. Polyaniline nanorings and flat hollow capsules synthesized by in situ sacrificial oxidative templates. Macromolecules, 2011, 44: 9319-9323

62 Tran HD, D'Arcy JM, Wang Y, et al. The oxidation of aniline to produce "polyaniline": a process yielding many different nanoscale structures. J Mater Chem, 2011, 21: 3534-3550

63 Huang J, Kaner RB. A general chemical route to polyaniline nanofibers. J Am Chem Soc, 2004, 126: 851-855
64 Zhang X, Chan-Yu-King R, Jose A, et al. Nanofibers of polyaniline synthesized by interfacial polymerization. Synth Met, 2004, 145: 23-29

65 Zhang X, Kolla H, Wang X, et al. Fibrillar growth in polyaniline. Adv Funct Mater, 2006, 16: 1145-1152

66 Su K, Nuraje N, Zhang L, et al. Fast conductance switching in single-crystal organic nanoneedles prepared from an interfacial polymerization-crystallization of 3,4-ethylenedioxythiophene. Adv Mater, 2007, 19: 669-672

67 Nuraje N, Su K, Yang NL, et al. Liquid/liquid interfacial polymerization to grow single crystalline nanoneedles of various conducting polymers. ACS Nano, 2008, 2: 502-506

68 Zhang X, Goux WJ, Manohar SK. Synthesis of polyaniline nanofibers by "nanofiber seeding". J Am Chem Soc, 2004, 126: 4502-4503

69 Zhang X, Manohar SK. Bulk synthesis of polypyrrole nanofibers by a seeding approach. J Am Chem Soc, 2004, 126: 12714-12715

70 Zhang X, MacDiarmid AG, Manohar SK. Chemical synthesis of PEDOT nanofibers. Chem Commun, 2005, 12: 5328-5330

71 Zhang X, Manohar SK. Narrow pore-diameter polypyrrole nanotubes. J Am Chem Soc, 2005, 127: 14156-14157

72 Liu Z, Liu Y, Poyraz S, et al. Green-nano approach to nanostructured polypyrrole. Chem Commun, 2011, 47: 4421-4423

73 Mijangos C, Hernández R, Martín J. A review on the progress of polymer nanostructures with modulated morphologies and properties, using nanoporous AAO templates. Prog Polymer Sci, 2016, 54-55: 148-182

74 Sapountzi E, Braiek M, Chateaux JF, Jaffrezic-Renault N, Lagarde F. Recent Advances in Electrospun Nanofiber Interfaces for Biosensing Devices. Sensors, 2017, 17: 1887

75 Amariei N, Manea LR, Bertea AP, et al. Electrospinning polyaniline for sensors. IOP Conf Ser-Mater Sci Eng, 2017, 209: 012091

76 Abd Razak SI, Wahab IF, Fadil F, et al. A review of electrospun conductive polyaniline based nanofiber composites and blends: processing features, applications, and future directions. Adv Mater Sci Eng, 2015, 2015: 1-19

77 Zhang Y, Kim JJ, Chen D, et al. Electrospun polyaniline fibers as highly sensitive room temperature chemiresistive sensors for ammonia and nitrogen dioxide gases. Adv Funct Mater, 2014, 24: 4005-4014

78 Pinto NJ, Johnson Jr. AT, MacDiarmid AG, et al. Electrospun polyaniline/polyethylene oxide nanofiber field-effect transistor. Appl Phys Lett, 2003, 83: 4244-4246

79 Cárdenas JR, França MGO, Vasconcelos EA, et al. Growth of submicron fibres of pure polyaniline using the electrospinning technique. J Phys D-Appl Phys, 2007, 40: 1068-1071

80 MacDiarmid AG, Jones Jr. WE, Norris ID, et al. Electrostaticallygenerated nanofibers of electronic polymers. Synth Met, 2001, 119: $27-30$

81 Kang TS, Lee SW, Joo J, et al. Electrically conducting polypyrrole fibers spun by electrospinning. Synth Met, 2005, 153: 61-64

82 Tian T, Deng J, Xie Z, et al. Polypyrrole hollow fiber for solid phase extraction. Analyst, 2012, 137: 1846-1852

$83 \mathrm{Wu}$, Cho W, Martin DC, et al. Highly aligned poly(3,4-ethylene dioxythiophene) (PEDOT) nano- and microscale fibers and tubes. Polymer, 2013, 54: 702-708

84 Pillalamarri SK, Blum FD, Tokuhiro AT, et al. Radiolytic synthesis of polyaniline nanofibers: a new templateless pathway. Chem Mater, 2005, 17: 227-229 
85 Karim MR, Lee CJ, Lee MS. Synthesis of conducting polypyrrole by radiolysis polymerization method. Polym Adv Technol, 2007, 18: 916-920

86 Lattach Y, Deniset-Besseau A, Guigner JM, et al. Radiation chemistry as an alternative way for the synthesis of PEDOT conducting polymers under "soft" conditions. Radiat Phys Chem, 2013, 82: 44-53

87 Lattach Y, Coletta C, Ghosh S, et al. Radiation-induced synthesis of nanostructured conjugated polymers in aqueous solution: fundamental effect of oxidizing species. ChemPhysChem, 2014, 15: 208-218

$88 \mathrm{Yu} \mathrm{X,} \mathrm{Li} \mathrm{Y,} \mathrm{Kalantar-zadeh} \mathrm{K.} \mathrm{Synthesis} \mathrm{and} \mathrm{electrochemical}$ properties of template-based polyaniline nanowires and templatefree nanofibril arrays: Two potential nanostructures for gas sensors. Sensors Actuators B-Chem, 2009, 136: 1-7

89 Nam DH, Kim MJ, Lim SJ, et al. Single-step synthesis of polypyrrole nanowires by cathodic electropolymerization. J Mater Chem A, 2013, 1: 8061-8068

90 Thapa PS, Yu DJ, Wicksted JP, et al. Directional growth of polypyrrole and polythiophene wires. Appl Phys Lett, 2009, 94: 033104

91 Qin D, Xia Y, Whitesides GM. Soft lithography for micro- and nanoscale patterning. Nat Protoc, 2010, 5: 491-502

92 Nie Z, Kumacheva E. Patterning surfaces with functional polymers. Nat Mater, 2008, 7: 277-290

93 Geissler M, Xia Y. Patterning: principles and some new developments. Adv Mater, 2004, 16: 1249-1269

94 Acikgoz C, Hempenius MA, Huskens J, et al. Polymers in conventional and alternative lithography for the fabrication of nanostructures. Eur Polymer J, 2011, 47: 2033-2052

95 Zhang F, Nyberg T, Inganäs O. Conducting polymer nanowires and nanodots made with soft lithography. Nano Lett, 2002, 2: 1373-1377

$96 \mathrm{Hu} \mathrm{Z}$, Muls B, Gence L, et al. High-throughput fabrication of organic nanowire devices with preferential internal alignment and improved performance. Nano Lett, 2007, 7: 3639-3644

97 Behl M, Seekamp J, Zankovych S, et al. Towards plastic electronics: patterning semiconducting polymers by nanoimprint lithography. Adv Mater, 2002, 14: 588-591

98 Huang C, Dong B, Lu N, et al. A strategy for patterning conducting polymers using nanoimprint lithography and isotropic plasma etching. Small, 2009, 5: 583-586

99 Feng X, Yang G, Xu Q, et al. Self-assembly of polyaniline/au composites: from nanotubes to nanofibers. Macromol Rapid Commun, 2006, 27: 31-36

100 Wang L, Liu N, Ma Z. Novel gold-decorated polyaniline derivatives as redox-active species for simultaneous detection of three biomarkers of lung cancer. J Mater Chem B, 2015, 3: 2867-2872

101 Williams PE, Jones ST, Walsh Z, et al. Synthesis of conducting polymer-metal nanoparticle hybrids exploiting RAFT polymerization. ACS Macro Lett, 2015, 4: 255-259

102 Hnida KE, Socha RP, Sulka GD. Polypyrrole-silver composite nanowire arrays by cathodic co-deposition and their electrochemical properties. J Phys Chem C, 2013, 117: 130916100825004

103 Hasan M, Ansari MO, Cho MH, et al. Electrical conductivity, optical property and ammonia sensing studies on $\mathrm{HCl}$ Doped Au@polyaniline nanocomposites. Electron Mater Lett, 2015, 11: $1-6$

104 Bogdanović U, Pašti I, Ćirić-Marjanović G, et al. Interfacial synthesis of gold-polyaniline nanocomposite and its electro- catalytic application. ACS Appl Mater Interfaces, 2015, 7: 2839328403

105 Dutt S, Siril PF, Sharma V, et al. Gold core $_{-}$polyaniline $_{\text {shell }}$ composite nanowires as a substrate for surface enhanced Raman scattering and catalyst for dye reduction. New J Chem, 2015, 39: 902908

106 Rong Q, Han H, Feng F, et al. Network nanostructured polypyrrole hydrogel/Au composites as enhanced electrochemical biosensing platform. Sci Rep, 2015, 5: 11440

107 Liu Y, Liu Z, Lu N, et al. Facile synthesis of polypyrrole coated copper nanowires: a new concept to engineered core-shell structures. Chem Commun, 2012, 48: 2621-2623

108 Liu Z, Poyraz S, Liu Y, et al. Seeding approach to noble metal decorated conducting polymer nanofiber network. Nanoscale, 2012, 4: 106-109

109 Poyraz S, Liu Z, Liu Y, et al. One-step synthesis and characterization of poly(o-toluidine) nanofiber/metal nanoparticle composite networks as non-enzymatic glucose sensors. Sensors Actuators B-Chem, 2014, 201: 65-74

110 Poyraz S, Cerkez I, Huang TS, et al. One-step synthesis and characterization of polyaniline nanofiber/silver nanoparticle composite networks as antibacterial agents. ACS Appl Mater Interfaces, 2014, 6: 20025-20034

111 Liu Y, Lu N, Poyraz S, et al. One-pot formation of multifunctional Pt-conducting polymer intercalated nanostructures. Nanoscale, 2013, 5: 3872-3879

112 Liu Z, Liu Y, Zhang L, et al. Controlled synthesis of transition metal/conducting polymer nanocomposites. Nanotechnology, 2012, 23: 335603

$113 \mathrm{Xu} \mathrm{J}$, Li X, Liu J, et al. Solution route to inorganic nanobeltconducting organic polymer core-shell nanocomposites. J Polym Sci A Polym Chem, 2005, 43: 2892-2900

114 Cai G, Tu J, Zhou D, et al. Multicolor electrochromic film based on $\mathrm{TiO}_{2} @$ polyaniline core/shell nanorod array. J Phys Chem C, 2013, 117: 15967-15975

115 Pan J, Li P, Cai L, et al. All-solution processed double-decked PEDOT:PSS $/ \mathrm{V}_{2} \mathrm{O}_{5}$ nanowires as buffer layer of high performance polymer photovoltaic cells. Sol Energ Mater Sol Cells, 2016, 144: 616-622

116 Zhang J, Han J, Wang $\mathrm{M}$, et al. $\mathrm{Fe}_{3} \mathrm{O}_{4} / \mathrm{PANI} / \mathrm{MnO}_{2}$ core-shell hybrids as advanced adsorbents for heavy metal ions. J Mater Chem A, 2017, 5: 4058-4066

117 Gülce H, Eskizeybek V, Haspulat B, et al. Preparation of a new polyaniline/CdO nanocomposite and investigation of its photocatalytic activity: comparative study under uv light and natural sunlight irradiation. Ind Eng Chem Res, 2013, 52: 10924-10934

118 Wen T, Fan Q, Tan X, et al. A core-shell structure of polyaniline coated protonic titanate nanobelt composites for both $\mathrm{Cr}(\mathrm{vi})$ and humic acid removal. Polym Chem, 2016, 7: 785-794

119 Yin Z, Fan W, Ding Y, et al. Shell structure control of PPymodified $\mathrm{CuO}$ composite nanoleaves for lithium batteries with improved cyclic performance. ACS Sustain Chem Eng, 2015, 3: 507-517

120 Ngaboyamahina E, Debiemme-Chouvy C, Pailleret A, et al. Electrodeposition of polypyrrole in $\mathrm{TiO}_{2}$ nanotube arrays by pulsed-light and pulsed-potential methods. J Phys Chem C, 2014, 118: 26341-26350

121 Su PG, Peng YT. Fabrication of a room-temperature $\mathrm{H}_{2} \mathrm{~S}$ gas sensor based on $\mathrm{PPy} / \mathrm{WO}_{3}$ nanocomposite films by in-situ photopolymerization. Sensors Actuators B-Chem, 2014, 193: 637-643 
122 Xia C, Chen W, Wang X, et al. Highly stable supercapacitors with conducting polymer core-shell electrodes for energy storage applications. Adv Energy Mater, 2015, 5: 1401805

123 Tang PY, Han LJ, Genç A, et al. Synergistic effects in 3D honeycomb-like hematite nanoflakes/branched polypyrrole nanoleaves heterostructures as high-performance negative electrodes for asymmetric supercapacitors. Nano Energy, 2016, 22: 189-201

124 Gao MR, Xu YF, Jiang J, et al. Nanostructured metal chalcogenides: synthesis, modification, and applications in energy conversion and storage devices. Chem Soc Rev, 2013, 42: 29863017

125 Sajedi-Moghaddam A, Saievar-Iranizad E, Pumera M. Two-dimensional transition metal dichalcogenide/conducting polymer composites: synthesis and applications. Nanoscale, 2017, 9: 80528065

126 Wang X, Xing W, Feng X, et al. $\mathrm{MoS}_{2} /$ polymer nanocomposites: preparation, properties, and applications. Polymer Rev, 2017, 57: 440-466

127 Zhu J, Sun W, Yang D, et al. Multifunctional architectures constructing of PANI nanoneedle arrays on $\mathrm{MoS}_{2}$ thin nanosheets for high-energy supercapacitors. Small, 2015, 11: 4123-4129

128 Wang G, Peng J, Zhang L, et al. Two-dimensional SnS $@$ @PANI nanoplates with high capacity and excellent stability for lithiumion batteries. J Mater Chem A, 2015, 3: 3659-3666

129 Sha C, Lu B, Mao H, et al. 3D ternary nanocomposites of molybdenum disulfide/polyaniline/reduced graphene oxide aerogel for high performance supercapacitors. Carbon, 2016, 99: 26-34

130 Gopalakrishnan K, Sultan S, Govindaraj A, et al. Supercapacitors based on composites of PANI with nanosheets of nitrogen-doped RGO, $\mathrm{BC}_{1.5} \mathrm{~N}, \mathrm{MoS}_{2}$ and $\mathrm{WS}_{2}$. Nano Energ, 2015, 12: 52-58

131 Zhang X, Lai Z, Tan C, et al. Solution-processed two-dimensional $\mathrm{MoS}_{2}$ nanosheets: preparation, hybridization, and applications. Angew Chem Int Ed, 2016, 55: 8816-8838

132 Huang YJ, Fan MS, Li CT, et al. $\mathrm{MoSe}_{2}$ nanosheet/poly(3,4ethylenedioxythiophene): poly(styrenesulfonate) composite film as a Pt-free counter electrode for dye-sensitized solar cells. Electrochim Acta, 2016, 211: 794-803

$133 \mathrm{Ju} \mathrm{H}$, Kim J. Chemically exfoliated SnSe nanosheets and their SnSe/Poly(3,4-ethylenedioxythiophene): poly(styrenesulfonate) composite films for polymer based thermoelectric applications. ACS Nano, 2016, 10: 5730-5739

134 Zhao X, Mai Y, Luo H, et al. Nano-MoS $/$ poly(3,4-ethylenedioxythiophene): poly(styrenesulfonate) composite prepared by a facial dip-coating process for Li-ion battery anode. Appl Surf Sci, 2014, 288: 736-741

135 Jiang F, Xiong J, Zhou W, et al. Use of organic solvent-assisted exfoliated $\mathrm{MoS}_{2}$ for optimizing the thermoelectric performance of flexible PEDOT:PSS thin films. J Mater Chem A, 2016, 4: 52655273

136 Bahuguna A, Kumar S, Sharma V, et al. Nanocomposite of $\mathrm{MoS}_{2}-$ RGO as facile, heterogeneous, recyclable, and highly efficient green catalyst for one-pot synthesis of indole alkaloids. ACS Sustain Chem Eng, 2017, 5: 8551-8567

137 Zhang Y, He T, Liu G, et al. One-pot mass preparation of $\mathrm{MoS}_{2}$ /C aerogels for high-performance supercapacitors and lithiumion batteries. Nanoscale, 2017, 9: 10059-10066

138 Lei J, Lu X, Nie G, et al. One-pot synthesis of algae-like $\mathrm{MoS}_{2} / \mathrm{PPy}$ nanocomposite: a synergistic catalyst with superior peroxidaselike catalytic activity for $\mathrm{H}_{2} \mathrm{O}_{2}$ Detection. Part Part Syst Charact, 2015, 32: 886-892
139 Liu Z, Zhang L, Wang R, et al. Ultrafast microwave nano-manufacturing of fullerene-like metal chalcogenides. Sci Rep, 2016, 6: 22503

140 Poyraz S, Zhang L, Schroder A, et al. Ultrafast microwave welding/reinforcing approach at the interface of thermoplastic materials. ACS Appl Mater Interfaces, 2015, 7: 22469-22477

141 Zhou H, Han G, Chang Y, et al. Highly stable multi-wall carbon nanotubes@poly(3,4-ethylenedioxythiophene)/poly(styrene sulfonate) core-shell composites with three-dimensional porous nano-network for electrochemical capacitors. J Power Sources, 2015, 274: 229-236

142 Wang J, Dai J, Yarlagadda T. Carbon nanotube-conductingpolymer composite nanowires. Langmuir, 2005, 21: 9-12

143 Bavio MA, Acosta GG, Kessler T, et al. Flexible symmetric and asymmetric supercapacitors based in nanocomposites of carbon cloth/polyaniline-carbon nanotubes. Energy, 2017, 130: 22-28

144 He X, Liu G, Yan B, et al. Significant enhancement of electrochemical behaviour by incorporation of carboxyl group functionalized carbon nanotubes into polyaniline based supercapacitor. Eur Polymer J, 2016, 83: 53-59

145 Qu G, Cheng J, Li X, et al. A fiber supercapacitor with high energy density based on hollow graphene/conducting polymer fiber electrode. Adv Mater, 2016, 28: 3646-3652

146 Cong HP, Ren XC, Wang P, et al. Flexible graphene-polyaniline composite paper for high-performance supercapacitor. Energ Environ Sci, 2013, 6: 1185

147 Choi H, Ahn KJ, Lee Y, et al. Free-standing, multilayered graphene/polyaniline-glue/graphene nanostructures for flexible, solid-state electrochemical capacitor application. Adv Mater Interfaces, 2015, 2: 1500117

148 Wang L, Wu T, Du S, et al. High performance supercapacitors based on ternary graphene/Au/polyaniline (PANI) hierarchical nanocomposites. RSC Adv, 2016, 6: 1004-1011

149 Moyseowicz A, Śliwak A, Miniach E, et al. Polypyrrole/iron oxide/reduced graphene oxide ternary composite as a binderless electrode material with high cyclic stability for supercapacitors. Composites Part B-Eng, 2017, 109: 23-29

150 Lee HU, Yin JL, Park SW, et al. Preparation and characterization of PEDOT:PSS wrapped carbon nanotubes $/ \mathrm{MnO}_{2}$ composite electrodes for flexible supercapacitors. Synth Met, 2017, 228: 8490

151 Zhao J, Yue P, Tricard S, et al. Prussian blue (PB)/carbon nanopolyhedra/polypyrrole composite as electrode: a high performance sensor to detect hydrazine with long linear range. Sensors Actuators B-Chem, 2017, 251: 706-712

152 Salam MA, Obaid AY, El-Shishtawy RM, et al. Synthesis of nanocomposites of polypyrrole/carbon nanotubes/silver nano particles and their application in water disinfection. RSC Adv, 2017, 7: 16878-16884

153 Tan Y, Zhang Y, Kong L, et al. Nano-Au@PANI core-shell nanoparticles via in-situ polymerization as electrode for supercapacitor. J Alloys Compd, 2017, 722: 1-7

154 Bhaumik M, Noubactep C, Gupta VK, et al. Polyaniline/ $\mathrm{Fe}^{0}$ composite nanofibers: an excellent adsorbent for the removal of arsenic from aqueous solutions. Chem Eng J, 2015, 271: 135-146

155 Chen T, Liu B. Enhanced dielectric properties of poly(vinylidene fluoride) composite filled with polyaniline-iron core-shell nanocomposites. Mater Lett, 2018, 210: 165-168

156 Bogdanović U, Vodnik V, Mitrić M, et al. Nanomaterial with high antimicrobial efficacy-copper/polyaniline nanocomposite. ACS 
Appl Mater Interfaces, 2015, 7: 1955-1966

157 Wang AL, Xu H, Feng JX, et al. Design of Pd/PANI/Pd sandwichstructured nanotube array catalysts with special shape effects and synergistic effects for ethanol electrooxidation. J Am Chem Soc, 2013, 135: 10703-10709

158 Xia Y, Liu N, Sun L, et al. Networked Pd(core)@polyaniline(shell) composite: highly electro-catalytic ability and unique selectivity. Appl Surf Sci, 2018, 428: 809-814

159 Wang K, Stenner C, Weissmüller J. A nanoporous gold-polypyrrole hybrid nanomaterial for actuation. Sensors Actuators BChem, 2017, 248: 622-629

$160 \mathrm{He} \mathrm{W}, \mathrm{Li}$ G, Zhang S, et al. Polypyrrole/silver coaxial nanowire aero-sponges for temperature-independent stress sensing and stress-triggered joule heating. ACS Nano, 2015, 9: 4244-4251

161 Singh A, Salmi Z, Jha P, et al. One step synthesis of highly ordered free standing flexible polypyrrole-silver nanocomposite films at air-water interface by photopolymerization. RSC Adv, 2013, 3: 13329-13336

162 Zhang RC, Sun D, Zhang R, et al. Gold nanoparticle-polymer nanocomposites synthesized by room temperature atmospheric pressure plasma and their potential for fuel cell electrocatalytic application. Sci Rep, 2017, 7: 46682

163 Cheng T, Zhang YZ, Yi JP, et al. Inkjet-printed flexible, transparent and aesthetic energy storage devices based on PEDOT: PSS/Ag grid electrodes. J Mater Chem A, 2016, 4: 13754-13763

164 Saravanan R, Sacari E, Gracia F, et al. Conducting PANI stimulated $\mathrm{ZnO}$ system for visible light photocatalytic degradation of coloured dyes. J Mol Liquids, 2016, 221: 1029-1033

165 Ghanbari K, Babaei Z. Fabrication and characterization of nonenzymatic glucose sensor based on ternary $\mathrm{NiO} / \mathrm{CuO} /$ polyaniline nanocomposite. Anal Biochem, 2016, 498: 37-46

$166 \mathrm{Yu} \mathrm{Z}$, Li H, Zhang X, et al. Facile synthesis of $\mathrm{NiCo}_{2} \mathrm{O}_{4} @$ polyaniline core-shell nanocomposite for sensitive determination of glucose. Biosens Bioelectron, 2016, 75: 161-165

167 Khilari S, Pandit S, Varanasi JL, et al. Bifunctional manganese ferrite/polyaniline hybrid as electrode material for enhanced energy recovery in microbial fuel cell. ACS Appl Mater Interfaces, 2015, 7: 20657-20666

168 Ullah H, Tahir AA, Mallick TK. Polypyrrole/ $\mathrm{TiO}_{2}$ composites for the application of photocatalysis. Sensors Actuators B-Chem, 2017, 241: 1161-1169

169 Li Y, Ban H, Yang M. Highly sensitive $\mathrm{NH}_{3}$ gas sensors based on novel polypyrrole-coated $\mathrm{SnO}_{2}$ nanosheet nanocomposites. Sensors Actuators B-Chem, 2016, 224: 449-457

170 Marimuthu T, Mohamad S, Alias Y. Needle-like polypyrrole-NiO composite for non-enzymatic detection of glucose. Synth Met, 2015, 207: 35-41

171 Zhou C, Zhang Y, Li Y, et al. Construction of high-capacitance 3D CoO@polypyrrole nanowire array electrode for aqueous asymmetric supercapacitor. Nano Lett, 2013, 13: 2078-2085

172 Zhong XB, Wang HY, Yang ZZ, et al. Facile synthesis of mesoporous $\mathrm{ZnCo}_{2} \mathrm{O}_{4}$ coated with polypyrrole as an anode material for lithium-ion batteries. J Power Sources, 2015, 296: 298-304

173 Liu LL, Wang XJ, Zhu YS, et al. Polypyrrole-coated $\mathrm{LiV}_{3} \mathrm{O}_{8}$-nanocomposites with good electrochemical performance as anode material for aqueous rechargeable lithium batteries. J Power Sources, 2013, 224: 290-294

174 Guo CX, Sun K, Ouyang J, et al. Layered $\mathrm{V}_{2} \mathrm{O}_{5} /$ PEDOT nanowires and ultrathin nanobelts fabricated with a silk reelinglike process. Chem Mater, 2015, 27: 5813-5819
175 Zheng M, Huo J, Tu Y, et al. An in situ polymerized PEDOT/ $\mathrm{Fe}_{3} \mathrm{O}_{4}$ composite as a Pt-free counter electrode for highly efficient dye sensitized solar cells. RSC Adv, 2016, 6: 1637-1643

176 Ko IH, Kim SJ, Lim J, et al. Effect of PEDOT:PSS coating on manganese oxide nanowires for lithium ion battery anodes. Electrochim Acta, 2016, 187: 340-347

177 Yang $\mathrm{H}, \mathrm{Xu} \mathrm{H}$, Li M, et al. Assembly of $\mathrm{NiO} / \mathrm{Ni}(\mathrm{OH})_{2} / \mathrm{PEDOT}$ nanocomposites on contra wires for fiber-shaped flexible asymmetric supercapacitors. ACS Appl Mater Interfaces, 2016, 8: 1774-1779

178 Simotwo SK, DelRe C, Kalra V. Supercapacitor electrodes based on high-purity electrospun polyaniline and polyaniline-carbon nanotube nanofibers. ACS Appl Mater Interfaces, 2016, 8: 2126121269

179 Wang H, Yi S, Pu X, et al. Simultaneously improving electrical conductivity and thermopower of polyaniline composites by utilizing carbon nanotubes as high mobility conduits. ACS Appl Mater Interfaces, 2015, 7: 9589-9597

180 Wen L, Li K, Liu J, et al. Graphene/polyaniline@carbon cloth composite as a high-performance flexible supercapacitor electrode prepared by a one-step electrochemical co-deposition method. RSC Adv, 2017, 7: 7688-7693

181 Parveen N, Mahato N, Ansari MO, et al. Enhanced electrochemical behavior and hydrophobicity of crystalline polyaniline@graphene nanocomposite synthesized at elevated temperature. Composites Part B-Eng, 2016, 87: 281-290

182 Tang W, Peng L, Yuan C, et al. Facile synthesis of 3D reduced graphene oxide and its polyaniline composite for super capacitor application. Synth Met, 2015, 202: 140-146

183 Liang L, Chen G, Guo CY. Enhanced thermoelectric performance by self-assembled layered morphology of polypyrrole nanowire/ single-walled carbon nanotube composites. Composites Sci Tech, 2016, 129: 130-136

184 Cai Z, Xiong H, Zhu Z, et al. Electrochemical synthesis of graphene/polypyrrole nanotube composites for multifunctional applications. Synth Met, 2017, 227: 100-105

185 Lee Y, Choi H, Kim MS, et al. Nanoparticle-mediated physical exfoliation of aqueous-phase graphene for fabrication of threedimensionally structured hybrid electrodes. Sci Rep, 2016, 6: 19761

186 Biswas S, Drzal LT. Multilayered nanoarchitecture of graphene nanosheets and polypyrrole nanowires for high performance supercapacitor electrodes. Chem Mater, 2010, 22: 5667-5671

187 Yang C, Zhang L, Hu N, et al. Reduced graphene oxide/polypyrrole nanotube papers for flexible all-solid-state supercapacitors with excellent rate capability and high energy density. J Power Sources, 2016, 302: 39-45

188 Benchirouf A, Palaniyappan S, Ramalingame R, et al. Electrical properties of multi-walled carbon nanotubes/PEDOT:PSS nanocomposites thin films under temperature and humidity effects. Sensors Actuators B-Chem, 2016, 224: 344-350

189 Ji T, Tan L, Bai J, et al. Synergistic dispersible graphene: sulfonated carbon nanotubes integrated with PEDOT for large-scale transparent conductive electrodes. Carbon, 2016, 98: 15-23

190 Sidhu NK, Rastogi AC. Bifacial carbon nanofoam-fibrous PEDOT composite supercapacitor in the 3-electrode configuration for electrical energy storage. Synth Met, 2016, 219: 1-10

191 Taylor IM, Robbins EM, Catt KA, et al. Enhanced dopamine detection sensitivity by PEDOT/graphene oxide coating on in vivo carbon fiber electrodes. Biosens Bioelectron, 2017, 89: 400- 
410

192 Xu J, Ding J, Zhou X, et al. Enhanced rate performance of flexible and stretchable linear supercapacitors based on polyaniline@Au@carbon nanotube with ultrafast axial electron transport. J Power Sources, 2017, 340: 302-308

$193 \mathrm{Hu}$ TH, Yin ZS, Guo JW, et al. Synthesis of Fe nanoparticles on polyaniline covered carbon nanotubes for oxygen reduction reaction. J Power Sources, 2014, 272: 661-671

194 Yang L, Tang Y, Yan D, et al. Polyaniline-reduced graphene oxide hybrid nanosheets with nearly vertical orientation anchoring palladium nanoparticles for highly active and stable electrocatalysis. ACS Appl Mater Interfaces, 2016, 8: 169-176

195 Dhibar S, Das CK. Silver nanoparticles decorated polyaniline/ multiwalled carbon nanotubes nanocomposite for high-performance supercapacitor electrode. Ind Eng Chem Res, 2014, 53: 3495-3508

196 Liu C, Xu Y, Wu L, et al. Fabrication of core-multishell $\mathrm{MWCNT} / \mathrm{Fe}_{3} \mathrm{O}_{4} / \mathrm{PANI} / \mathrm{Au}$ hybrid nanotubes with high-performance electromagnetic absorption. J Mater Chem A, 2015, 3: 10566-10572

197 Nguyen VH, Shim JJ. Ultrasmall $\mathrm{SnO}_{2}$ nanoparticle-intercalated graphene@polyaniline composites as an active electrode material for supercapacitors in different electrolytes. Synth Met, 2015, 207 : $110-115$

198 Luo J, Xu Y, Yao W, et al. Synthesis and microwave absorption properties of reduced graphene oxide-magnetic porous nanospheres-polyaniline composites. Composites Sci Tech, 2015, 117: 315-321

$199 \mathrm{Mu} \mathrm{B}$, Wang A. One-pot fabrication of multifunctional superparamagnetic attapulgite $/ \mathrm{Fe}_{3} \mathrm{O}_{4} /$ polyaniline nanocomposites served as an adsorbent and catalyst support. J Mater Chem A, 2015, 3: 281-289

200 Mini V, Archana K, Raghu S, et al. Nanostructured multifunctional core/shell ternary composite of polyaniline-chitosancobalt oxide: Preparation, electrical and optical properties. Mater Chem Phys, 2016, 170: 90-98

201 Wang W, Hao Q, Lei W, et al. Ternary nitrogen-doped graphene/ nickel ferrite/polyaniline nanocomposites for high-performance supercapacitors. J Power Sources, 2014, 269: 250-259

202 Moon S, Jung YH, Kim DK. Enhanced electrochemical performance of a crosslinked polyaniline-coated graphene oxide-sulfur composite for rechargeable lithium-sulfur batteries. J Power Sources, 2015, 294: 386-392

203 Xie Y, Xia C, Du H, et al. Enhanced electrochemical performance of polyaniline/carbon/titanium nitride nanowire array for flexible supercapacitor. J Power Sources, 2015, 286: 561-570

204 Jiang L, Lu X, Xie C, et al. Flexible, free-standing $\mathrm{TiO}_{2}$-graphenepolypyrrole composite films as electrodes for supercapacitors. J Phys Chem C, 2015, 119: 3903-3910

205 de Oliveira AHP, de Oliveira HP. Carbon nanotube/polypyrrole nanofibers core-shell composites decorated with titanium dioxide nanoparticles for supercapacitor electrodes. J Power Sources, 2014, 268: 45-49

206 Huang J, Yang Z, Feng Z, et al. A novel ZnO@Ag@polypyrrole hybrid composite evaluated as anode material for zinc-based secondary cell. Sci Rep, 2016, 6: 24471

207 De A, Datta J, Haldar I, et al. Catalytic intervention of $\mathrm{MoO}_{3}$ toward ethanol oxidation on ptpd nanoparticles decorated $\mathrm{MoO}_{3}$-polypyrrole composite support. ACS Appl Mater Interfaces, 2016, 8: 28574-28584
208 Zeng $\mathrm{Y}$, Han $\mathrm{Y}$, Zhao $\mathrm{Y}$, et al. Advanced Ti-doped $\mathrm{Fe}_{2} \mathrm{O}_{3} @$ PEDOT core/shell anode for high-energy asymmetric supercapacitors. Adv Energ Mater, 2015, 5: 1402176

209 Cho S, Kim M, Jang J. Screen-printable and flexible $\mathrm{RuO}_{2}$ nanoparticle-decorated PEDOT:PSS/graphene nanocomposite with enhanced electrical and electrochemical performances for highcapacity supercapacitor. ACS Appl Mater Interfaces, 2015, 7: 10213-10227

210 Jiang W, Yu D, Zhang Q, et al. Ternary hybrids of amorphous nickel hydroxide-carbon nanotube-conducting polymer for supercapacitors with high energy density, excellent rate capability, and long cycle life. Adv Funct Mater, 2015, 25: 1063-1073

211 Lin X, Nishio K, Nakamura R, et al. Encapsulation of shewanella in the redox phospholipid polymer hydrogel for microbial fuel cell fabrication. Trans Mat Res Soc Jpn, 2012, 37: 529-532

212 Kurra N, Hota MK, Alshareef HN. Conducting polymer microsupercapacitors for flexible energy storage and AC line-filtering. Nano Energ, 2015, 13: 500-508

213 Chmiola J, Largeot C, Taberna PL, et al. Monolithic carbidederived carbon films for micro-supercapacitors. Science, 2010, 328: 480-483

214 Pech D, Brunet M, Durou H, et al. Ultrahigh-power micrometresized supercapacitors based on onion-like carbon. Nat Nanotech, 2010, 5: 651-654

215 Kaempgen M, Chan CK, Ma J, et al. Printable thin film supercapacitors using single-walled carbon nanotubes. Nano Lett, 2009, 9: 1872-1876

216 El-Kady MF, Kaner RB. Scalable fabrication of high-power graphene micro-supercapacitors for flexible and on-chip energy storage. Nat Commun, 2013, 4: 1475

217 Eftekhari A, Li L, Yang Y. Polyaniline supercapacitors. J Power Sources, 2017, 347: 86-107

218 Woo SW, Dokko K, Nakano H, et al. Incorporation of polyaniline into macropores of three-dimensionally ordered macroporous carbon electrode for electrochemical capacitors. J Power Sources, 2009, 190: 596-600

219 Eftekhari A, Fan Z. Ordered mesoporous carbon and its applications for electrochemical energy storage and conversion. Mater Chem Front, 2017, 1: 1001-1027

220 Salunkhe RR, Tang J, Kobayashi N, et al. Ultrahigh performance supercapacitors utilizing core-shell nanoarchitectures from a metal-organic framework-derived nanoporous carbon and a conducting polymer. Chem Sci, 2016, 7: 5704-5713

$221 \mathrm{Hu} \mathrm{C}, \mathrm{He}$ S, Jiang S, et al. Natural source derived carbon paper supported conducting polymer nanowire arrays for high performance supercapacitors. RSC Adv, 2015, 5: 14441-14447

222 Anothumakkool B, Soni R, Bhange SN, et al. Novel scalable synthesis of highly conducting and robust PEDOT paper for a high performance flexible solid supercapacitor. Energ Environ Sci, 2015, 8: 1339-1347

223 Wang Z, Tammela P, Huo J, et al. Solution-processed poly $(3,4-$ ethylenedioxythiophene) nanocomposite paper electrodes for high-capacitance flexible supercapacitors. J Mater Chem A, 2016, 4: $1714-1722$

224 Das TK, Prusty S. Review on conducting polymers and their applications. Polymer-Plastics Tech Eng, 2012, 51: 1487-1500

225 Jiang $\mathrm{HR}, \mathrm{Lu} \mathrm{Z}, \mathrm{Wu} \mathrm{MC}$, et al. Borophene: a promising anode material offering high specific capacity and high rate capability for lithium-ion batteries. Nano Energ, 2016, 23: 97-104

226 Nie A, Gan LY, Cheng Y, et al. Twin boundary-assisted lithium 
ion transport. Nano Lett, 2015, 15: 610-615

227 Li H, Wang Z, Chen L, et al. Research on advanced materials for Li-ion batteries. Adv Mater, 2009, 21: 4593-4607

228 Goodenough JB, Park KS. The Li-ion rechargeable battery: a perspective. J Am Chem Soc, 2013, 135: 1167-1176

229 Tan P, Jiang HR, Zhu XB, et al. Advances and challenges in lithium-air batteries. Appl Energ, 2017, 204: 780-806

230 Sengodu P, Deshmukh AD. Conducting polymers and their inorganic composites for advanced Li-ion batteries: a review. RSC Adv, 2015, 5: 42109-42130

231 Yang $\mathrm{Y}, \mathrm{Yu}$ G, Cha JJ, et al. Improving the performance of lithium-sulfur batteries by conductive polymer coating. ACS Nano, 2011, 5: 9187-9193

232 Chen H, Dong W, Ge J, et al. Ultrafine sulfur nanoparticles in conducting polymer shell as cathode materials for high performance lithium/sulfur batteries. Sci Rep, 2013, 3: 1910

233 Liu G, Xun S, Vukmirovic N, et al. Polymers with tailored electronic structure for high capacity lithium battery electrodes. Adv Mater, 2011, 23: 4679-4683

$234 \mathrm{Wu}$ H, Yu G, Pan L, et al. Stable Li-ion battery anodes by in-situ polymerization of conducting hydrogel to conformally coat silicon nanoparticles. Nat Commun, 2013, 4: 1943

235 Bai S, Ma Y, Jiang X, et al. Greatly improved cyclability for Li-ion batteries with a PEDOT-PSS coated nanostructured Ge anode. Surfs Interfaces, 2017, 8: 214-218

236 Chao D, Xia X, Liu J, et al. A $\mathrm{V}_{2} \mathrm{O}_{5} /$ conductive-polymer core/shell nanobelt array on three-dimensional graphite foam: a high-rate, ultrastable, and freestanding cathode for lithium-ion batteries. Adv Mater, 2014, 26: 5794-5800

237 Wang $\mathrm{S}, \mathrm{Hu} \mathrm{L}, \mathrm{Hu} \mathrm{Y}$, et al. Conductive polyaniline capped $\mathrm{Fe}_{2} \mathrm{O}_{3}$ composite anode for high rate lithium ion batteries. Mater Chem Phys, 2014, 146: 289-294

$238 \mathrm{Xu}$ GL, Li Y, Ma T, et al. PEDOT-PSS coated $\mathrm{ZnO} / \mathrm{C}$ hierarchical porous nanorods as ultralong-life anode material for lithium ion batteries. Nano Energ, 2015, 18: 253-264

239 Seh ZW, Wang H, Hsu PC, et al. Facile synthesis of $\mathrm{Li}_{2} \mathrm{~S}-$ polypyrrole composite structures for high-performance $\mathrm{Li}_{2} \mathrm{~S}$ cathodes. Energ Environ Sci, 2014, 7: 672

240 Lawes S, Sun Q, Lushington A, et al. Inkjet-printed silicon as high performance anodes for Li-ion batteries. Nano Energ, 2017, 36: 313-321

241 Dang ZM, Yuan JK, Yao SH, et al. Flexible nanodielectric materials with high permittivity for power energy storage. Adv Mater, 2013, 25: 6334-6365

242 Prateek, Thakur VK, Gupta RK. Recent progress on ferroelectric polymer-based nanocomposites for high energy density capacitors: synthesis, dielectric properties, and future aspects. Chem Rev, 2016, 116: 4260-4317

243 Chen Q, Shen Y, Zhang S, et al. Polymer-based dielectrics with high energy storage density. Annu Rev Mater Res, 2015, 45: 433458

244 Zhang M, Zhang L, Zhu M, et al. Controlled functionalization of poly(4-methyl-1-pentene) films for high energy storage applications. J Mater Chem A, 2016, 4: 4797-4807

245 Shan X, Zhang L, Yang X, et al. Dielectric composites with a high and temperature-independent dielectric constant. J Adv Ceram, 2012, 1: 310-316

246 Zhang L, Xu Z, Feng Y, et al. Synthesis, sintering and characterization of PNZST ceramics from high-energy ball milling process. Ceramics Int, 2008, 34: 709-713
247 Jin L, Huo R, Guo R, et al. Diffuse phase transitions and giant electrostrictive coefficients in lead-free $\mathrm{Fe}^{3+}$-doped $0.5 \mathrm{Ba}$ $\left(\mathrm{Zr}_{0.2} \mathrm{Ti}_{0.8}\right) \mathrm{O}_{3}-0.5\left(\mathrm{Ba}_{0.7} \mathrm{Ca}_{0.3}\right) \mathrm{TiO}_{3}$ ferroelectric ceramics. ACS Appl Mater Interfaces, 2016, 8: 31109-31119

248 Jin L, Li F, Zhang S. Decoding the fingerprint of ferroelectric loops: comprehension of the material properties and structures. J Am Ceram Soc, 2014, 97: 1-27

249 Zhang L, Xu Z, Li Z, et al. Preparation and characterization of high $\mathrm{Tc}_{(1-x)} \mathrm{BiScO}_{3-x} \mathrm{PbTiO}_{3}$ ceramics from high energy ball milling process. J Electroceram, 2008, 21: 605-608

250 Wu P, Zhang $\mathrm{M}$, Wang $\mathrm{H}$, et al. Effect of coupling agents on the dielectric properties and energy storage of $\mathrm{Ba}_{0.5} \mathrm{Sr}_{0.5} \mathrm{TiO}_{3} / \mathrm{P}(\mathrm{VDF}-$ CTFE) nanocomposites. AIP Adv, 2017, 7: 075210

251 Zhang L, Shan X, Bass P, et al. Process and microstructure to achieve ultra-high dielectric constant in ceramic-polymer composites. Sci Rep, 2016, 6: 35763

252 Zhang $\mathrm{L}$, Shan $\mathrm{X}$, Wu $\mathrm{P}$, et al. Dielectric characteristics of $\mathrm{CaCu}_{3} \mathrm{Ti}_{4} \mathrm{O}_{12} / \mathrm{P}(\mathrm{VDF}-\mathrm{TrFE})$ nanocomposites. Appl Phys A, 2012, 107: 597-602

253 Samsur R, Rangari VK, Jeelani S, et al. Fabrication of carbon nanotubes grown woven carbon fiber/epoxy composites and their electrical and mechanical properties. J Appl Phys, 2013, 113: 214903-214903

254 Zhang L, Shan X, Wu P, et al. Microstructure and dielectric properties of CCTO-P(VDF-TrFE) nanocomposites. Ferroelectrics, 2010, 405: 92-97

255 Wang CC, Song JF, Bao HM, et al. Enhancement of electrical properties of ferroelectric polymers by polyaniline nanofibers with controllable conductivities. Adv Funct Mater, 2008, 18: 1299-1306

256 Shehzad K, Ul-Haq A, Ahmad S, et al. All-organic PANI-DBSA/ PVDF dielectric composites with unique electrical properties. J Mater Sci, 2013, 48: 3737-3744

257 Singh VP, Ramani R, Singh AS, et al. Dielectric and conducting behavior of pyrene functionalized PANI/P(VDF-co-HFP) blend. J Appl Polym Sci, 2016, 133: 44077

258 Huang C, Zhang Q. Enhanced dielectric and electromechanical responses in high dielectric constant all-polymer percolative composites. Adv Funct Mater, 2004, 14: 501-506

259 Yuan JK, Dang ZM, Yao SH, et al. Fabrication and dielectric properties of advanced high permittivity polyaniline/poly(vinylidene fluoride) nanohybrid films with high energy storage density. J Mater Chem, 2010, 20: 2441-2447

260 Zhang Y, Huo P, Liu X, et al. High dielectric constant polyaniline/ sulfonated poly(aryl ether ketone) composite membranes with good thermal and mechanical properties. J Appl Polym Sci, 2013, 130: 1990-1995

261 Zhang L, Liu Z, Lu X, et al. Nano-clip based composites with a low percolation threshold and high dielectric constant. Nano Energ, 2016, 26: 550-557

262 Yu S, Qin F, Wang G. Improving the dielectric properties of poly (vinylidene fluoride) composites by using poly(vinyl pyrrolidone)-encapsulated polyaniline nanorods. J Mater Chem C, 2016, 4: $1504-1510$

263 Kim BG, Kim YS, Kim YH, et al. Nano-scale insulation effect of polypyrrole/polyimide core-shell nanoparticles for dielectric composites. Composites Sci Tech, 2016, 129: 153-159

264 Zhang L, Wang W, Wang X, et al. Metal-polymer nanocomposites with high percolation threshold and high dielectric constant. Appl Phys Lett, 2013, 103: 232903 
Liao X, Ye W, Chen L, et al. Flexible hdC-G reinforced polyimide composites with high dielectric permittivity. Composites Part AAppl Sci Manufacturing, 2017, 101: 50-58

266 Zhang L, Bass P, Cheng ZY. Revisiting the percolation phenomena in dielectric composites with conducting fillers. Appl Phys Lett, 2014, 105: 042905

267 Zhang L, Wang X, Cheng ZY. A case study of conductor-dielectric 0-3 composites using Ni-P(VDF-CTFE) nanocomposites. J Adv Phys, 2015, 4: 362-369

268 Zhang L, Bass P, Cheng ZY. Physical aspects of 0-3 dielectric composites. J Adv Dielect, 2015, 05: 1550012

269 Xu W, Ding Y, Yu Y, et al. Highly foldable PANi@CNTs/PU dielectric composites toward thin-film capacitor application. Mater Lett, 2017, 192: 25-28

270 Zhang YY, Wang GL, Zhang J, et al. Preparation and properties of core-shell structured calcium copper titanate@polyaniline/silicone dielectric elastomer actuators. Polym Compos, 2017, 85

271 Huang X, Jiang P. Core-shell structured high- $k$ polymer nanocomposites for energy storage and dielectric applications. Adv Mater, 2015, 27: 546-554

272 Himanshu AK, Bandyopadhayay SK, Bahuguna R, et al. Synthesis and dielectric studies of polyaniline-polyacrylamide conducting polymer composites. AIP Conference Proceedings, 2011, 1349: 204-205

273 Zhang L, Bass P, Wang G, Tong Y, et al. Dielectric response and percolation behavior of Ni-P(VDF-TrFE) nanocomposites. J Adv Dielectr, 2017, 7: 1750015

274 Janata J, Josowicz M. Conducting polymers in electronic chemical sensors. Nat Mater, 2003, 2: 19-24

275 Virji S, Huang J, Kaner RB, et al. Polyaniline nanofiber gas sensors: examination of response mechanisms. Nano Lett, 2004, 4: 491-496

276 Fratoddi I, Venditti I, Cametti C, et al. Chemiresistive polyaniline-based gas sensors: A mini review. Sensors Actuators BChem, 2015, 220: 534-548

277 Gong X, Wang Y, Kuang T. ZIF-8-based membranes for carbon dioxide capture and separation. ACS Sustain Chem Eng, 2017, 5: 11204-11214

278 Patil UV, Ramgir NS, Karmakar N, et al. Room temperature ammonia sensor based on copper nanoparticle intercalated polyaniline nanocomposite thin films. Appl Surf Sci, 2015, 339: 69-74

279 Shirsat MD, Bangar MA, Deshusses MA, et al. Polyaniline nanowires-gold nanoparticles hybrid network based chemiresistive hydrogen sulfide sensor. Appl Phys Lett, 2009, 94: 083502

280 Bai S, Sun C, Wan P, et al. Transparent conducting films of hierarchically nanostructured polyaniline networks on flexible substrates for high-performance gas sensors. Small, 2015, 11: 306-310

281 Wang L, Huang H, Xiao S, et al. Enhanced sensitivity and stability of room-temperature $\mathrm{NH}_{3}$ sensors using core-shell $\mathrm{CeO}_{2}$ nanoparticles@cross-linked PANI with p-n heterojunctions. ACS Appl Mater Interfaces, 2014, 6: 14131-14140

282 Guo Y, Wang T, Chen F, et al. Hierarchical graphene-polyaniline nanocomposite films for high-performance flexible electronic gas sensors. Nanoscale, 2016, 8: 12073-12080

283 Eising M, Cava CE, Salvatierra RV, et al. Doping effect on selfassembled films of polyaniline and carbon nanotube applied as ammonia gas sensor. Sensors Actuators B-Chem, 2017, 245: 2533
284 Abdulla S, Mathew TL, Pullithadathil B. Highly sensitive, room temperature gas sensor based on polyaniline-multiwalled carbon nanotubes (PANI/MWCNTs) nanocomposite for trace-level ammonia detection. Sensors Actuators B-Chem, 2015, 221: 15231534

285 Wu Z, Chen X, Zhu S, et al. Enhanced sensitivity of ammonia sensor using graphene/polyaniline nanocomposite. Sensors Actuators B-Chem, 2013, 178: 485-493

286 Gavgani JN, Hasani A, Nouri M, et al. Highly sensitive and flexible ammonia sensor based on $\mathrm{S}$ and $\mathrm{N}$ co-doped graphene quantum dots/polyaniline hybrid at room temperature. Sensors Actuators B-Chem, 2016, 229: 239-248

287 Yang X, Li L, Yan F. Polypyrrole/silver composite nanotubes for gas sensors. Sensors Actuators B-Chem, 2010, 145: 495-500

288 Hong L, Li Y, Yang M. Fabrication and ammonia gas sensing of palladium/polypyrrole nanocomposite. Sensors Actuators BChem, 2010, 145: 25-31

289 Nalage SR, Mane AT, Pawar RC, et al. Polypyrrole-NiO hybrid nanocomposite films: highly selective, sensitive, and reproducible $\mathrm{NO}_{2}$ sensors. Ionics, 2014, 20: 1607-1616

290 Mane AT, Navale ST, Sen S, et al. Nitrogen dioxide $\left(\mathrm{NO}_{2}\right)$ sensing performance of $\mathrm{p}$-polypyrrole/n-tungsten oxide hybrid nanocomposites at room temperature. Org Electron, 2015, 16: 195-204

291 Xiang C, Jiang D, Zou Y, et al. Ammonia sensor based on polypyrrole-graphene nanocomposite decorated with titania nanoparticles. Ceramics Int, 2015, 41: 6432-6438

292 Park E, Kwon O, Park S, et al. One-pot synthesis of silver nanoparticles decorated poly(3,4-ethylenedioxythiophene) nanotubes for chemical sensor application. J Mater Chem, 2012, 22: 1521-1526

293 Dehsari HS, Gavgani JN, Hasani A, et al. Copper(II) phthalocyanine supported on a three-dimensional nitrogen-doped graphene/PEDOT-PSS nanocomposite as a highly selective and sensitive sensor for ammonia detection at room temperature. RSC Adv, 2015, 5: 79729-79737

294 Arabloo F, Javadpour S, Memarzadeh R, et al. The interaction of carbon monoxide to $\mathrm{Fe}(\mathrm{III})($ salen)-PEDOT:PSS composite as a gas sensor. Synth Met, 2015, 209: 192-199

295 Zheng Y, Lee D, Koo HY, et al. Chemically modified graphene/ PEDOT:PSS nanocomposite films for hydrogen gas sensing. Carbon, 2015, 81: 54-62

296 Timmer B, Olthuis W, Berg A. Ammonia sensors and their applications-a review. Sensors Actuators B-Chem, 2005, 107: 666677

297 Bandgar DK, Navale ST, Nalage SR, et al. Simple and low-temperature polyaniline-based flexible ammonia sensor: a step towards laboratory synthesis to economical device design. J Mater Chem C, 2015, 3: 9461-9468

298 Kumar L, Rawal I, Kaur A, et al. Flexible room temperature ammonia sensor based on polyaniline. Sensors Actuators BChem, 2017, 240: 408-416

299 Jun J, Oh J, Shin DH, et al. Wireless, room temperature volatile organic compound sensor based on polypyrrole nanoparticle immobilized ultrahigh frequency radio frequency identification tag. ACS Appl Mater Interfaces, 2016, 8: 33139-33147

300 Sarfraz J, Tobjork D, Osterbacka R, et al. Low-cost hydrogen sulfide gas sensor on paper substrates: fabrication and demonstration. IEEE Sensors J, 2012, 12: 1973-1978

301 Sarfraz J, Ihalainen P, Määttänen A, et al. Printed hydrogen sulfide gas sensor on paper substrate based on polyaniline com- 
posite. Thin Solid Films, 2013, 534: 621-628

302 Virji S, Fowler JD, Baker CO, et al. Polyaniline nanofiber composites with metal salts: chemical sensors for hydrogen sulfide. Small, 2005, 1: 624-627

303 Mousavi S, Kang K, Park J, et al. A room temperature hydrogen sulfide gas sensor based on electrospun polyaniline-polyethylene oxide nanofibers directly written on flexible substrates. RSC Adv, 2016, 6: 104131-104138

304 Lei W, Si W, Xu Y, et al. Conducting polymer composites with graphene for use in chemical sensors and biosensors. Microchim Acta, 2014, 181: 707-722

305 Turner APF. Biosensors: sense and sensibility. Chem Soc Rev, 2013, 42: 3184-3196

306 Chen C, Xie Q, Yang D, et al. Recent advances in electrochemical glucose biosensors: a review. RSC Adv, 2013, 3: 4473-4491

307 Sun F, Wu K, Hung HC, et al. Paper sensor coated with a poly (carboxybetaine)-multiple DOPA conjugate via dip-coating for biosensing in complex media. Anal Chem, 2017, 89: 10999-11004

308 Shrivastava S, Jadon N, Jain R. Next-generation polymer nanocomposite-based electrochemical sensors and biosensors: a review. Trends Anal Chem, 2016, 82: 55-67

309 Aydemir N, Malmström J, Travas-Sejdic J. Conducting polymer based electrochemical biosensors. Phys Chem Chem Phys, 2016, 18: 8264-8277

310 Mahmoudian MR, Alias Y, Basirun WJ, et al. Synthesis of polypyrrole coated silver nanostrip bundles and their application for detection of hydrogen peroxide. J Electrochem Soc, 2014, 161: H487-H492

311 Nia PM, Meng WP, Alias Y. One-step electrodeposition of polypyrrole-copper nano particles for $\mathrm{H}_{2} \mathrm{O}_{2}$ detection. J Electrochem Soc, 2016, 163: B8-B14

312 Qi C, Zheng J. Novel nonenzymatic hydrogen peroxide sensor based on $\mathrm{Fe}_{3} \mathrm{O}_{4} / \mathrm{PPy} / \mathrm{Ag}$ nanocomposites. J Electroanal Chem, 2015, 747: 53-58

313 Siao HW, Chen SM, Lin KC. Electrochemical study of PEDOTPSS-MDB-modified electrode and its electrocatalytic sensing of hydrogen peroxide. J Solid State Electrochem, 2011, 15: 11211128

314 Zhai D, Liu B, Shi Y, et al. Highly sensitive glucose sensor based on Pt nanoparticle/polyaniline hydrogel heterostructures. ACS Nano, 2013, 7: 3540-3546

$315 \mathrm{Xu} \mathrm{M}$, Song Y, Ye Y, et al. A novel flexible electrochemical glucose sensor based on gold nanoparticles/polyaniline arrays/carbon cloth electrode. Sensors Actuators B-Chem, 2017, 252: 11871193

316 Fang L, Liang B, Yang G, et al. A needle-type glucose biosensor based on PANI nanofibers and PU/E-PU membrane for longterm invasive continuous monitoring. Biosens Bioelectron, 2017, 97: 196-202

317 Zhuang X, Tian C, Luan F, et al. One-step electrochemical fabrication of a nickel oxide nanoparticle/polyaniline nanowire/ graphene oxide hybrid on a glassy carbon electrode for use as a non-enzymatic glucose biosensor. RSC Adv, 2016, 6: 9254192546

318 Zhybak M, Beni V, Vagin MY, et al. Creatinine and urea biosensors based on a novel ammonium ion-selective copper-polyaniline nano-composite. Biosens Bioelectron, 2016, 77: 505-511

319 Bayram E, Akyilmaz E. Development of a new microbial biosensor based on conductive polymer/multiwalled carbon nanotube and its application to paracetamol determination. Sensors
Actuators B-Chem, 2016, 233: 409-418

$320 \mathrm{Li} \mathrm{J,} \mathrm{Hu} \mathrm{H,} \mathrm{Li} \mathrm{H,} \mathrm{et} \mathrm{al.} \mathrm{Recent} \mathrm{developments} \mathrm{in} \mathrm{electrochemical}$ sensors based on nanomaterials for determining glucose and its byproduct $\mathrm{H}_{2} \mathrm{O}_{2}$. J Mater Sci, 2017, 52: 10455-10469

321 Yang MH, Kim DS, Yoon JH, et al. Nanopillar films with polyoxometalate-doped polyaniline for electrochemical detection of hydrogen peroxide. Analyst, 2016, 141: 1319-1324

322 Han J, Li L, Guo R. Novel approach to controllable synthesis of gold nanoparticles supported on polyaniline nanofibers. Macromolecules, 2010, 43: 10636-10644

323 Yang L, Zhang Z, Nie G, et al. Fabrication of conducting polymer/ noble metal composite nanorings and their enhanced catalytic properties. J Mater Chem A, 2015, 3: 83-86

324 Song W, Chi M, Gao M, et al. Self-assembly directed synthesis of $\mathrm{Au}$ nanorices induced by polyaniline and their enhanced peroxidase-like catalytic properties. J Mater Chem C, 2017, 5: 74657471

325 Chi M, Nie G, Jiang Y, et al. Self-assembly fabrication of coaxial Te@poly(3,4-ethylenedioxythiophene) nanocables and their conversion to Pd@poly(3,4-ethylenedioxythiophene) nanocables with a high peroxidase-like activity. ACS Appl Mater Interfaces, 2016, 8: 1041-1049

326 Yang Z, Ma F, Zhu Y, et al. A facile synthesis of $\mathrm{CuFe}_{2} \mathrm{O}_{4} / \mathrm{Cu}_{9} \mathrm{~S}_{8} /$ $\mathrm{PPy}$ ternary nanotubes as peroxidase mimics for the sensitive colorimetric detection of $\mathrm{H}_{2} \mathrm{O}_{2}$ and dopamine. Dalton Trans, 2017, 46: 11171-11179

327 Jiang Y, Gu Y, Nie G, et al. Synthesis of $\mathrm{rGO} / \mathrm{Cu}_{8} \mathrm{~S}_{5} / \mathrm{PPy}$ composite nanosheets with enhanced peroxidase-like activity for sensitive colorimetric detection of $\mathrm{H}_{2} \mathrm{O}_{2}$ and phenol. Part Part Syst Charact, 2017, 34: 1600233

328 Miao Z, Wang P, Zhong AM, et al. Development of a glucose biosensor based on electrodeposited gold nanoparticles-polyvinylpyrrolidone-polyaniline nanocomposites. J Electroanal Chem, 2015, 756: 153-160

329 Zheng W, Hu L, Lee LYS, et al. Copper nanoparticles/polyaniline/ graphene composite as a highly sensitive electrochemical glucose sensor. J Electroanal Chem, 2016, 781: 155-160

330 Wei X, Panindre $\mathrm{P}$, Zhang $\mathrm{Q}$, et al. Increasing the detection sensitivity for DNA-morpholino hybridization in sub-nanomolar regime by enhancing the surface ion conductance of PEDOT:PSS membrane in a microchannel. ACS Sens, 2016, 1: 862-865

331 Zhang Q, Khajo A, Sai T, et al. Intramolecular transport of charge carriers in trimeric aniline upon a three-step acid doping process. J Phys Chem A, 2012, 116: 7629-7635

332 Qi Zhang, Majumdar HS, Kaisti M, et al. Surface functionalization of ion-sensitive floating-gate field-effect transistors with organic electronics. IEEE Trans Electron Devices, 2015, 62: 12911298

333 Yu Y, Zhang Q, Chang CC, et al. Design of a molecular imprinting biosensor with multi-scale roughness for detection across a broad spectrum of biomolecules. Analyst, 2016, 141: 5607-5617

334 Yu Y, Zhang Q, Buscaglia J, et al. Quantitative real-time detection of carcinoembryonic antigen (CEA) from pancreatic cyst fluid using 3-D surface molecular imprinting. Analyst, 2016, 141: 4424-4431

335 Zhang Q, Prabhu A, San A, et al. A polyaniline based ultrasensitive potentiometric immunosensor for cardiac troponin complex detection. Biosens Bioelectron, 2015, 72: 100-106

336 Cheng Z, Zhang Q. Field-activated electroactive polymers. MRS 
Bull, 2011, 33: 183-187

337 Bass PS, Zhang L, Cheng ZY. Time-dependence of the electromechanical bending actuation observed in ionic-electroactive polymers. J Adv Dielectr, 2017 : 1720002

338 Jaaoh D, Putson C, Muensit N. Deformation on segment-structure of electrostrictive polyurethane/polyaniline blends. Polymer, 2015, 61: 123-130

339 Molberg M, Crespy D, Rupper P, et al. High breakdown field dielectric elastomer actuators using encapsulated polyaniline as high dielectric constant filler. Adv Funct Mater, 2010, 20: 32803291

340 Jaaoh D, Putson C, Muensit N. Enhanced strain response and energy harvesting capabilities of electrostrictive polyurethane composites filled with conducting polyaniline. Composites Sci Tech, 2016, 122: 97-103

341 Putson C, Jaaoh D, Muensit N. Large electromechanical strain at low electric field of modified polyurethane composites for flexible actuators. Mater Lett, 2016, 172: 27-31

342 Fan FR, Tian ZQ, Lin Wang Z. Flexible triboelectric generator. Nano Energy, 2012, 1: 328-334

343 Zhu G, Chen J, Zhang T, et al. Radial-arrayed rotary electrification for high performance triboelectric generator. Nat Commun, 2014, 5: 3426

344 Wang J, Wen Z, Zi Y, et al. Self-powered electrochemical synthesis of polypyrrole from the pulsed output of a triboelectric nanogenerator as a sustainable energy system. Adv Funct Mater, 2016, 26: 3542-3548

345 Wang J, Wen Z, Zi Y, et al. All-plastic-materials based selfcharging power system composed of triboelectric nanogenerators and supercapacitors. Adv Funct Mater, 2016, 26: 1070-1076

346 Sultana A, Alam MM, Garain S, et al. An effective electrical throughput from PANI supplement ZnS nanorods and PDMSbased flexible piezoelectric nanogenerator for power up portable electronic devices: an alternative of MWCNT filler. ACS Appl Mater Interfaces, 2015, 7: 19091-19097

347 Chen ZG, Han G, Yang L, et al. Nanostructured thermoelectric materials: current research and future challenge. Prog Nat SciMater Int, 2012, 22: 535-549

348 Liu W, Yan X, Chen G, et al. Recent advances in thermoelectric nanocomposites. Nano Energ, 2012, 1: 42-56

349 Wang H, Yin L, Pu X, et al. Facile charge carrier adjustment for improving thermopower of doped polyaniline. Polymer, 2013, 54: $1136-1140$

350 See KC, Feser JP, Chen CE, et al. Water-processable polymer -nanocrystal hybrids for thermoelectrics. Nano Lett, 2010, 10: 4664-4667

351 Coates NE, Yee SK, McCulloch B, et al. Effect of interfacial properties on polymer-nanocrystal thermoelectric transport. Adv Mater, 2013, 25: 1629-1633

352 Wang Y, Zhang SM, Deng Y. Flexible low-grade energy utilization devices based on high-performance thermoelectric polyaniline/tellurium nanorod hybrid films. J Mater Chem A, 2016, 4: 3554-3559

353 Kim D, Kim Y, Choi K, et al. Improved thermoelectric behavior of nanotube-filled polymer composites with poly(3,4-ethylenedioxythiophene) poly(styrenesulfonate). ACS Nano, 2010, 4: 513523

354 Yao Q, Chen L, Zhang W, et al. Enhanced thermoelectric performance of single-walled carbon nanotubes/polyaniline hybrid nanocomposites. ACS Nano, 2010, 4: 2445-2451
355 Harima Y, Fukumoto S, Zhang L, et al. Thermoelectric performances of graphene/polyaniline composites prepared by one-step electrosynthesis. RSC Adv, 2015, 5: 86855-86860

356 Wang L, Yao Q, Bi H, et al. Large thermoelectric power factor in polyaniline/graphene nanocomposite films prepared by solutionassistant dispersing method. J Mater Chem A, 2014, 2: 1110711113

357 Cho C, Stevens B, Hsu JH, et al. Completely organic multilayer thin film with thermoelectric power factor rivaling inorganic tellurides. Adv Mater, 2015, 27: 2996-3001

358 Zhang Z, Chen G, Wang H, et al. Enhanced thermoelectric property by the construction of a nanocomposite $3 \mathrm{D}$ interconnected architecture consisting of graphene nanolayers sandwiched by polypyrrole nanowires. J Mater Chem C, 2015, 3: 1649-1654

359 Wang Y, Yang J, Wang L, et al. Polypyrrole/graphene/polyaniline ternary nanocomposite with high thermoelectric power factor. ACS Appl Mater Interfaces, 2017, 9: 20124-20131

360 Wang L, Yao Q, Shi W, et al. Engineering carrier scattering at the interfaces in polyaniline based nanocomposites for high thermoelectric performances. Mater Chem Front, 2017, 1: 741-748

361 Wang L, Liu Y, Zhang Z, et al. Polymer composites-based thermoelectric materials and devices. Composites Part B-Eng, 2017, 122: $145-155$

362 Meng C, Liu C, Fan S. A promising approach to enhanced thermoelectric properties using carbon nanotube networks. Adv Mater, 2010, 22: 535-539

363 Du Y, Shen SZ, Yang W, et al. Simultaneous increase in conductivity and Seebeck coefficient in a polyaniline/graphene nanosheets thermoelectric nanocomposite. Synth Met, 2012, 161: 2688-2692

364 Xiang J, Drzal LT. Templated growth of polyaniline on exfoliated graphene nanoplatelets (GNP) and its thermoelectric properties. Polymer, 2012, 53: 4202-4210

365 Ates M. A review on conducting polymer coatings for corrosion protection. J Adhes Sci Tech, 2016, 30: 1510-1536

366 Hosseini MG, Sabouri M, Shahrabi T. Corrosion protection of mild steel by polypyrrole phosphate composite coating. Prog Org Coatings, 2007, 60: 178-185

367 Mengoli G, Munari MT, Bianco P, et al. Anodic synthesis of polyaniline coatings onto Fe sheets. J Appl Polym Sci, 1981, 26: 4247-4257

368 DeBerry DW. Modification of the electrochemical and corrosion behavior of stainless steels with an electroactive coating. J Electrochem Soc, 1985, 132: 1022-1026

369 Ahmad N, MacDiarmid AG. Inhibition of corrosion of steels with the exploitation of conducting polymers. Synth Met, 1996, 78: 103-110

370 Camalet JL, Lacroix JC, Nguyen TD, et al. Aniline electropolymerization on platinum and mild steel from neutral aqueous media. J Electroanal Chem, 2000, 485: 13-20

371 Ferreira CA, Aeiyach S, Aaron JJ, et al. Electrosynthesis of strongly adherent polypyrrole coatings on iron and mild steel in aqueous media. Electrochim Acta, 1996, 41: 1801-1809

372 Nautiyal A, Qiao M, Cook JE, et al. High performance polypyrrole coating for corrosion protection and biocidal applications. Appl Surf Sci, 2018, 427: 922-930

373 Genies EM, Bidan G, Diaz AF. Spectroelectrochemical study of polypyrrole films. J Electroanal Chem Interfacial Electrochem, 1983, 149: 101-113 
374 Nguyen Thi Le H, Garcia B, Deslouis C, et al. Corrosion protection and conducting polymers: polypyrrole films on iron. Electrochim Acta, 2001, 46: 4259-4272

375 Van Schaftinghen T, Deslouis C, Hubin A, et al. Influence of the surface pre-treatment prior to the film synthesis, on the corrosion protection of iron with polypyrrole films. Electrochim Acta, 2006, 51: $1695-1703$

376 Bandeira RM, van Drunen J, Tremiliosi-Filho G, et al. Polyaniline/polyvinyl chloride blended coatings for the corrosion protection of carbon steel. Prog Org Coatings, 2017, 106: 50-59

377 Hermas AA, Salam MA, Al-Juaid SS, et al. Electrosynthesis and protection role of polyaniline-polvinylalcohol composite on stainless steel. Prog Org Coatings, 2014, 77: 403-411

378 Lenz DM, Delamar M, Ferreira CA. Application of polypyrrole/ $\mathrm{TiO}_{2}$ composite films as corrosion protection of mild steel. J Electroanal Chem, 2003, 540: 35-44

379 Ates M, Topkaya E. Nanocomposite film formations of polyaniline via $\mathrm{TiO}_{2}, \mathrm{Ag}$, and $\mathrm{Zn}$, and their corrosion protection properties. Prog Org Coatings, 2015, 82: 33-40

380 Radhakrishnan S, Siju CR, Mahanta D, et al. Conducting polyaniline-nano-TiO2 composites for smart corrosion resistant coatings. Electrochim Acta, 2009, 54: 1249-1254

381 Zubillaga O, Cano FJ, Azkarate I, et al. Corrosion performance of anodic films containing polyaniline and $\mathrm{TiO}_{2}$ nanoparticles on AA3105 aluminium alloy. Surf Coatings Tech, 2008, 202: 59365942

382 Pagotto JF, Recio FJ, Motheo AJ, et al. Multilayers of PAni/n- $-\mathrm{TiO}_{2}$ and PAni on carbon steel and welded carbon steel for corrosion protection. Surf Coatings Tech, 2016, 289: 23-28

383 Bhandari H, Kumar SA, Dhawan SK. Conducting polymer nanocomposites for anticorrosive and antistatic applications. in: nanocomposites - new trends and developments. Rijeka: InTech 2012

384 Bai X, Tran TH, Yu D, et al. Novel conducting polymer based composite coatings for corrosion protection of zinc. Corrosion Sci, 2015, 95: 110-116

385 Qiu G, Zhu A, Zhang C. Hierarchically structured carbon nanotube-polyaniline nanobrushes for corrosion protection over a wide $\mathrm{pH}$ range. RSC Adv, 2017, 7: 35330-35339

386 Jafari Y, Ghoreishi SM, Shabani-Nooshabadi M. Polyaniline/ graphene nanocomposite coatings on copper: electropolymerization, characterization, and evaluation of corrosion protection performance. Synth Met, 2016, 217: 220-230

387 Mišković-Stanković V, Jevremović I, Jung I, et al. Electrochemical study of corrosion behavior of graphene coatings on copper and aluminum in a chloride solution. Carbon, 2014, 75: 335-344

388 Cai K, Zuo S, Luo S, et al. Preparation of polyaniline/graphene composites with excellent anti-corrosion properties and their application in waterborne polyurethane anticorrosive coatings. RSC Adv, 2016, 6: 95965-95972

389 Qiu C, Liu D, Jin K, et al. Electrochemical functionalization of 316 stainless steel with polyaniline-graphene oxide: Corrosion resistance study. Mater Chem Phys, 2017, 198: 90-98

390 Marimuthu M, Veerapandian M, Ramasundaram S, et al. Sodium functionalized graphene oxide coated titanium plates for improved corrosion resistance and cell viability. Appl Surf Sci, 2014, 293: $124-131$

391 He P, Wang J, Lu F, et al. Synergistic effect of polyaniline grafted basalt plates for enhanced corrosion protective performance of epoxy coatings. Prog Org Coatings, 2017, 110: 1-9
392 Li Y, Wang X. Intrinsically conducting polymers and their composites for anticorrosion and antistatic applications. in: Yang $\mathrm{X}$ (Ed.). Semiconducting Polymer Composites. Weinheim: WileyVCH Verlag GmbH \& Co. KGaA, 2012. 269-298

393 Trivedi DC, Dhawan SK. Antistatic applications of conducting polyaniline. Polym Adv Technol, 1993, 4: 335-340

394 Zheng A, Xu X, Xiao H, et al. Antistatic modification of polypropylene by incorporating Tween/modified Tween. Appl Surf Sci, 2012, 258: 8861-8866

395 Wang Q, Wang Y, Meng Q, et al. Preparation of high antistatic HDPE/polyaniline encapsulated graphene nanoplatelet composites by solution blending. RSC Adv, 2017, 7: 2796-2803

396 Wang J, Bao L, Zhao H, et al. Preparation and characterization of permanently anti-static packaging composites composed of high impact polystyrene and ion-conductive polyamide elastomer. Composites Sci Tech, 2012, 72: 976-981

397 Tsurumaki A, Bertasi F, Vezzù K, et al. Dielectric relaxations of polyether-based polyurethanes containing ionic liquids as antistatic agents. Phys Chem Chem Phys, 2016, 18: 2369-2378

398 Wang H, Sun L, Fei G, et al. A facile approach to fabricate waterborne, nanosized polyaniline-graft-(sulfonated polyurethane) as environmental antistatic coating. J Appl Polym Sci, 2017, 134: 45412

399 Zhang M, Zhang C, Du Z, et al. Preparation of antistatic polystyrene superfine powder with polystyrene modified carbon nanotubes as antistatic agent. Composites Sci Tech, 2017, 138: 1-7 400 Wessling B. Passivation of metals by coating with polyaniline: corrosion potential shift and morphological changes. Adv Mater, 1994, 6: 226-228

401 Soto-Oviedo MA, Araújo OA, Faez R, et al. Antistatic coating and electromagnetic shielding properties of a hybrid material based on polyaniline/organoclay nanocomposite and EPDM rubber. Synth Met, 2006, 156: 1249-1255

$402 \mathrm{Xu}$ J, Xiao J, Zhang Z, et al. Modified polyaniline and its effects on the microstructure and antistatic properties of PP/PANI-APP/ CPP composites. J Appl Polym Sci, 2014, 131: 40732

403 Shi X, Hu Y, Fu F, et al. Construction of PANI-cellulose composite fibers with good antistatic properties. J Mater Chem A, 2014, 2: 7669-7673

404 Zhao Y, Ma J, Chen K, et al. One-pot preparation of graphenebased polyaniline conductive nanocomposites for anticorrosion coatings. NANO, 2017, 12: 1750056

405 Wang J, Zhang C, Du Z, et al. Functionalization of MWCNTs with silver nanoparticles decorated polypyrrole and their application in antistatic and thermal conductive epoxy matrix nanocomposite. RSC Adv, 2016, 6: 31782-31789

406 Kizildag N, Ucar N, Onen A, et al. Polyacrylonitrile/polyaniline composite nanofiber webs with electrostatic discharge properties. J Composite Mater, 2016, 50: 3981-3994

407 Shahzad F, Alhabeb M, Hatter CB, et al. Electromagnetic interference shielding with 2D transition metal carbides (MXenes). Science, 2016, 353: 1137-1140

408 Deng J, Wang Q, Zhou Y, et al. Facile design of a ZnO nanorodNi core-shell composite with dual peaks to tune its microwave absorption properties. RSC Adv, 2017, 7: 9294-9302

409 Deng J, Li S, Zhou Y, et al. Enhancing the microwave absorption properties of amorphous $\mathrm{CoO}$ nanosheet-coated Co (hexagonal and cubic phases) through interfacial polarizations. J Colloid Interface Sci, 2018, 509: 406-413

410 Zeng $\mathrm{Z}$, Chen $\mathrm{M}$, Jin $\mathrm{H}$, et al. Thin and flexible multi-walled 
carbon nanotube/waterborne polyurethane composites with highperformance electromagnetic interference shielding. Carbon, 2016, 96: 768-777

411 Saini P, Choudhary V, Singh BP, et al. Polyaniline-MWCNT nanocomposites for microwave absorption and EMI shielding. Mater Chem Phys, 2009, 113: 919-926

412 Chen Z, Xu C, Ma C, et al. Lightweight and flexible graphene foam composites for high-performance electromagnetic interference shielding. Adv Mater, 2013, 25: 1296-1300

413 Kuang T, Chang L, Chen F, et al. Facile preparation of lightweight high-strength biodegradable polymer/multi-walled carbon nanotubes nanocomposite foams for electromagnetic interference shielding. Carbon, 2016, 105: 305-313

414 Wu F, Sun M, Jiang W, et al. A self-assembly method for the fabrication of a three-dimensional (3D) polypyrrole (PPy)/poly (3,4-ethylenedioxythiophene) (PEDOT) hybrid composite with excellent absorption performance against electromagnetic pollution. J Mater Chem C, 2016, 4: 82-88

415 Fang F, Li YQ, Xiao HM, et al. Layer-structured silver nanowire/ polyaniline composite film as a high performance X-band EMI shielding material. J Mater Chem C, 2016, 4: 4193-4203

416 Li H, Lu X, Yuan D, et al. Lightweight flexible carbon nanotube/ polyaniline films with outstanding EMI shielding properties. J Mater Chem C, 2017, 5: 8694-8698

417 Joseph N, Varghese J, Sebastian MT. A facile formulation and excellent electromagnetic absorption of room temperature curable polyaniline nanofiber based inks. J Mater Chem C, 2016, 4: 999-1008

418 Mohan RR, Varma SJ, Faisal M, et al. Polyaniline/graphene hybrid film as an effective broadband electromagnetic shield. RSC Adv, 2015, 5: 5917-5923

419 Zhang Y, Qiu M, Yu Y, et al. A novel polyaniline-coated bagasse fiber composite with core-shell heterostructure provides effective electromagnetic shielding performance. ACS Appl Mater Interfaces, 2017, 9: 809-818

420 Lyu J, Zhao X, Hou X, et al. Electromagnetic interference shielding based on a high strength polyaniline-aramid nanocomposite. Composites Sci Tech, 2017, 149: 159-165

421 Zhao H, Hou L, Bi S, et al. Enhanced X-band electromagneticinterference shielding performance of layer-structured fabricsupported polyaniline/cobalt-nickel coatings. ACS Appl Mater Interfaces, 2017, 9: 33059-33070

422 Gahlout P, Choudhary V. 5-Sulfoisophthalic acid monolithium salt doped polypyrrole/multiwalled carbon nanotubes composites for EMI shielding application in X-band (8.2-12.4 GHz). J Appl Polym Sci, 2017, 134: 45370

423 Babayan V, Kazantseva NE, Moučka R, et al. Electromagnetic shielding of polypyrrole-sawdust composites: polypyrrole globules and nanotubes. Cellulose, 2017, 24: 3445-3451

424 Agnihotri N, Chakrabarti K, De A. Highly efficient electromagnetic interference shielding using graphite nanoplatelet/poly (3,4-ethylenedioxythiophene)-poly(styrenesulfonate) composites with enhanced thermal conductivity. RSC Adv, 2015, 5: 4376543771

$425 \mathrm{Wu}$ Y, Wang Z, Liu X, et al. Ultralight graphene foam/conductive polymer composites for exceptional electromagnetic interference shielding. ACS Appl Mater Interfaces, 2017, 9: 9059-9069

426 Li P, Du D, Guo L, et al. Stretchable and conductive polymer films for high-performance electromagnetic interference shielding. J Mater Chem C, 2016, 4: 6525-6532

427 Geetha S, Satheesh Kumar KK, Rao CRK, et al. EMI shielding: Methods and materials-A review. J Appl Polym Sci, 2009, 112: 2073-2086

428 Bhattacharjee Y, Arief I, Bose S. Recent trends in multi-layered architectures towards screening electromagnetic radiation: challenges and perspectives. J Mater Chem C, 2017, 5: 7390-7403

429 Zhao H, Hou L, Lu Y. Electromagnetic interference shielding of layered linen fabric/polypyrrole/nickel (LF/PPy/Ni) composites. Mater Des, 2016, 95: 97-106

Acknowledgements This work was partially supported by the National Institute of Food and Agriculture, USDA and AU-IGP award.

Author contributions Zhang L was responsible for sections (Introduction, Synthetic approaches to nanostructured conducting polymers, Strategies to fabricate advanced functional nanocomposites, Applications of conducting polymer nanocomposites (Energy Storage and conversion devices, Chemical sensors, Biosensors, Energy harvesting devices)), Du W contributed for sections (Applications of conducting polymer nanocomposites (Corrosion protection, Antistatic agent, Electromagnetic interference shielding)) and organized the references, Liu Z contributed for section (Strategies to fabricate advanced functional nanocomposites). Nautiyal A worked on all sections and tables. All authors involved in writing and refinement of the manuscript under the direction of Zhang $\mathrm{X}$ who revised the manuscript.

Conflict of interest The authors declare no conflict of interests. 

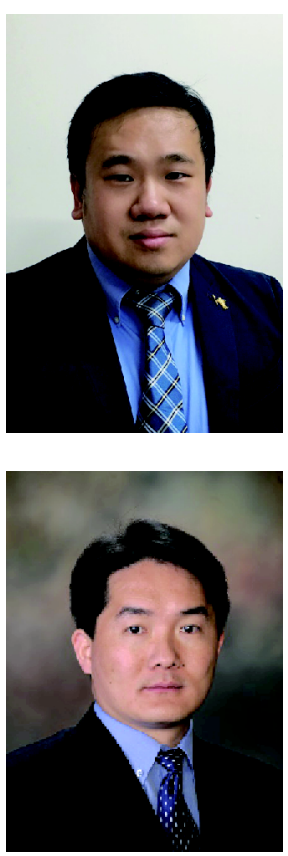

Lin Zhang received his BSc and MSc in Electronic Science and Technology at Xi'an Jiaotong University, China. He obtained his PhD degree in Materials Engineering at Auburn University, USA in 2013. From 2013 to 2017, he was postdoctoral research fellow in Materials Engineering at Auburn University and in NanoEngineering at UC San Diego. Dr. Zhang's scientific interests include polymer-based dielectric composites, piezoelectric and ferroelectric ceramics, flexible/wearable devices, and green approaches to conducting polymer based nanocomposites. He joined the Department of Electronic Science and Technology at Xi'an Jiaotong University.
Xinyu Zhang studied in Chemistry Department at the University of Texas at Dallas (UTD) under the supervision of Professors Alan G. MacDiarmid and Sanjeev K. Manohar. After receiving his PhD degree in 2005, he started his postdoctoral stay at the University of Massachusetts Lowell. He started his career at Auburn University in 2008 in the Department of Polymer and Fiber Engineering. His research interests include the microwave approach to ultrafast production of nanomaterials, mechanism study of polymeric material self-assembly using the nanoseeding approach, chemical/electrochemical sensors, and polymer-metal nanocomposites. Currently, he is an Associate Professor in Chemical Engineering at Auburn University.

\section{纳米结构导电聚合物及其复合材料的研究进展: 制备, 应用和展望}

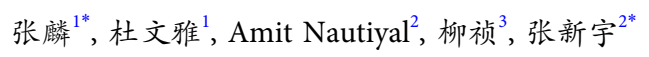

摘要 导电聚合物既具有金属材料的导电性, 又具备高分子材料的特性, 因此近年来得到全世界的广泛研究和应用. 导电聚合物具有较宽 和可调的电导率、简捷的制备工艺、可靠稳定的机械性能, 以及轻质低价的优点. 相比大尺度的导电聚合物, 具有纳米结构的导电聚合物 呈现出较高的导电性, 较大的比表面积和较好的电化学活性. 纳米导电聚合物和其他纳米材料结合形成的功能性纳米复合材料实现了性 能的改进, 在诸如电子电器、能量储存、能量收集、传感器和电磁保护防腐等各个领域有着潜在和广泛的应用前景. 在这篇综述中, 作者 总结了近几年来(涵盖四百多篇文献)纳米结构导电聚合物及其复合材料的研究进展, 讨论了纳米导电聚合物和复合材料的制备方法, 列举 了不同的形貌和结构及其对应的导电机理和改性方法. 结合大量的实例, 介绍了纳米复合材料在各领域的应用和最新动态. 最后对纳米导 电聚合物复合材料这一领域存在的挑战和亟待研究的热点问题进行了展望. 